\author{
Universidade de São Paulo \\ Instituto de Astronomia, Geofísica e Ciências Atmosféricas \\ Departamento de Geofísica
}

Giovanni Moreira

\title{
PALEOMAGNETISMO DA FORMAÇÃO PENATECAUA DA PROVÍNCIA MAGMÁTICA DO ATLÂNTICO CENTRAL NA BACIA AMAZÔNICA, BRASIL
}

São Paulo, 

Giovanni Moreira

\section{PALEOMAGNETISMO DA FORMAÇÃO PENATECAUA DA PROVÍNCIA MAGMÁTICA DO ATLÂNTICO CENTRAL NA BACIA AMAZÔNICA, BRASIL}

Dissertação apresentada ao Departamento de Geofísica do Instituto de Astronomia, Geofísica e Ciências Atmosféricas da Universidade de São Paulo como requisito parcial para a obtenção do título de Mestre em Geofísica.

Área de Concentração: Geofísica

Orientadora: Dra. Marcia Ernesto

São Paulo, 

O magmatismo Penatecaua no Estado do Pará faz parte da Província Magmática do Atlântico Central (CAMP) cuja formação precedeu a ruptura do Pangea, o mais recente supercontinente. Nos arredores das cidades de Medicilândia, Placas, Rurópolis, Monte Alegre e Alenquer afloram uma grande quantidade de soleiras de diabásio e diques observados ao longo de estradas. Idades ${ }^{40} \mathrm{Ar} /{ }^{39} \mathrm{Ar}$ recentes atribuem a idade de $\sim 201$ Ma para o magmatismo CAMP nessa região. Estudo paleomagnético nessas intrusões foi realizado em trinta sítios de amostragem nas cinco áreas acima citadas. A magnetização remanente característica dos sítios estudados é de polaridade normal e foi identificada através de desmagnetizações por campos magnéticos alternados e térmicas e interpretada como termorremanente, adquirida na época do resfriamento da rocha. Os portadores magnéticos são magnetitas ou titano-magnetitas com baixo conteúdo de Titânio. O polo paleomagnético calculado com base em 20 sítios de amostragem e incorporando dados da literatura para o mesmo magmatismo, situa-se a $76.5^{\circ} \mathrm{N} 80.5^{\circ} \mathrm{E}\left(\mathrm{N}=30 ; \alpha_{95}=3.8 ; \mathrm{k}=50\right)$ e é coerente com polos de outras ocorrências ígneas da América do Sul já identificadas como pertencentes ao evento CAMP. Essa similaridade de resultados reforça as observações de que o CAMP na América do Sul foi um evento muito rápido e isso é notado claramente no registro magnético das rochas do Penatecaua.

Palavras-chave: Paleomagnetismo, magmatismo Penatecaua, sill de Medicilândia, Província Magmática do Atlântico Central. 


\section{ABSTRACT}

The Penatecaua magmatism occurring in northern Brazil (Pará State) belongs to the so-called Central Atlantic Magmatic Province (CAMP), which preceded the Pangaea breakup. Near the cities of Medicilândia, Placas. Rurópolis, Monte Alegre e Alenquer diabase sills and dikes outcrop along roads. Recent ${ }^{40} \mathrm{Ar} /{ }^{39} \mathrm{Ar}$ dating give an age of $\sim 201 \mathrm{Ma}$ for the CAMP magmatism in the area. The paleomagnetic study on 20 sampling sites of the Penatecaua magamtism, revealed stable characteristic magnetization components through alternating magnetic field and thermal demagnetizations. The main magnetic carriers are magnetite or low-Ti titanomagnetites. The paleomagnetic pole based on the studied sites and incorporating data from the literature for the same magmatism is located at $76.5^{\circ} \mathrm{N} 80.5^{\circ} \mathrm{E}\left(\mathrm{N}=30 ; \alpha_{95}=3.8\right.$; $\mathrm{k}=50$ ) and is coherent to other South American CAMP paleomagnetic poles for which good age control is available. This similarity of results reinforces the observations that the CAMP in South America was a very fast event and this is noticed in the magnetic record of the Penatecaua rocks.

Keywords: Paleomagnetism, Penatecaua magmatism, Medicilandia sill, Central Atlantic Magmatic Province. 
"It pays to be obvious, especially if you have a reputation for subtlety" Salvor Hardin 


\section{Agradecimento}

Em especial para a elaboração deste trabalho agradeço minha orientadora por confiar e criticar quando necessário fazendo o trabalho agradável e produtivo. Aos colegas geólogos pelas lições no campo, trabalho de laboratório e nas conversas amigas. Às instituições de fomento CAPES e CNPQ pelo financiamento que possibilita a pesquisa.

Agradeço a todos que me ajudaram e acreditaram na minha trajetória e no meu trabalho. Aos colegas de trabalho do laboratório de Paleomagnetismo USPMAG, Departamento de Geofísica, IAG, Física, IME, MAE, IO, IGC, IQ, USP, UNESP, outras universidades e institutos de pesquisa. Incluo nessa lista estudantes, técnicos, pesquisadores e curiosos que visitaram o laboratório. Todos que demonstraram interesse nesta área a qual me dedico me inspiram a continuar.

A minha família por ter me dado condição de uma educação privilegiada. Aos professores que não só me ensinaram o conteúdo como foram exemplos de vida. Os amigos que me incentivaram com boas conversas e pelo apoio.

Não escrevo nomes, pois quem lê pode se identificar e não quero deixar ninguém de fora. Para não errar por uma pequena falta deixo nesta grande lacuna abstrata espaço para ser preenchido por qualquer pessoa que ler isso. Saiba que você foi importante para mim mesmo não tendo sido mencionado nominalmente. Afinal, qual o real valor tem o nome em um agradecimento? 


\section{Sumário}

Capa

Resumo

Capítulo 1 Introdução

Capítulo 2 - Aspectos Geológicos

2.1. Bacia Sedimentar do Amazonas

2.2. O Magmatismo Penatecaua

Capítulo 3 - Fundamentos do Magnetismo de Rochas

3.1. Minerais Magnéticos em Rochas Ígneas

3.2. Estrutura de domínio

3.3. Aquisição de Magnetização Remanente

3.4. Anisotropia de suscetibilidade magnética

3.5. O Registro Paleomagnético

3.6. Polos Paleomagnéticos e Curvas de Deriva Polar Aparente

Capítulo 4 - Procedimentos Experimentais

4.1. Amostragem e preparação de amostras

4.2. Análises de Laboratório

4.2.1. Anisotropia de susceptibilidade magnética (ASM)

4.2.2. Desmagnetizações AF e Térmica

4.2.3. Identificação das Componentes de Magnetização

4.3. Mineralogia magnética

4.3.1. Curvas termomagnéticas 
4.3.2. Curvas de histerese e magnetização remanente isotérmica (MRI)

Capítulo 5 - Apresentação dos Resultados

5.1. Mineralogia magnética

5.2. Anisotropia de Susceptibilidade Magnética

5.3. Identificação das componentes características de magnetização Capítulo 6 - Discussão e Conclusões

Anexo I 


\section{Capítulo 1 - Introdução}

\subsection{A Província Magmática do Atlântico Central — CAMP}

O supercontinente Pangea existiu entre o Carbonífero e o Jurássico. Sua amalgamação, por volta de 300 Ma se deu pela junção da maioria dos principais blocos cratônicos atuais, já majoritariamente agrupados em dois grandes continentes, Laurásia e Gondwana. Esta junção de blocos resultou em gigantescas zonas de sutura que possivelmente chegaram à escala de milhares de quilômetros. Seu ápice de empacotamento aconteceu próximo a $250 \mathrm{Ma}$ (Rogers, 2004) cercado por um grande oceano, o Pantalassa, provavelmente alguns poucos blocos continentais pequenos, ilhas oceânicas já subductadas e o mar de Tethys a Leste. Durante os cerca de 50 Ma seguintes o supercontinente era cercado por subducções em um círculo de fogo análogo ao atual do Oceano Pacífico que deixou um registro abundante em suas regiões Norte, Sul e Oeste. Sua quebra afetou o registro geológico, com processos que podem ser observados globalmente, como a mudança da Paleogeografia, do clima e da biosfera na transição entre o Triássico e o Jurássico.

Os processos que resultam em quebra de supercontinentes, em geral, envolvem a formação de grandes províncias ígneas, como é o caso da Província Magmática do Paraná-Etendeka (Piccirillo \& Melfi, 1988). A Província Magmática do Atlântico Central (CAMP; Central Atlantic Magmatic Province; Marzoli et al., 1999), é um exemplo dessa classe de província,com sub-províncias espalhadas pelos ex-blocos do Pangea que circundavam o atual Atlântico e que são relacionadas pela idade e pela geoquímica. As idades do CAMP variam do final do Triássico ao início do Jurássico. Datações de ${ }^{40} \mathrm{Ar} /{ }^{39} \mathrm{Ar}$ e U/Pb para as soleiras de diabásio da Amazônia, associadas a idades de outras regiões (Davies et al., 2017) atribuem uma idade de $201.52 \pm 0.07$ Ma para o pico desse magmatismo e que se coloca muito próximo do limite Triássico-Jurássico $(201.36 \pm 0.17 \mathrm{Ma})$. Estes novos resultados no Penatecaua indicam uma idade compatível com a interpretação que o CAMP possa ser um mecanismo gatilho para mudanças climáticas relacionadas à extinção do final do Triássico, embora essa associação já tenha sido contestada (Whiteside et al., 2007). O principal mecanismo proposto é a liberação de voláteis pelas camadas sedimentares em que se encaixam as intrusões, adicionando à atmosfera uma enorme quantidade de gases $\mathrm{SO}_{2}$ e $\mathrm{CO} 2$. 


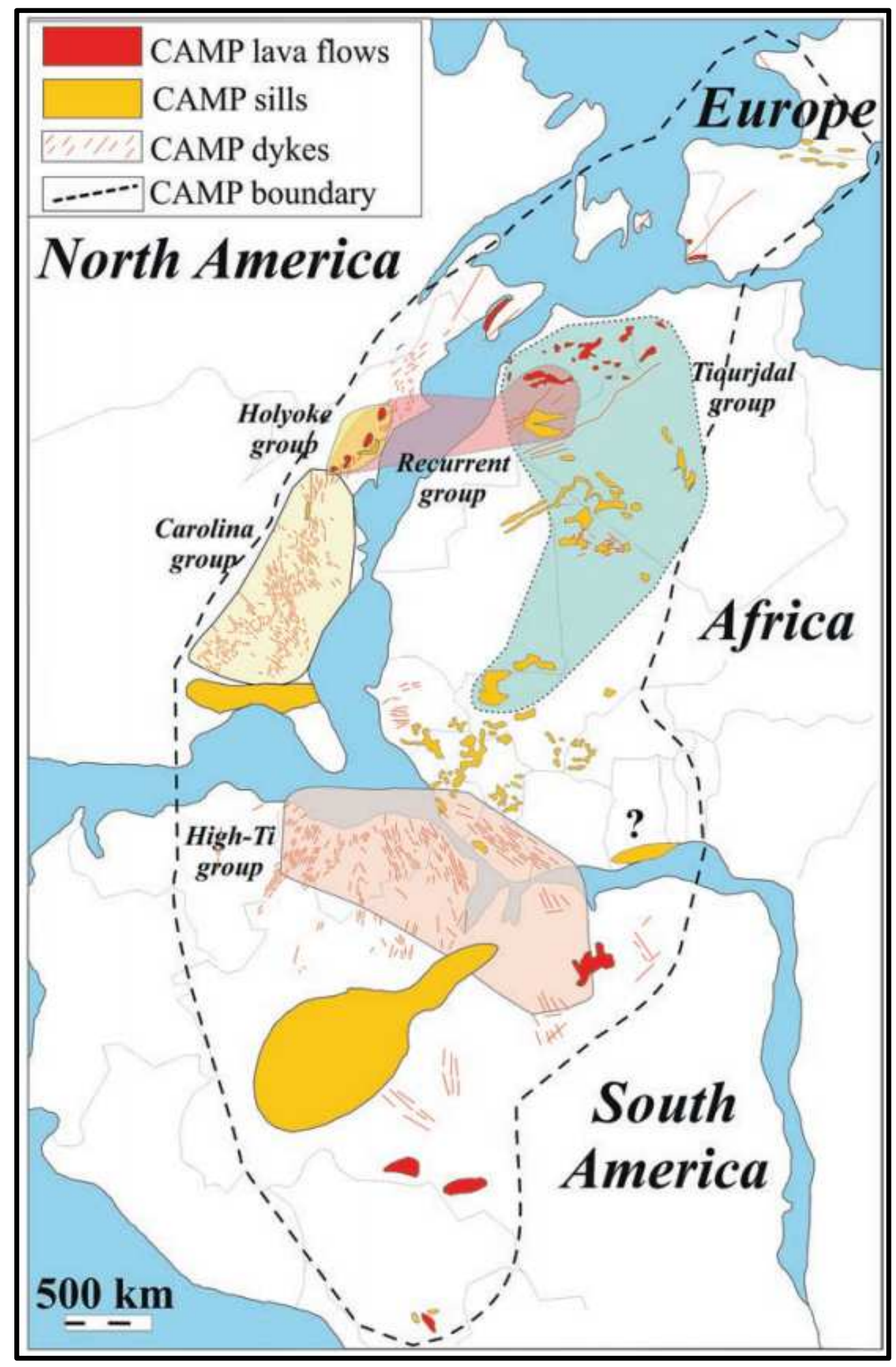

Fig. 1.1. Mapa esquemático da província CAMP reconstruída para o Pangea (Marzoli et al., 2017). A linha tracejada demarca a área das ocorrências já conhecidas. Na figura estão demarcadas algumas áreas de ocorrência de alguns tipos específicos de basaltos, inclusive o tipo altoTitânio (H-Ti). 
A Província CAMP é caracterizada por uma extensa região onde ocorrem basaltos toleíticos com idades do limite Triássico-Jurássico (T-J). Esses basaltos são encontrados em todos os continentes que uma vez estiveram amalgamados formando o supercontinente Pangea: América do Norte, Europa, África e América do Sul (Fig. 1.1). A CAMP é uma das maiores províncias ígneas da Terra e deve exceder 10 milhões de $\mathrm{km}^{2}$, sendo representada por intrusões rasas e campos de lavas. O pico da atividade ocorreu em cerca de $201 \mathrm{Ma}$ e durou não mais do que um milhão de anos (Marzoli et al., 2017), embora o magmatismo tenha continuado por alguns milhões de anos. Nesse intervalo, deve ter acumulado pelo menos 3 milhões de $\mathrm{km}^{3}$ de magma, na forma de soleiras muito volumosas, diques que capazes de atingir $800 \mathrm{~km}$ de extensão e, embora poucos, campos de lavas que podem ser seguidas por alguns quilômetros nas bacias sedimentares.

De acordo com Marzoli et al. (2017) CAMP é uma província ígnea peculiar porque, diferentemente de outras (Paraná-Etendeka, Deccan e outras), além de apresentar poucos empilhamentos de lavas preservados, não existem rochas alcalinas e tipos ácidos são raros. Os autores observam que as rochas CAMP são enriquecidas em relação aos basaltos das cadeias meso-oceânicas e ilhas oceânicas e que o manto superior que deu origem àquelas rochas deve ter sido contaminado com material da crosta superior e inferior. Estudos geoquímicos e isotópicos mostraram que os basaltos do CAMP não carregam evidências para o envolvimento de uma pluma de manto profundo, mas são originadas no manto superior que foi enriquecido em elementos incompatíveis e em voláteis durante o Proterozóico ou Paleozóico em eventos de subducção (por exemplo, Merle et al., 2011; Callegaro et al., 2013). Entretanto, ainda não é claro qual o mecanismo que geraria fonte de calor tão intensa para gerar um magmatismo dessas proporções em tão pouco tempo. 

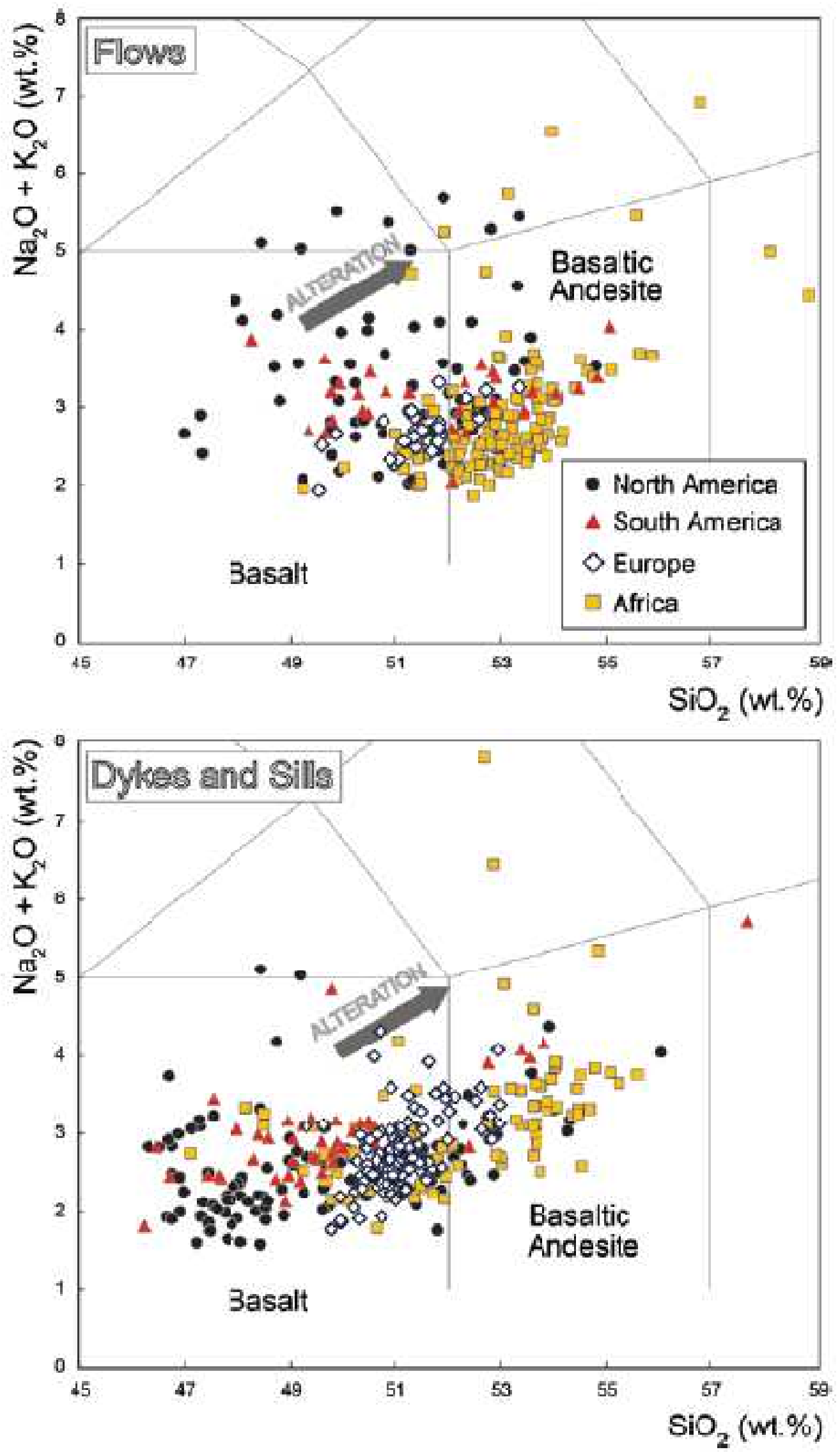

Fig. 1.2. Diagrama de classificação Alkali-Silica total (Le Bas et al., 1986) para as intrusivas e efusivas do CAMP dos diversos continentes (Marzoli et al., 2017). 


\subsection{CAMP na América do Sul}

Como se observa na Fig. 1.1, na América do Sul as ocorrências do magmatismo CAMP concentram-se no Brasil, Guianas (Nomade et al., 2000), mas existem registros também na Bolívia (Bertrand et al., 2014) e talvez na Venezuela. No Brasil o magmatismo CAMP é reconhecido a até $2000 \mathrm{~km}$ da margem atlântica, na forma de soleiras, diques e alguns derrames, como os das formações Anari e Tapirapuã, Mosquito e Lavras da Mangabeira (Montes-Lauar et al., 1994; De Min et al., 2003). Os principais enxames de diques estão em Roraima e Amapá (Marzoli et al., 1999; De Min et al., 2003), mas também no nordeste do Brasil e na Bacia do Paranaíba (Ernesto et al., 2003), bem como na Bacia do Amazonas (Davies et al., 2017). As soleiras de diabásio são muito volumosas na Bacia do Amazonas a Formação Penatecaua (Davies et al., 2017), e também na Bacia do Parnaíba — Formação Mosquito (Merle et al., 2011; Silva et al., 2017).

Os enxames de diques que afloram de Roraima ao Amapá, incluindo as Guianas, são muito densos, com diques espessos com até 200-300m e estendo-se a até $300 \mathrm{~km}$. Por essa razão podem ser vistos como alimentadores do magma de outras áreas. As soleiras da Bacia do Amazonas têm espessura média de $500 \mathrm{~m}$ e ocupam área de 1,3 milhões de $\mathrm{km}^{2}$, o que representa uma atividade muito intensa.

A região norte brasileira foi intensamente afetada pelo magmatismo CAMP, mas registros de mesma idades são encontrados também na região nordeste. Essas rochas colocam-se na forma de diques (Amapá - magmatismo Caciporé; Roraima - magmatismo Apoteri; e similares nas Guianas ), soleiras (Maranhão — magmatismo Mosquito; Bacias Amazônicas magmatismo Penatecaua) e raramente derrames (Rondonia - magmatismo; Mato Grosso magmatismo Tapirapuã; Rio Grande do Norte — Lavras da Mangabeira).

Os volumes mais espessos conhecidos de magmas do CAMP estão preservados na região norte. As soleiras da Amazônia (basaltos Pentecaua), como mostrado por De Min et al. (2003). 


\subsection{Paleomagnetismo das ocorrências CAMP da América do Sul}

Alguns trabalhos de Paleomagnetismo já foram executados sobre rochas do CAMP, como Anari-Tapirapuã (Montes-Lauar et al., 1994), Formação Mosquito, Lavras da Mangabeira e diques do Ceará e Rio Grande do Norte (Ernesto et al., 2003), Suriname (Veldkamp et al., 1971), Guiana Francesa (Nomade et al., 2000); da Bacia do Amazonas existem dados de diques da Fm. Penatecaua (Guerreiro\& Schult, 1986) e uma soleira da mesma formação (Medicilândia; Moreira \& Ernesto, 2017).

A maioria dos dados existentes mostra que essas rochas adquiriram magnetização durante um período de polaridade normal do campo geomagnético. Isto implica que a colocação desses magmas deve ter ocorrido em intervalo muito curto, uma vez que o Jurássico Inferior (época do CAMP) é um período de muitas reversões magnéticas.

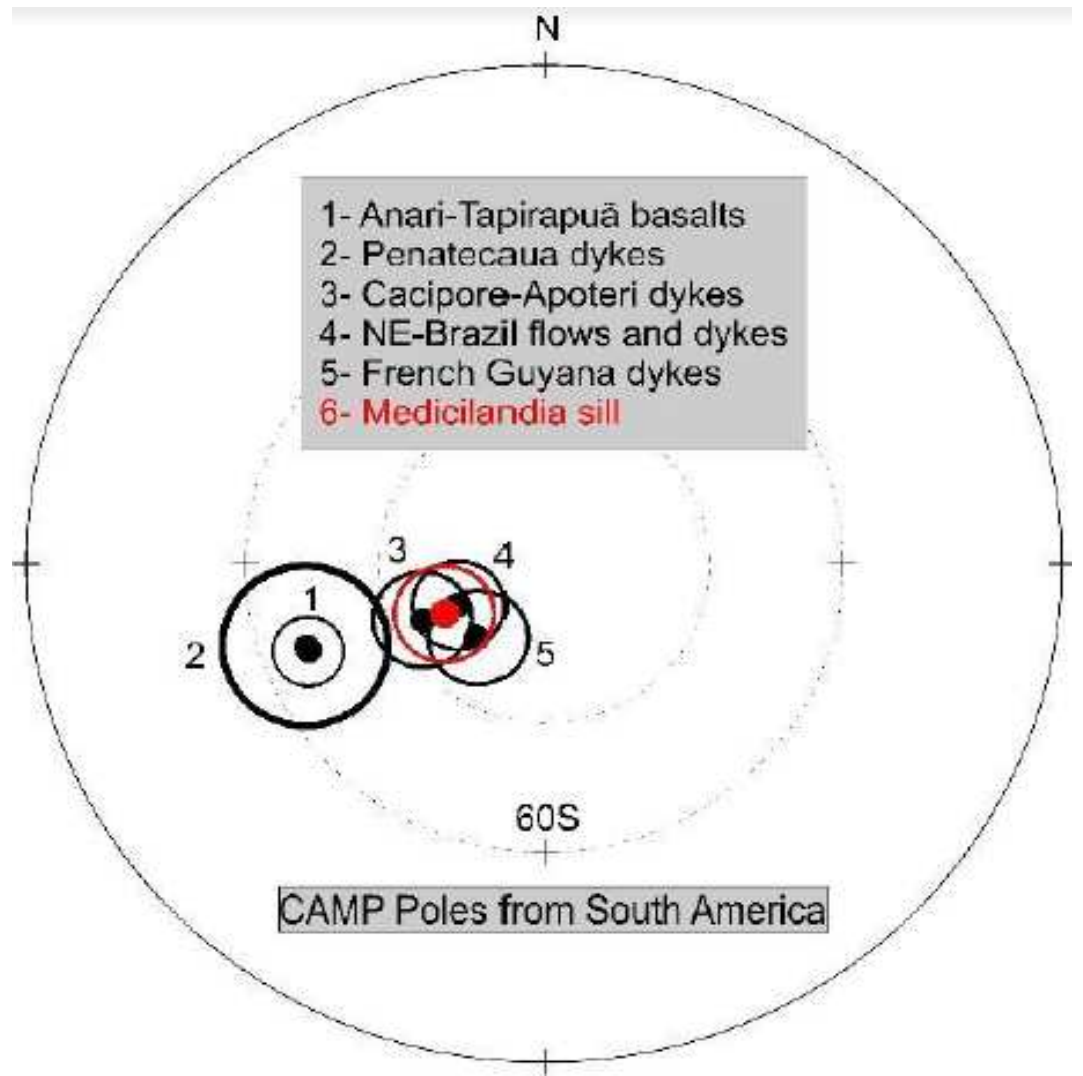

Fig. 1.3. Polos paleomagnéticos das ocorrências CAMP da América do Sul, representados no polo sul através dos círculos de confiança (Moreira \& Ernesto, 2017).

Na Fig. 1.3 os polos paleomagnéticos CAMP da América do Sul, compilados por Moreira \& Ernesto (2017) mostra que a maioria dos polos é muito coerente, como se espera para polos 
de mesma idade. Entretanto, os polos para Anari-Tapirapuã e diques Penatecaua, coincidem entre si, mas discordam dos demais. A princípio esse resultado pode sugerir diferenças de idade ou deformações internas da placa. Entretanto, os dados preliminares para a soleira de diabásio de Medicilândia diferem do polo dos diques de Guerreiro \& Schult (1986) e combina com os demais polos. Isto sugere que, na verdade, as diferenças podem significar apenas problemas nas determinações dos polos paleomagnéticos, devido às influências das variações geomagnéticas (variação secular) que não foi bem removida.

Desta forma, é importante estender o trabalho paleomagnético da formação Penatecaua na Bacia do amazonas, para que se tenha um polo paleomagnético robusto e comparável com dados de outras regiões da América do Sul e de outros continentes. Neste caso, pode-se contribuir para definir melhor as idades das diversas ocorrências e verificar se houve migração do magmatismo, no tempo e no espaço.

O trabalho aqui apresentado refere-se ao Paleomagnetismo de várias soleiras de diabásio da Bacia do Amazonas, Formação Penatecaua, tanto na porção sul como norte da bacia. A amostragem foi feita concomitantemente com amostragens para estudos geoquímicos e geocronológicos, que estão sendo desenvolvidos paralelamente a este trabalho. 


\section{Capítulo 2 - Aspectos Geológicos}

\subsection{Bacia Sedimentar do Amazonas}

Duas das mais importantes bacias sedimentares cratônicas da América do Sul situam-se na região amazônica: as bacias do Solimões e do Amazonas (Fig. 2.1). Juntas essas bacias ocupam uma área de cerca de 1.1 milhões de $\mathrm{km}^{2}$, ao longo dos rios Solimões-Amazonas.

A Bacia do Amazonas ocupa partes dos estados do Amazonas, Pará e Amapá, este último em menor proporção. Sua área total é de cerca de $515.000 \mathrm{~km}^{2}$, com $1.300 \mathrm{~km}$ de comprimento e, em média, $380 \mathrm{~km}$ de largura. Essa bacia é delimitada pelo Arco de Gurupá a leste, que a separa da Bacia do Solimões e pelo Arco de Purus a oeste. Limita-se ao norte com o Escudo das Guianas e ao sul com o Escudo Brasileiro.

Seu preenchimento sedimentar teve início no Paleozoico Inferior (Ordoviciano) e, de acordo com Cunha (2007), acumulou cerca de $5.000 \mathrm{~m}$ de preenchimento sedimentar e ígneo. Esse autor divide o arcabouço estratigráfico em duas megasequências de primeira ordem: uma paleozoica, constituída por rochas sedimentares de naturezas variadas, associadas a um grande volume de intrusões de diques e soleiras de diabásio e outra mesozoica-cenozoica. A sequência paleozoica é marcada por expressivas discordâncias regionais decorrentes dos eventos tectônicos atuantes nas bordas da Placa Gonduânica.

Durante o Carbonífero-Permiano, depositou-se o Grupo Tapajós (Silva et al., 2003), composto pelas formações Monte Alegre, Itaituba, Nova Olinda e Andirá que representam distintos ambientes de sedimentação. O magmatismo basáltico associado ocorreu no início do Jurássico, formando diques e soleiras situados entre as formações Nova Olinda e Alter do Chão (Santos et al. 2002). Esse magmatismo está associado à Província CAMP (Marzolli et al. 1999) e é denominado magmatismo Penatecaua. A sedimentação na Bacia do Amazonas é encerrada pela deposição de duas sequências continentais, uma do Cretáceo Superior (Formação Alter do Chão) e outra Cenozoica (formações, Solimões e Içá), ambas de caráter fluvial. 


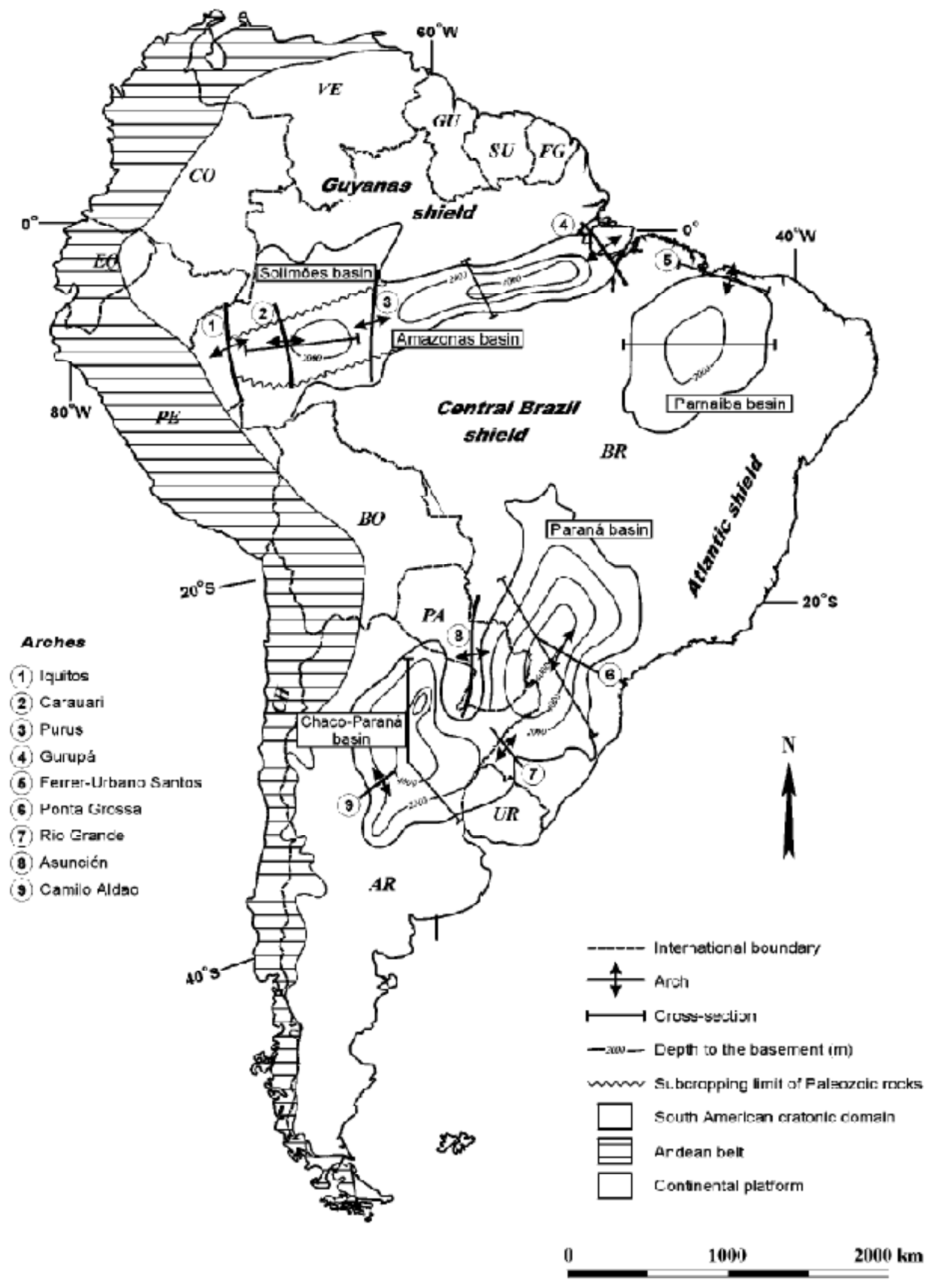

Fig. 2.1. Mapa de localização das grandes bacias sedimentares da América do Sul (Milani \& Zalán, 1999). 


\subsection{O Magmatismo Penatecaua}

O magmatismo Penatecaua, do Jurássico Inferior (Marzolli et al. 1999; Davis et. al. 2017), está presente nas bacias do Amazonas e Solimões (De Min et al., 2003). Análises de amostras provenientes de poços da Petrobras, associadas a estudos geofísicos indicam que quase um milhão de quilômetros cúbicos de magma basáltico foram injetados em vários níveis dentro das sequências sedimentares paleozoicas (Carboníferas e Permianas, principalmente) dessas bacias.

Os afloramentos foram primeiramente descritos pelo projeto RADAM (DNPM, 1974) e também pela CPRM (Vasquez, 2008), principalmente nas margens da bacia e com direções aproximadamente paralelas ao curso atual do rio Amazonas. As soleiras apresentam grandes extensões laterais de até $50 \mathrm{~km}$, como é o caso da soleira de Medicilândia (PA). A maioria das ocorrências é identificada como soleiras, porém no Noroeste da bacia também são descritos diques. Na Bacia do Amazonas as soleiras apresentam basculamento desprezível diferentemente do que ocorre na Bacia do Solimões, provavelmente afetada pela orogenia andina (Caputo, 2016; Munis 2013). Em sub-superfície foram reconhecidos na bacia Amazônica até oito níveis de diabásio encaixados nos sedimentos paleozoicos e com até algumas centenas de metros de espessura. 


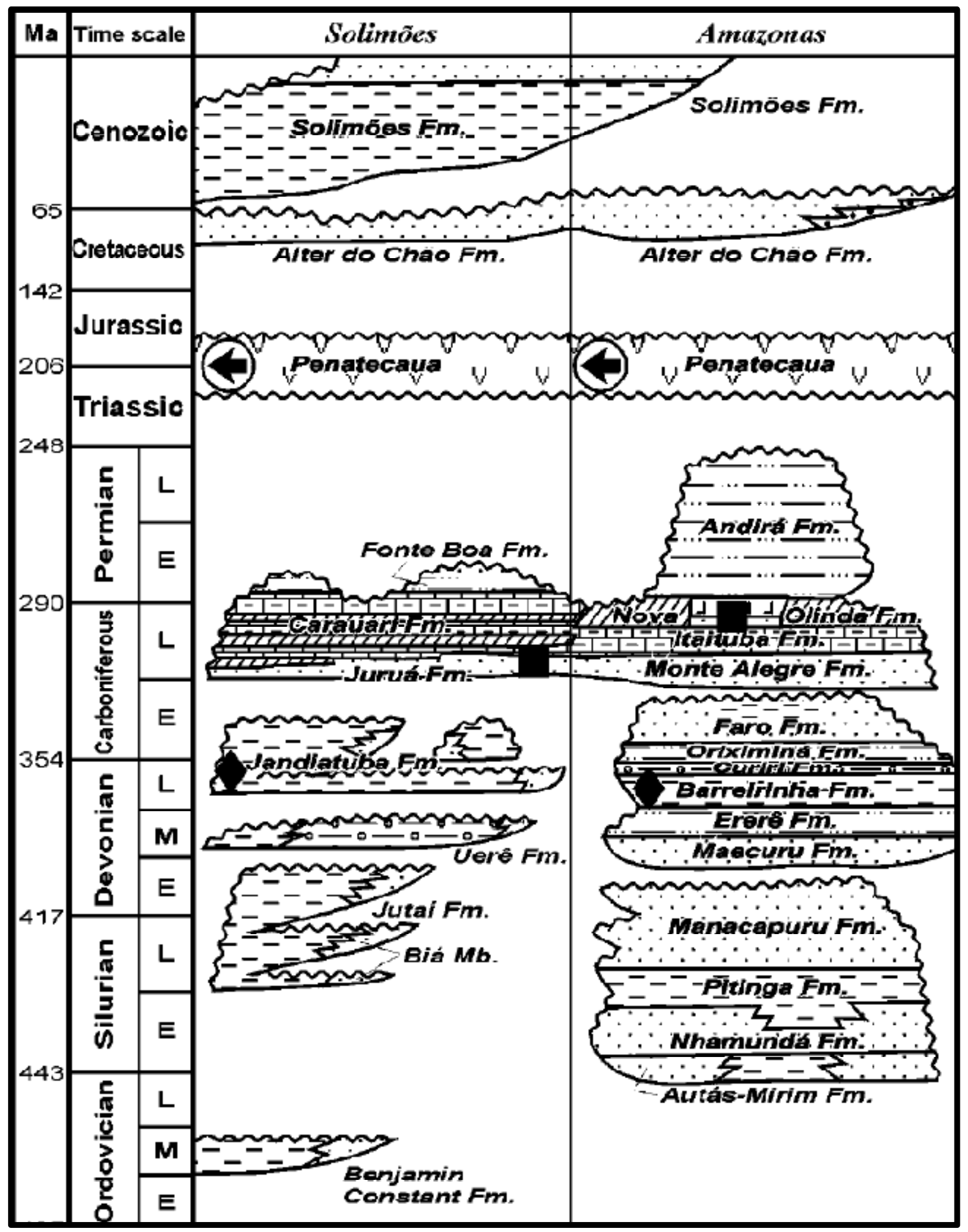

Fig. 2.2. Coluna estratigráfica das bacias do Amazonas e Solimões, baseado em Milani \& Zalán (1999). A flecha indica o momento da geração, migração e acumulação ou remobilização do hidrocarboneto. 


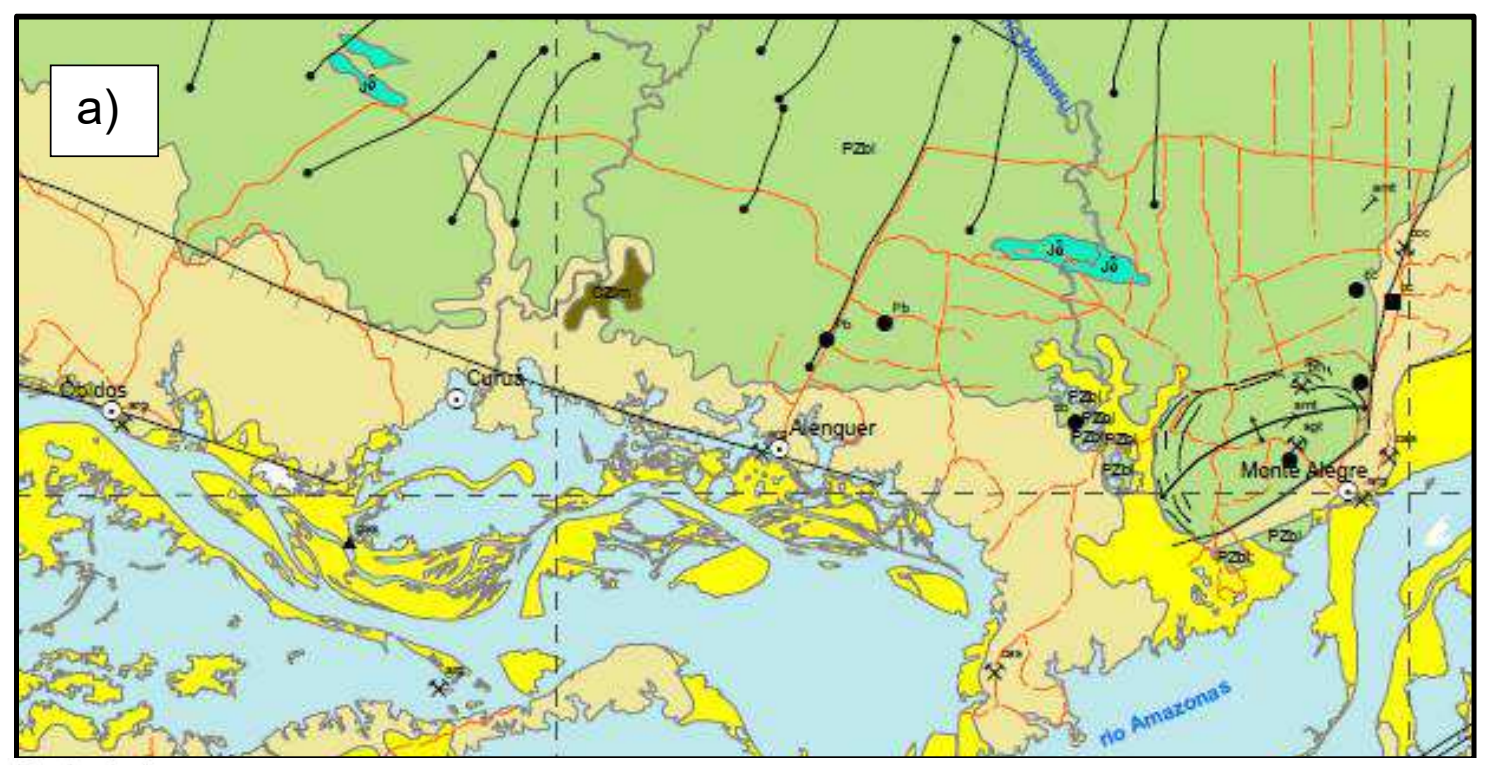

\section{Bacia do Amazonas}

\begin{tabular}{|c|c|c|}
\hline & K2E1ac & F. Alter do Chäo (G. Javari): arenitos com estratificação cruzada, pelitos e conglomerados, de sistema lacustrino deltáico com influência marinha. \\
\hline & Jôpe & Diabásio Penatecaua: diques e soleiras de diabásio. $259 \pm 6$ a $130 \pm 6 \mathrm{Ma}$ (K-Ar) \\
\hline & C2no & F. Nova Olinda: evaporitos e lentes de calcário, no topo; arenitos, folhelhos e siltitos, na base. Ambiente marinho restrito hipersalino e flúvio-lacustrino. \\
\hline & $\mathrm{C} 2 \mathrm{i}$ & F. Itaituba: arenitos com calcários e pelitos intercalados. Ambiente marinho raso e planície de inframaré. \\
\hline & $\mathrm{C} 2 \mathrm{ma}$ & F. Monte Alegre: arenitos conglomeráticos, folhelhos e carbonatos. Ambiente flúvio-eólico e marinho raso a restrito. \\
\hline & D3C1c & G. Curuá: folhelhos negros, diamictitos, folhelhos, siltitos e arenitos. Ambiente marinho, glacial e flúvio-deltáico. \\
\hline & Cif & F. Faro: arenitos e, siltitos com intercalações de folhelhos. Ambiente flúvio-deltáico, com influência de tempestade. \\
\hline & D3C10 & F. Oriximiná: arenitos finos com siltitos, folhelhos e diamictitos intercalados. Ambiente flúvio-deltáico, com contribuição glacial. \\
\hline & D3c & F. Curiri: folhelhos, siltitos, diamictitos e subordinados arenitos. Ambiente glacial. \\
\hline & D3b & F. Barre irinha: folhelhos negros laminados, carbonosos, piritosos e micáceos, com arenitos finos intercalados. Ambiente marinho anóxico. \\
\hline & $\mathrm{D} 2 \mathrm{e}$ & F. Ererê: siltitos, com intercalações de folhelhos e arenitos. Ambiente de planície de maré. \\
\hline & $\mathrm{D} 2 \mathrm{ml}$ & F. Maecuru: Mb. Lontra (ml): arenitos finos a conglomeráticos, de ambiente de leques deltáicos. \\
\hline & D1mj & F. Maecuru: Mb. Jatapu (mj): arenitos finos, folhelhos e sittitos, de ambiente flúvio-deltáico. \\
\hline & O3D1t & $\begin{array}{l}\text { Grupo Trombetas: folhelhos bioturbados, arenitos e siltitos, além de diamictitos subordinados. Ambiente flúvio-estuarino, marinho raso, glácio-marinho } \\
\text { e nerítico-litorâneo. }\end{array}$ \\
\hline & NP3pr & sperança (G. Purus): arenitos, siltitos e arcóseos, com intercalações de conglomerados. Ambiente de leques aluviais, canais fluviais e lagos. \\
\hline
\end{tabular}

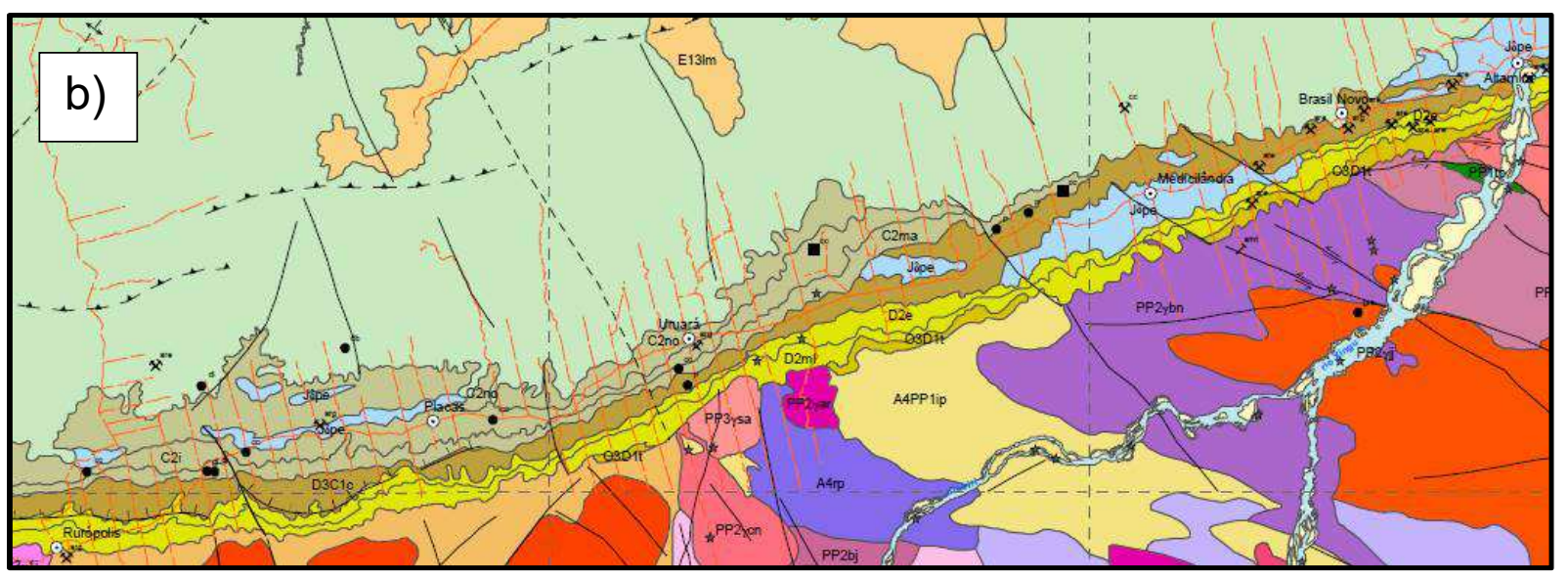

Fig. 2.3. Mapas geológicos das bordas norte e sul da Bacia do Amazonas, extraídos do Mapa Geológico do Estado do Pará - CPRM (Vasquez et. al., 2008). 
Além das soleiras, também são descritos diques cortando a sequência sedimentar, embora Bigarella (1973) enfatize que os diques que cortam o pacote Siluriano-Devoniano são em maior número que aqueles cortando o Paleozoico Superior. Os diques normalmente tendem NNE-SSW, com espessura média de 150-200 m. Em afloramentos os diques apresentam espessura variando de 5 a $25 \mathrm{~m}$, com alinhamentos preferenciais a NE e raramente E-W (Bischoff, 1963, citado por Caputo, 1984), na borda sul. Na borda norte a direção preferencial é NE, mas também NW e E-W. Entretanto, em campo o reconhecimento desses diques não é tarefa muito simples.

O magmatismo Penatecaua, em geral, ainda é pouco estudado, mas recentemente, alguns estudos concentrados em regiões ou soleiras foram divulgados. A soleira de Medicilândia, localizada em cidade homônima no estado do Pará é a maior em extensão aflorando na borda sul da Bacia Amazônica. Abrange cerca de $300 \mathrm{~km}^{2}$ e é composta por diabásios e gabros (Costa \& al., 2012). Quimicamente essas rochas são supersaturadas em $\mathrm{SiO}_{2}$ e classificam-se como basaltos e andesito-basaltos da série toleítica, em diagrama de De La Roche (1980). Distingue-se também quanto ao conteúdo de Titânio, com valores de $\mathrm{TiO}_{2}<2 \%$ para algumas amostras, enquanto outras têm $\mathrm{TiO}_{2}$ entre 2 e $3 \%$. Segundo Costa et al. (2012), a soleira mostra zoneamento onde as fácies primitivas localizam-se nas bordas, enquanto as evoluídas concentram-se no centro da intrusão. A hipótese provável de evolução da soleira indica uma origem relacionada com diferentes taxas de fusão parcial de uma mesma fonte, seguida por processo de cristalização fracionada.

Mais a oeste, um corpo de diabásio aflora próximo de Rurópolis (PA), onde cortes recentes da BR-163 expõem longo afloramento. De acordo com Silva \& al. (2014) esse corpo encontra-se bem preservado, com pouca ação intempérica. Apresenta planos preferenciais de fratura orientados a ENE-WSW, concordando com as estruturas da rocha encaixante. Através de análises petrográficas, os autores concluíram que o corpo de Rurópolis é similar aos outros diabásios Penatecaua encontrados na borda sul da Bacia.

Pouco se sabe sobre as rochas de outras áreas de ocorrência. Alguns trabalhos da literatura têm caráter mais estrutural. Por exemplo, Montalvão \& Oliveira (1975) procuraram explicar a ocorrência do domo de Monte Alegre, a aproximadamente $10 \mathrm{~km}$ a noroeste da cidade homônima na borda norte da bacia, associando-o às intrusões toleíticas. Figueira et al. (2012) estudaram o registro das deformações nas soleiras e diques do magmatismo Penatecaua que afloram nessa região buscando determinar as paleoextensões que atuaram após o evento 
Penatecaua. Lopes \& al. (2013) realizaram levantamento gravimétrico no domo de Monte Alegre e concluíram sobre a existência de um corpo com forma tabular similar a um lacólito que teria originado a estrutura do domo. Concluíram também sobre a presença de um graben, colocando em contato rochas da Formação Alter do Chão (Cretáceo) com as rochas do Paleozoico.

Resultados mais abrangentes estão sendo obtidos no âmbito do projeto "Investigações paleomagnéticas, geoquímicas e geocronológicas dos eventos relacionados à Província Magmática do Atlântico Central na América do Sul”, do qual faz parte este trabalho. Resultados parciais (Davies \& al., 2017) baseados em datações U-Pb das bordas sul e norte (Fig. 2.3), demonstraram que os eventos magmáticos foram muito rápidos, com idades concentradas em $201.525 \pm 0.065$ para o baixo-Ti e $201.364 \pm 0.023$ para o alto-Ti (Davies et al., 2017). Esses dados levam à conclusão de que os magmas foram injetados continuamente durante cerca de 200 milhares de anos. 


\section{Capítulo 3 -Fundamentos do Magnetismo de Rochas}

O estudo científico do campo magnético começou com Petrus Peregrinus, e depois com Gilbert e Gauss, abrindo os caminhos para o conhecimento e interpretação da informação magnética gravada nas rochas. Uma das primeiras grandes provas da teoria de Wegener veio do Paleomagnetismo e foi a construção da curva de deriva polar aparente entre a Europa e a América do Norte, com a análise do Paleoclima (Irving, 1956). Brunhes e Matuyama determinaram períodos recentes de inversão de polaridade (ou reversão) do campo geomagnético. Vine,Matthewse Morley interpretaram as anomalias magnéticas oceânicas em face da magnetização da crosta e das reversões o que permitiuconfirmar a hipótese do "espalhamento do assoalho oceânico" (Hess, 1962). Hoje, observatórios, ainda esparsos pelo mundo e satélites que cobrem toda a área terrestre, registram as variações do CMT que ainda deixam marcas nas rochas e sedimentos.

\subsection{Minerais Magnéticos em Rochas Ígneas}

Algumas categorias de minerais apresentam magnetismo remanente, ou seja, ao serem expostos a um campo magnético, registraram as propriedades desse campo (direção, sentido e intensidade relativa). O mineral que mais se destaca nessa categoria é a magnetita, um óxido de ferro $\left(\mathrm{Fe}_{3} \mathrm{O}_{4}\right)$ muito comum em rochas ígneas. A remanência é uma propriedade dos materiais ferromagnéticos e é a resposta ao campo magnético aplicado,com a mesma direção e sentido deste, e que persiste mesmo após a remoção do campo. Essa propriedade é o resultado do arranjo de spins magnéticos na estrutura cristalina. Em geral, os minerais magnéticos nas rochas classificam-se nas seguintes categorias de ferromagnetismo:

a) Ferromagnetismo stricto sensu, onde todos os momentos magnéticos são paralelos, resultando em uma magnetização espontânea relativamente intensa;

b) Ferrimagnetismo, onde os momentos magnéticos se dispõem de forma antiparalela, porém, com maior intensidade num sentido doque no outro, resultando também em magnetização espontânea, embora mais fraca que no caso anterior. É nesta categoria que se coloca a magnetita. 
c) Antiferromagnetismo, é a situação análoga ao ferrimagnetismo, porém, os momentos de spin se anulam totalmente.

(A)

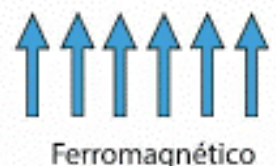

(B)

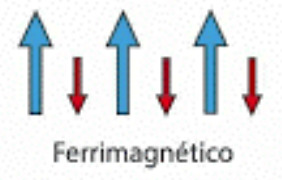

(C)

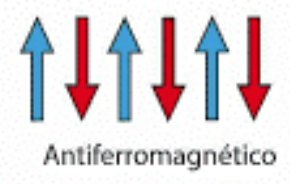

Fig. 3.1. Representação esquemática dos arranjos de momentos magnéticos em materiais do tipo ferromagnético.

Entretanto, a maior parte dos minerais formadores das rochas pertence às categorias dos minerais paramagnéticos - quando a remanência adquirida decai rapidamente depois de cessados os efeitos do campo magnético indutor; e diamagnéticos, quando a resposta ao campo aplicado se dá no sentido oposto e também não há remanência.

Mesmo em quantidades menores, minerais ferromagnéticos dominam o sinal magnético induzido. Isto porque, o fator de proporcionalidade entre campo aplicado e magnetização induzida é a suscetibilidade magnética, que é maior no grupo dos ferromagnéticos. Vale lembrar que no grupo dos diamagnéticos a suscetibilidade é negativa.

\subsection{Estrutura de domínio}

Os grãos de minerais magnéticos podem desenvolver regiões denominadas domínios magnéticos. Esses domínios se desenvolvem à medida que os grãos se tornam maiores, possibilitando assim, a diminuição da energia magnetostática.

Grãos pequenos $(\mathrm{d}<0,1 \mu \mathrm{m}$ em magnetita cúbica) apresentam um só domínio e são chamados de monodomínio. Grãos assim pequenos são mais difíceis de serem polarizados emodificaremsuasorientações por um campo indutor, o que é refletido pela alta coercividade, ou seja, a energia necessária para magnetizar ou desmagnetizar o grão. Conforme o tamanho do grão cresce, a coercividade cai. Desta forma, a direção de magnetização remanente pode ser alterada com mais facilidade por influência de mudançasno campo magnético. Quanto mais coercivo for o mineral, mais hipótese ele terá de preservar o registrado campo magnético do passado. 

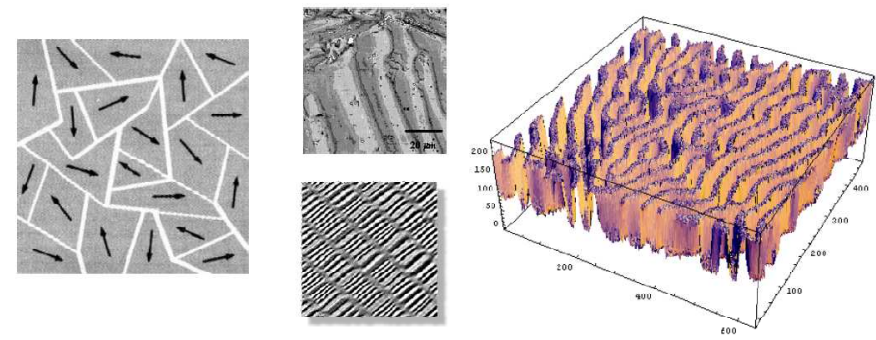

Fig. 3.2.Representação esquemática de domínios magnéticos (esquerda) em grão multidomínio. Os limites entre os domínios são chamados de paredes de domínio (direita) e podem ser visualizados em microscópio, através de técnicas especiais.

A coercividade é medida pelo campo magnético necessário para destruir a magnetização remanente adquirida por um mineral ferromagnético, ao ser submetido a um campo magnético indutor (Fig. 3.3), num ciclo de histerese.

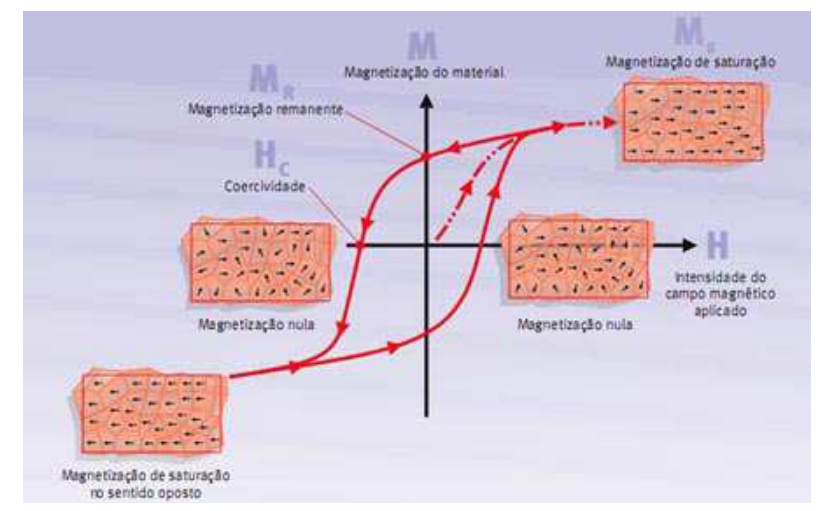

Fig. 3.3. Representação do ciclo de histerese (fonte: Ciência Hoje, 22/12/2007)

\subsection{Aquisição de Magnetização Remanente}

O processo de aquisição da magnetização em rochas ígneas é o processo termorremanente. Neste processo, as forças magnéticas internas dos grãos magnéticos crescem, à medida que a temperatura do magma diminui, diminuindo também a agitação térmica que impede o alinhamento dos momentos magnéticos. Às temperaturas em que magmas ascendem à superfície, cerca de $1000^{\circ} \mathrm{C}$, o magma já está em processo de cristalização e, com o resfriamento, os grãos minerais deixam de mover. Porém,os momentos magnéticos dos minerais ainda estão em agitação térmica impedindo a orientação ou polarização dos mesmos, o que caracteriza a aquisição da magnetização remanente. Isto só vai acontecer quando a temperatura da rocha caia abaixo da temperatura de bloqueiodos minerais 
magnéticos. Para a magnetita, essa temperatura é de aproximadamente $580^{\circ} \mathrm{C}$ e corresponde à chamada temperatura de Curie $\left(\mathrm{T}_{\mathrm{C}}\right)$. As temperaturas próximas da $\mathrm{T}_{\mathrm{C}}$ a remanência ainda não é estável e decai rapidamente, pois, o tempo de relaxação é muito curto. O tempo de relaxação, segundo Louis Néel, é definido por:

$$
\tau=\frac{1}{C} \exp \left(\frac{v h_{C} j_{S}}{2 k T}\right)
$$

Onde, $\mathrm{C}=$ fator de frequência

$$
\begin{aligned}
& v=\text { volume do grão SD } \\
& \mathrm{h}_{\mathrm{C}}=\text { força coerciva } \\
& \mathrm{j}_{\mathrm{S}}=\text { magnetização de saturação } \\
& \mathrm{kT}=\text { energia térmica }
\end{aligned}
$$

Portanto, o tempo de relaxação depende da temperatura, mas também da coercividade e tamanho do grão. À temperatura ambiente a magnetização remanente pode permanecer estável por bilhões de anos, como mostra o gráfico da Fig. 3.4:

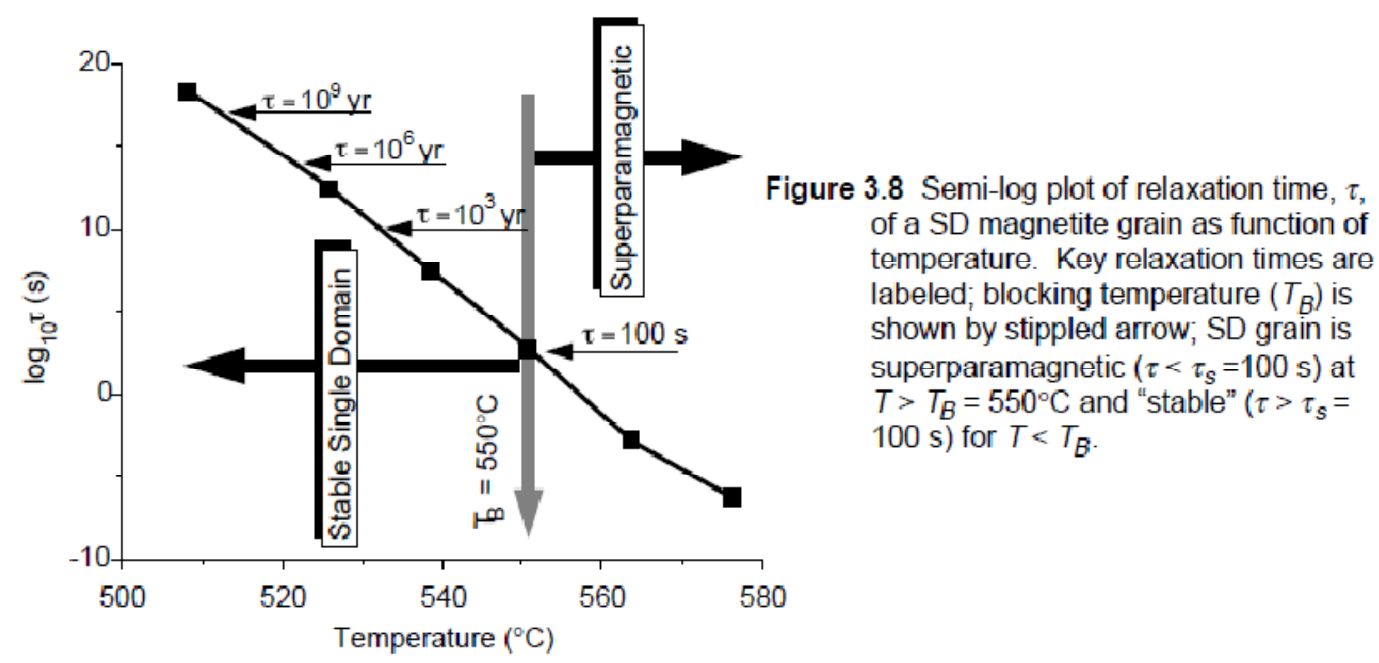

Fig. 3. 4. Gráfico semi-log do tempo de relaxação de magnetita SD em função da temperatura (Fonte: Butler, 1992)

Numa rocha, a magnetização remanente natural $(\mathrm{MRN})$ corresponde à soma dasremanências de todos os minerais magnéticos presentes. Estes podem ser magnetitas de diferentes tamanhos, diferentes composições (conteúdo de Titânio variável) ou diferentes minerais (hematita, maghemita ou outros). Os minerais pouco coercivos tendema perder a magnetização primária e adquirir magnetização secundária de origem viscosa. Essa 
magnetização é o resultado da ação do campo magnético ambiente através do tempo. Em Paleomagnetismo essa magnetização é indesejável e considerada ruído; quando ela é intensa, pode mascarar a magnetização primária de origem termorremanente.

Os processos de intemperismo a baixa temperatura podem resultar na oxidação e/ou transformação dos minerais magnéticos e consequente alteração da magnetização primária. A componente de magnetização secundária gerada dessa forma é de origem química. Nesse processo a magnetita dá origem a maghemita e hematita.

\subsection{Anisotropia de suscetibilidade magnética}

Quando um material é exposto a um campo $\vec{H}$, ele adquire magnetização induzida $\vec{M}_{i}$. Estas grandezas são relacionadas através da susceptibilidade magnética $(k)$.

$$
\vec{M}_{i}=k \cdot \vec{H}
$$

A Anisotropia de Susceptibilidade Magnética (ASM) mostra a variação espacial dessa grandeza física num mineral magnético. A ASM depende fortemente do tamanho e da forma desses minerais.Uma análise da resposta magnética em diferentes direções revela um tensor que possui três autovalores e podem ser interpretados como direções preferenciais dos minerais da rocha.Geralmente, representa-se a ASM num elipsóide triaxial $\left(k_{1}, k_{2}, k_{3}\right)$, onde $k_{1} \geq k_{2} \geq k_{3}$, como representado na figura abaixo.

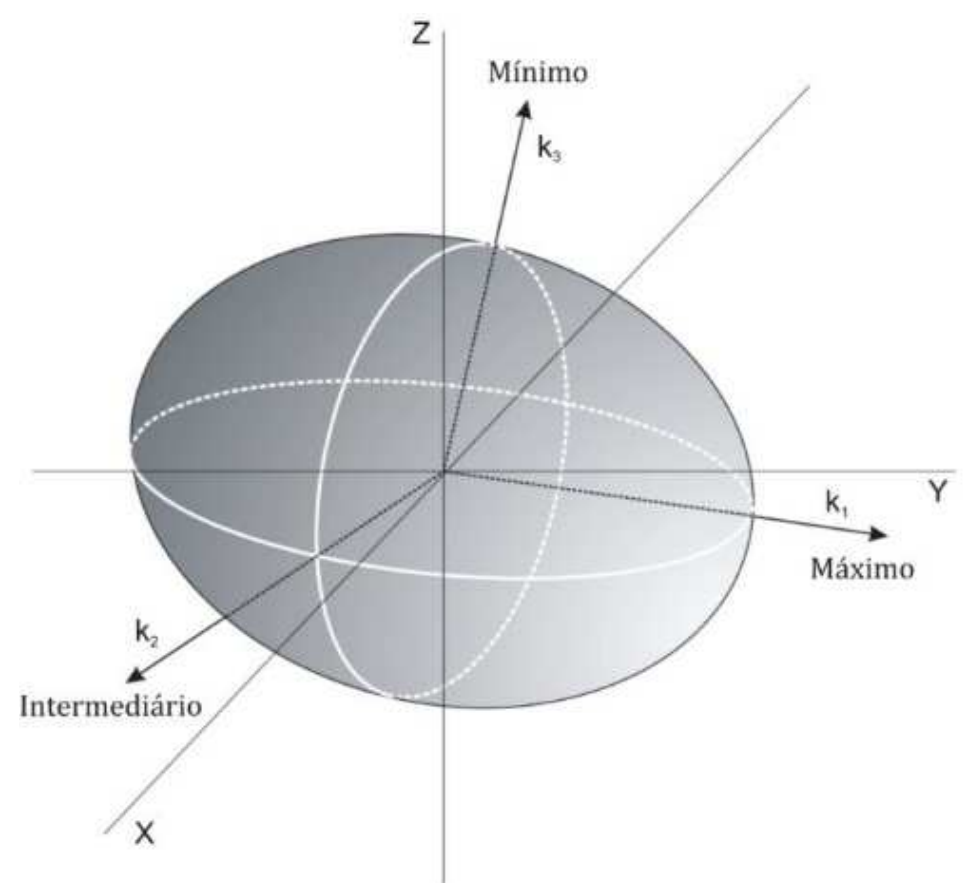

Fig. 3. 5. Elipsóide representante da ASM com os eixos principais e planos. (Bispo-Santos, 2017) 
A ASM é determinada se integrando uma série de medidas da magnetização em diferentes direções de campo aplicado para produzir um tensor que relaciona a direção da medida e a intensidade da magnetização. Os erros relacionados a cada autovalor são obtidos através da estatística de Jelinek que utiliza matrizes covariantes. Os erros são assumidos como maiores que os erros de medida e que não existe tendência significativa na distribuição dos erros experimentais.

A proporção entre os autovalores define a forma elipsóide resultante se $k_{1} \gg k_{2} \cong k_{3}$ temos uma forma prolata, se $k_{3} \ll k_{2} \cong k_{1}$ temos uma forma oblata. Nos prolatos o autovalor maior define a direção da lineação magnética, nos oblatos o menor autovalor define o polo do plano de foliação magnética.

\subsection{O Registro Paleomagnético}

O registro paleomagnético impresso nas rochas pode ser recuperado através de técnicas de laboratório que serão descritas no capítulo seguinte. Através dele é possível reunir informações que contribuem para modelar o campo geomagnético em épocas cada vez mais remotas. O primeiro aspecto ainda em debate é a validade da hipótese do Dipolo Geocêntrico Axial (GAD - 'geocentric axial dipole'). Embora tenha sido demonstrado que o campo médio dos últimos 5 milhões de anos se comportou com um GAD, ainda existem questionamentos sobre se, em outros períodos, essa hipótese se mantém (Evans, 2005; Panzik \& Evans, 2014)

A variação secular (VS)corresponde a um conjunto de mudanças no campo geomagnético em diversas escalas de tempo, tanto em intensidade como em direção. Em registros sedimentares a VS pode ser estudada em detalhe, inclusive suas características temporais (Courtillot \& Le Mouel, 1988). Em rochas ígneas, devido ao caráter descontínuo do magmatismo, investiga-se principalmente a dispersão angular do campo geomagnético em função da paleolatitude (Cox, 2007). Esses modelos são importantes para testar a validade de polos paleomagnéticos de referência.

\subsection{Polos Paleomagnéticos e Curvas de Deriva Polar Aparente}


A direçãode magnetização de um sítio de amostragem está associada a uma posição instantânea do polo magnético da Terra, ou polo geomagnético virtual (PGV). Um conjunto de PGVs que cubram um intervalo de tempo suficientemente longo para amostrar adequadamente a variação secular (pelo menos 10.000 anos), permite o cálculo de um polo paleomagnético de referência. A sucessão de polos paleomagnéticos, de um mesmo bloco continental com bom controle geocronológico, descreve a curva de deriva polar aparente (CDPA) para esse bloco. A CDPA representa os deslocamentos do continente através do tempo. 


\section{Capítulo 4 - Procedimentos Experimentais}

\subsection{Amostragem e preparação de amostras}

Os trabalhos de campo aconteceram em duas campanhas nos anos de 2014 e 2017, sendo que minha participação se deu na segunda etapa. Foram realizadas amostragens simultâneas para paleomagnetismo, geoquímica e geocronologia. A localização de afloramentos baseou-se em informações prévias da literatura e no mapa da Companhia de Pesquisa de Recursos Minerais (CPRM). Percorrem-se as estradas principais, onde há a maior probabilidade de cortes e exposição de afloramentos, mas também muitos travessões, caminhos atravessando propriedades e pedreiras. A localização dos sítios amostrados pode ser visualizada na imagem de satélite extraída do Google Earthvista abaixo (Fig. 4.1):

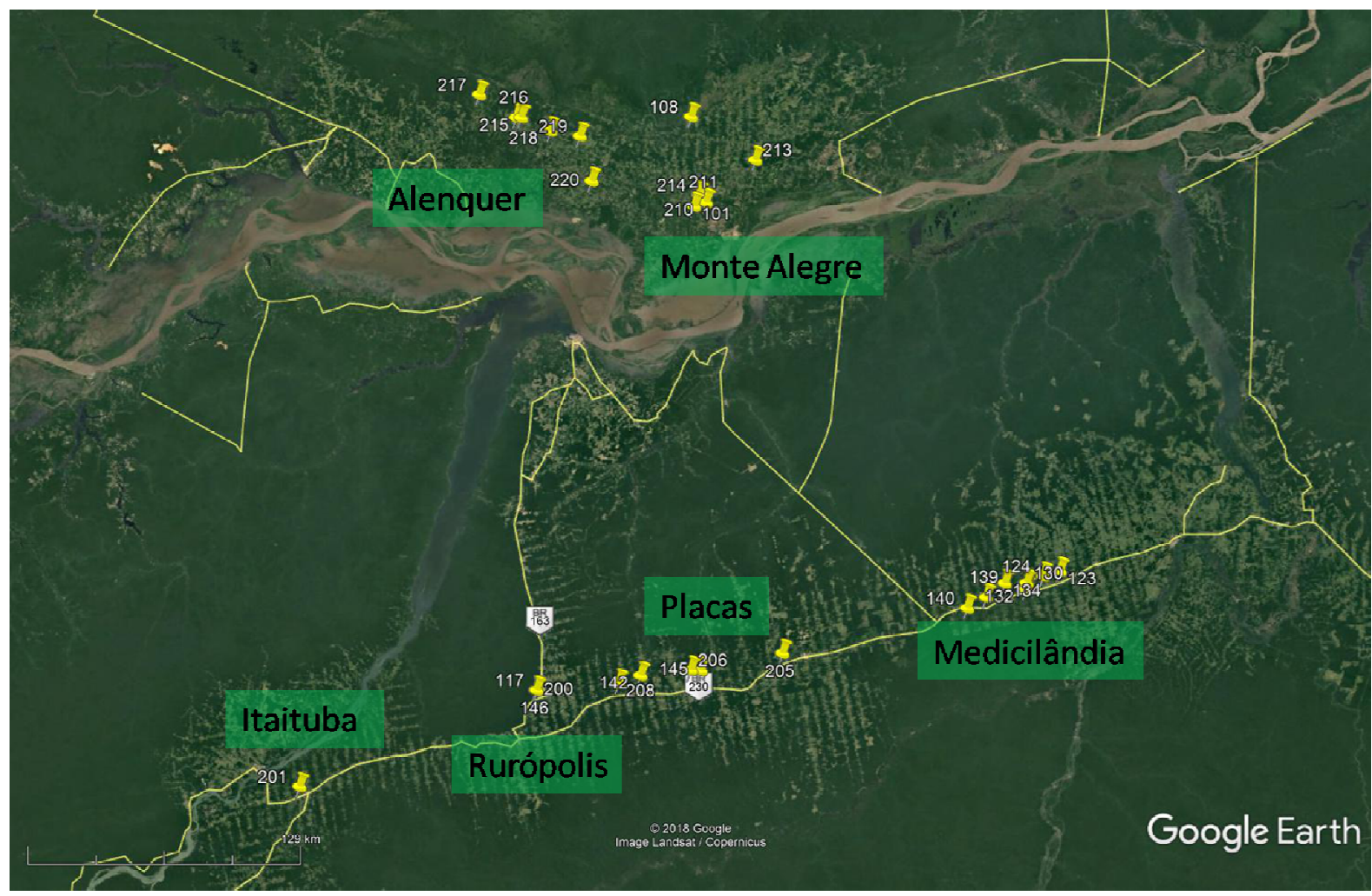

Fig.4.1 Mapa com a localização dos pontos de amostragem e com a indicação das localidades de referência para os afloramentos. 
Ao sul do Rio Amazonas percorreu-se a rodovia BR-230 (Transamazônica), partindo de Altamiraem direção ao Rio Tapajós. Os afloramentos apropriados para o paleomagnetismo foram encontrados nas cercanias dos municípios de Medicilândia, Placas e Rurópolis. Ao norte do Rio Amazonas os pontos de referência são Monte Alegre, a leste e Alenquer a oeste, sendo que a amostragem estendeu-se a noroeste de Alenquer.No total foram amostrados 28 sítios e que estão descritos na Tabela 4.1. Amostrou-se também um sítio na região de Itaituba, provavelmente correspondente ao Grupo Curuá (Neodevoniano), de acordo com o mapa de Santos et al. (2011). Esta região foi explorada devido às indicações fornecidas por esses autores de que seria cortada por diques mesozóicos, mas nada foi encontrado na área.

Tabela 4.1 Dados de localidades de referência, identificação e localização dos sítios de amostragem.

\begin{tabular}{lcccc} 
Localidade & Sítio & Altitude $(\mathbf{m})$ & Latitude $\left.\mathbf{(}^{\mathbf{}}\right)$ & Longitude $\left.\mathbf{(}^{\mathbf{}}\right)$ \\
\hline Alenquer & 215 & 35 & -1.5769 & -54.9856 \\
Alenquer & 216 & 33 & -1.5772 & -55.0058 \\
Alenquer & 217 & 59 & -1.4850 & -55.1614 \\
Alenquer & 218 & 41 & -1.6293 & -54.8625 \\
Alenquer & 218 & 41 & -1.6293 & -54.8625 \\
Alenquer & 219 & 61 & -1.6479 & -54.7402 \\
Alenquer & 220 & 80 & -1.8324 & -54.6866 \\
Monte Alegre & 101 & 86 & -1.9258 & -54.2620 \\
Monte Alegre & 108 & 57 & -1.5557 & -54.2847 \\
Monte Alegre & 210 & 35 & -1.9086 & -54.2139 \\
Monte Alegre & 21 & 35 & -1.9086 & -54.2139 \\
Monte Alegre & 213 & 90 & -1.7000 & -54.0000 \\
Monte Alegre & 214 & 56 & -1.8788 & -54.2435 \\
Medicilândia & 123 & 157 & -3.3898 & -52.7078 \\
Medicilândia & 124 & 165 & -3.4114 & -52.7766 \\
Medicilândia & 125 & 196 & -3.4411 & -52.8412 \\
Medicilândia & 127 & 196 & -3.4411 & -52.8412 \\
Medicilândia & 130 & 177 & -3.4416 & -52.8451 \\
Medicilândia & 132 & 227 & -3.4670 & -52.8471 \\
Medicilândia & 134 & 102 & -3.4454 & -52.9359 \\
Medicilândia & 139 & 217 & -3.5057 & -53.0113 \\
Medicilândia & 140 & 150 & -3.5524 & -53.0888 \\
Placas & 142 & 98 & -3.8663 & -54.4301 \\
Placas & 145 & 114 & -3.8378 & -54.1827 \\
Placas & 205 & 227 & -3.7584 & -53.8476 \\
Placas & 206 & 117 & -3.8375 & -54.2242 \\
Placas & 208 & 107 & -3.9006 & -54.5203 \\
Rurópolis & 117 & 156 & -3.9391 & -54.8582 \\
Rurópolis & 146 & 156 & -3.9391 & -54.8582 \\
Rurópolis & 200 & 156 & -3.9391 & -54.8582 \\
Itaituba & 201 & 27 & -4.1741 & -55.8374 \\
\hline & & & &
\end{tabular}


Em geral, a qualidade dos afloramentos foi bastante boa, com bons cortes nas estradas, uma vez que as obras de asfaltamento nas mesmas expuseram bem as rochas, como ilustrado nas imagens da Fig. 4.2 (a e b). Em alguns casos a situação não foi tão favorável e só foram encontrados blocos enterrados no chão. Nesses casos, sempre foram amostrados pelo menos três blocos para confrontar os resultados e verificar se estavam in situ.

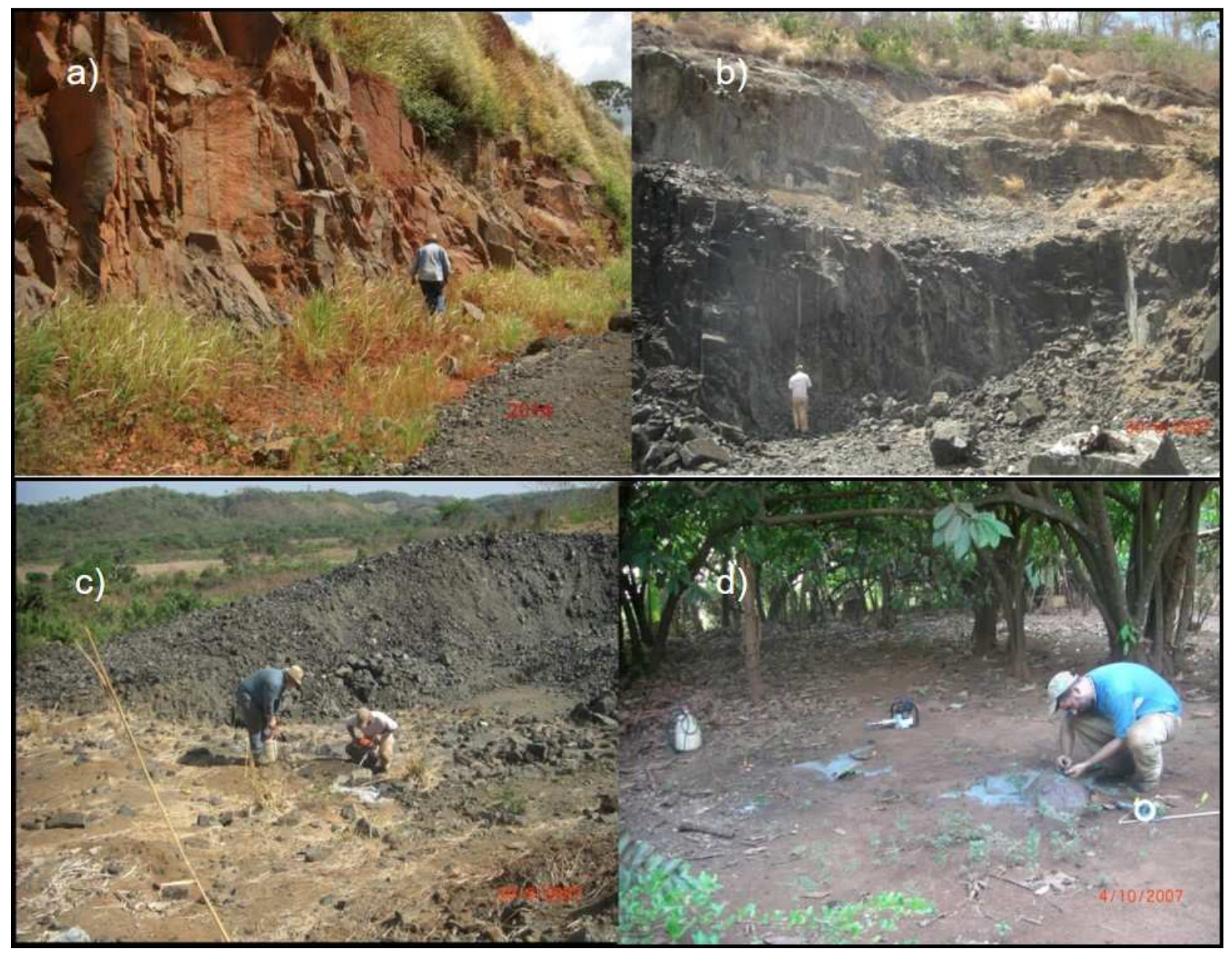

Fig. 4.2. Afloramento na região de Medicilândia (a); pedreira em Monte Alegre (b); blocos no chão da mesma pedreira (c) e na entrada de Alenquer (d).

No trabalho de campo buscamos encontrar o contato entre a rocha intrusiva e a encaixante, para realizar o teste de contato, porém o intemperismo acentuado da região amazônica não permitiu encontrar afloramentoscom os sedimentos preservados. Outra preocupação durante a amostragem foi à observação de evidências que indicassem se houve qualquer alteração da paleohorizontal provocada por alterações no declive do terreno, acomodação com a alteração, plantas ou mesmo a ação antrópica. 
A maioria das amostras coletadas para paleomagnetismo foram cilindros orientados, extraídos com um amostrador portátil (moto-serra adaptada); apenas dois blocos de mão foram coletados onde não foi possível utilizar o amostrador. Para orientação dos cilindros utilizou-se o aparato da Pomeroy, OR-2 OrientingFixture acoplado a uma bússola Brunton; insere-se o aparato no furo feito com o amostrador e nivela-se a bússola. Lendo-se o inclinômetro, obtem-se o mergulho do testemunho. É necessário marcar uma linha fiducial na direção axial do cilindro, com um fio de cobre passando por uma fenda no cano do orientador e que serve como referência para a medida do azimute com uma bússola. São descritos na caderneta de campo as posições e diferentes blocos que foram amostrados, muitas vezes um croqui para a análise de possíveis variações locais. Com o mesmo amostrador fazemos a medida do azimute solar que é obtido pelo ângulo da sombra de uma vareta vertical em uma escala angular e ligada à mesma marca fiducial. A leitura da bússola solar é importante para comparar com a leitura da bússola magnética que pode ser afetada pela própria magnetização da rocha, em grandes afloramentos, ou outros efeitos locais - linhas de alta tensão, massas metálicas nas proximidades, etc.

Retira-se então o cilindro orientado que será levado ao laboratório para ser preparado nas medidas padrão (espécimes); alternativamente podemos retirar blocos de mão orientados e levá-los diretamente ao laboratório para a preparação dos espécimes (Fig. 4.3).

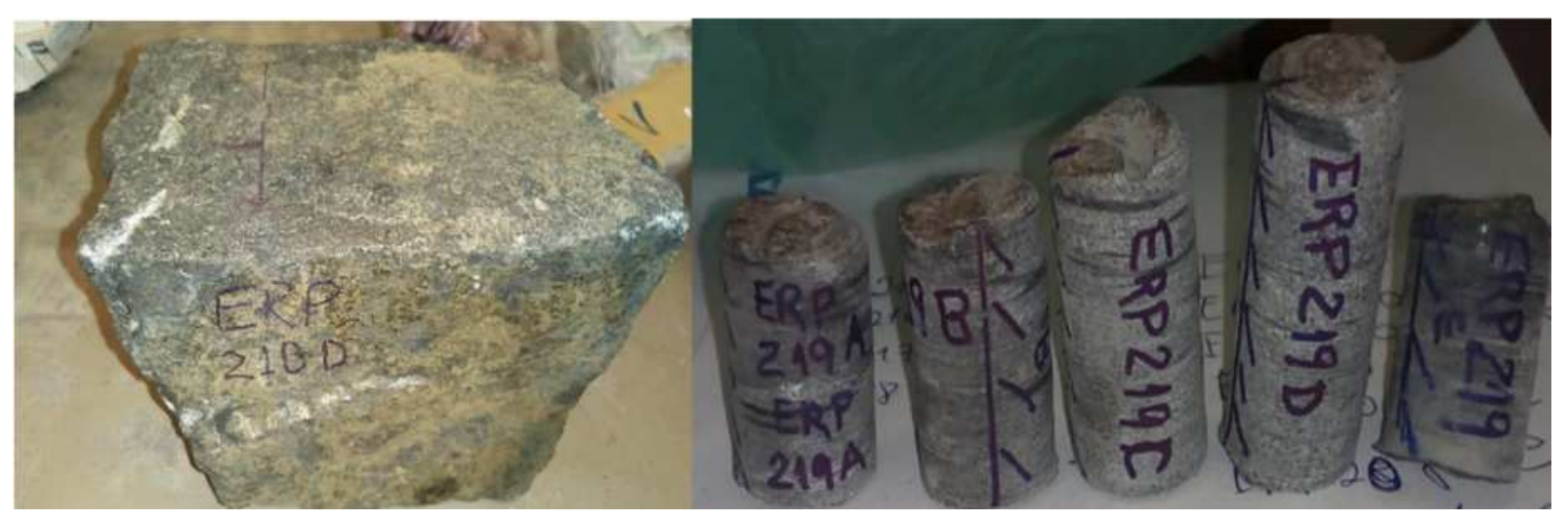

Figure 4.3. Foto de bloco de mão já orientado e cilindros extraídos em campo com suas marcas fiduciais.

Em cada sítio foram coletados, em média, cinco cilindros sempre procurando distribuí-los em partes diferentes do afloramento, afastadas de alguns metros, e extraindo pelo menos dois cilindros de cada parte (ou blocos) para avaliar possíveis variações nas direções paleomagnéticas ou problemas do afloramento. 
No laboratório de Paleomagnetismodo IAG/USP os cilindros foram cortados no tamanho padrão de $2 \mathrm{~cm}$ de altura e $2.5 \mathrm{~cm}$ de diâmetro (Fig. 4.4). Dos blocos orientados foram extraídos cilindros e destes, os espécimes padrão.No total preparou-se 322espécimes.

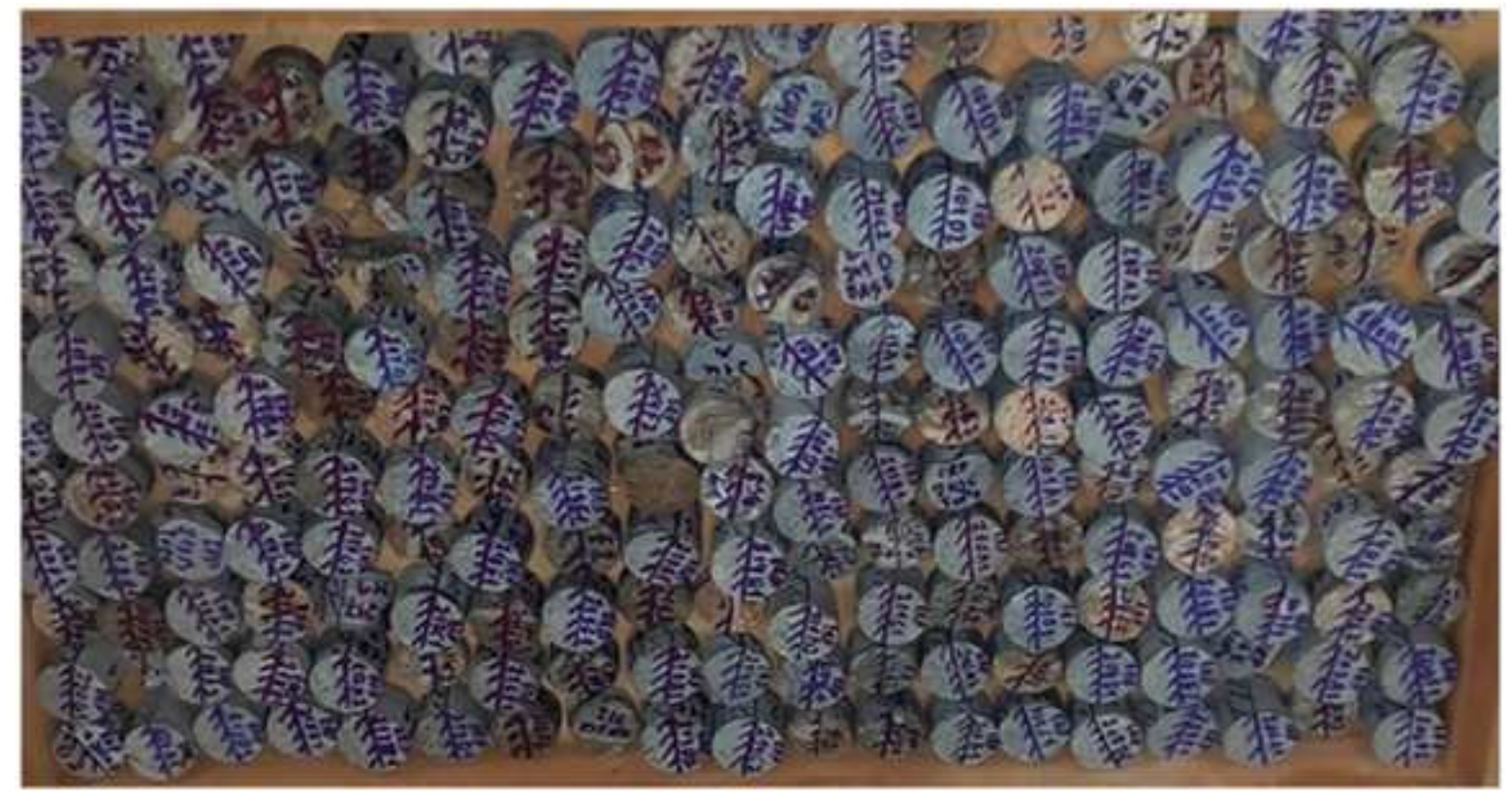

Fig. 4.4. Conjunto de espécimes padrão preparados para as medidas de magnetização e outros procedimentos.

\subsection{Análises de Laboratório}

\subsubsection{Anisotropia de susceptibilidade magnética (ASM)}

Rotineiramente, mede-se a ASM de todas as amostras, antes de serem submetidas aos processos de desmagnetização. As amostras são embaladas em filme plástico para evitar contaminação e a anisotropia medida no aparelho MFK da AGICO. A medida de cada espécime demora cerca de 5 minutos. A determinação da ASM é feita através da indução de campo muito fraco em vários eixos do espécime e a magnetização induzida é então medida. Através do programa SAFYR veiculado pela AGICO obtêm-se os resultados, com as estatísticas correspondentes, como na tela abaixo. Os resultados são posteriormente analisados com ajuda de visualização gráfica oferecida pelo programa ANISOFT, o qual também calcula os parâmetros, médias e estatísticas necessárias. 


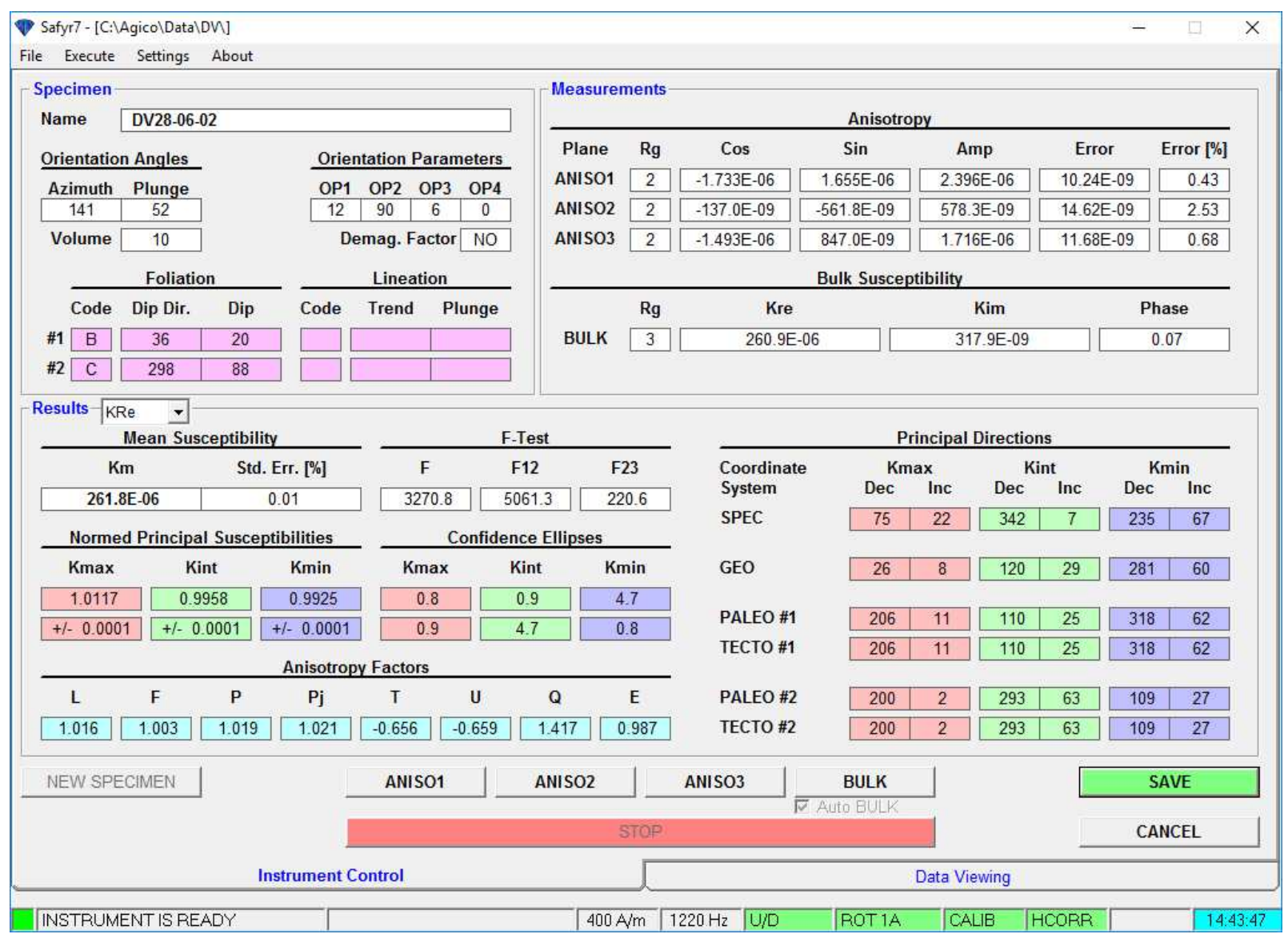

Fig. 4.5. Captura de tela do softwareSafyr7 da Agico, mostrando o resultado das medidas de ASM e os principais cálculos relacionados à determinação do elipsóide.

\subsubsection{Desmagnetizações AF e Térmica}

Os processos de desmagnetizações sucessivas são utilizados para identificar as componentes de magnetização nas amostras.

A desmagnetização por campos magnéticos alternados(AF)é eficiente em eliminar eventuais componentes secundárias e isolar a magnetização primária das rochas ígneas. O método consiste em aplicar campos alternados de intensidade máxima inicial igual $\mathrm{H}_{\mathrm{AF}}$ que possui forma de onda senoidal e decresce linearmente com o tempo (Figura 4.6). Esse processo é repetido diversas vezes com valores de $\mathrm{H}_{\mathrm{AF}}$ cada vez maiores. Ao final de cada etapa de desmagnetização, os minerais que possuírem coercividade magnética inferior a ao campo aplicado terão direções de magnetização aleatórias. Caso não haja campo magnético ambiente, a resultante será nula.Desta forma, obtêm-se uma resultante de magnetização nula nos minerais de coercividade inferior ao campo aplicado, enquanto os minerais de 
coercividade superior preservam suas remanências. Incrementos progressivos no campo AF (p.ex. de $5 \mathrm{mT}$ )são utilizados na desmagnetização AF,até a completa desmagnetização da amostra. O procedimento foi executadonos aparelhos LDA 3 e LDA 5 da Agico que possuem blindagem magnética para garantir que não haja campo magnético ambiente que induza magnetização nas amostras.

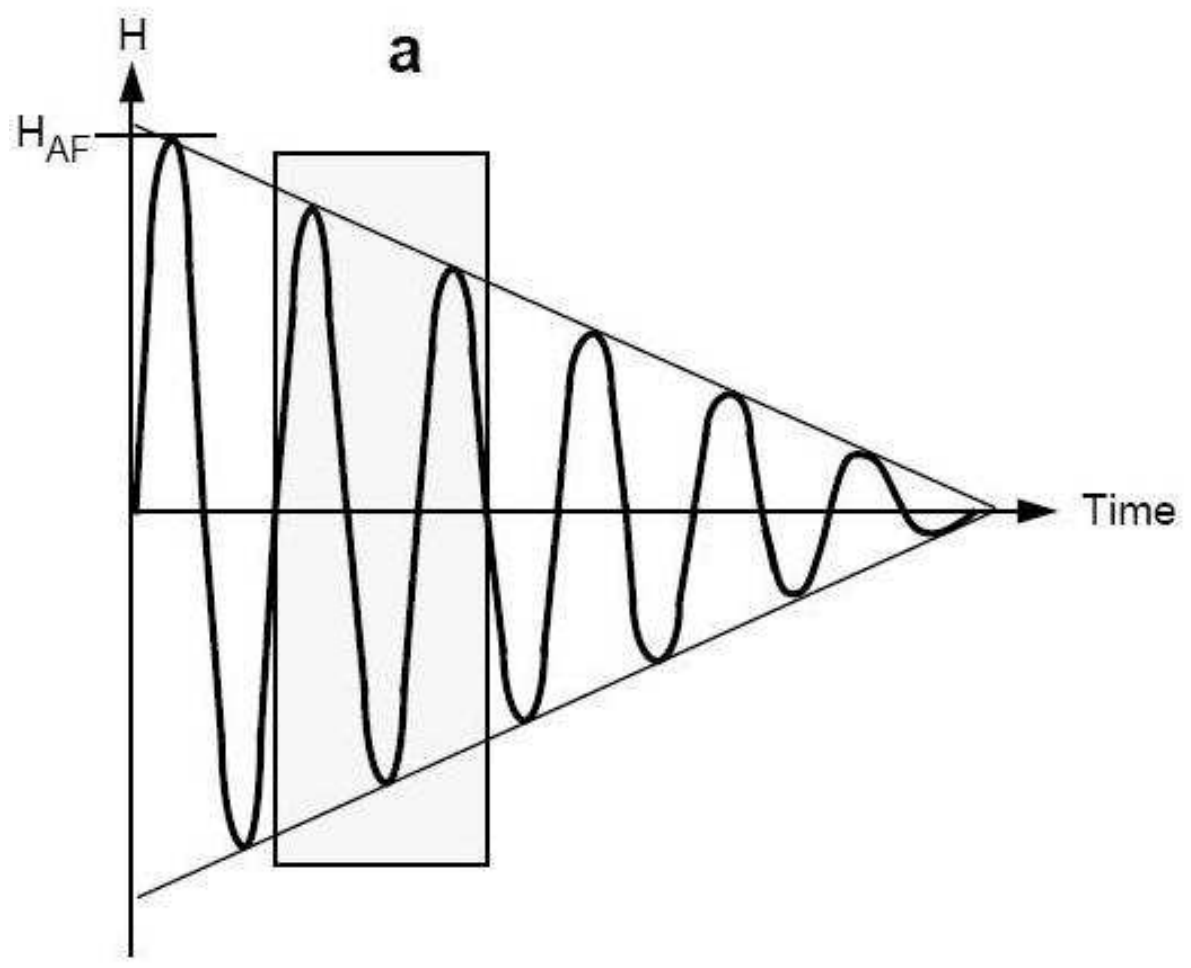

Fig. 4.6. Representação do decaimento do campo magnético alternado de intensidade máxima $\mathrm{H}_{\mathrm{AF}}$, com o tempo.

A magnetização remanente depois de cada passo de desmagnetização foi medida no magnetômetro JR6 da AGICO. Todo o processo demora em média cerca de uma hora por amostra. O objetivo é aplicar campos magnéticos sucessivamente maiores até a completa desmagnetização da amostra. Quando o portador magnético é de baixa coercividade, como a magnetita, campos magnéticos máximos da ordem de $60 \mathrm{mT}$ são suficientes para eliminar toda a remanência.

O procedimento para a desmagnetização térmica envolve aquecer uma amostra em uma temperatura $\left(\mathrm{T}_{\text {demag }}\right)$ e depois levar as amostras à temperatura ambiente novamente, em 
campo magnético nulo. Isso faz com que os grãos com temperatura de bloqueio $\left(\mathrm{T}_{\mathrm{B}}\right)$

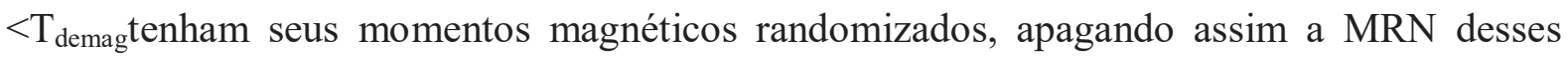
grãos. Se o processo for repetido sucessivamente a temperaturas crescentes, até a mais alta temperatura de Curie dos minerais presentes na rocha, o espécime será totalmente desmagnetizado. Cada etapa de aquecimento e resfriamento é seguida pela medida da magnetização remanente. Neste trabalho foi utilizado o forno TD48 da marca ASCScientific.

Antes de submeter às amostras às etapas de aquecimento, realizou-se etapas de desmagnetização AF até $15 \mathrm{mT}$, removendo assim, total ou parcialmente, a componente viscosa. A desmagnetização térmica, ao contrário da desmagnetização $\mathrm{AF}$, pode alterar a mineralogia magnética devido a processos de oxidação, destruição de minerais (caso da maguemita), ou outras alterações do estado físico-químico. Portanto, é importante controlar a suscetibilidade magnética após cada etapa de aquecimento-resfriamento.

\subsubsection{Identificação das Componentes de Magnetização}

Após as etapas de desmagnetização, as componentes de remanência magnética presentes nos minerais magnéticos de cada espécime, são identificadas através da Análise de Componentes Principais (PCA), usando do software REMASOFT da Agico, Fig. 4.7.Cada vetor magnetização é decomposto em suas componentes de um sistema triortogonal, que vem a ser o diagrama de Zijderveld (Zijderveld, 1967). Através de inspeção visual, segmentos de retas são ajustados aos dados da componente horizontal e vertical, com os respectivos valores das variâncias, estatística dos erros e outros parâmetros envolvidos que ajudam a superar a sobreposição de coercividades de diferentes conjuntos de minerais, e que pode prejudicar a separação correta das componentes. 


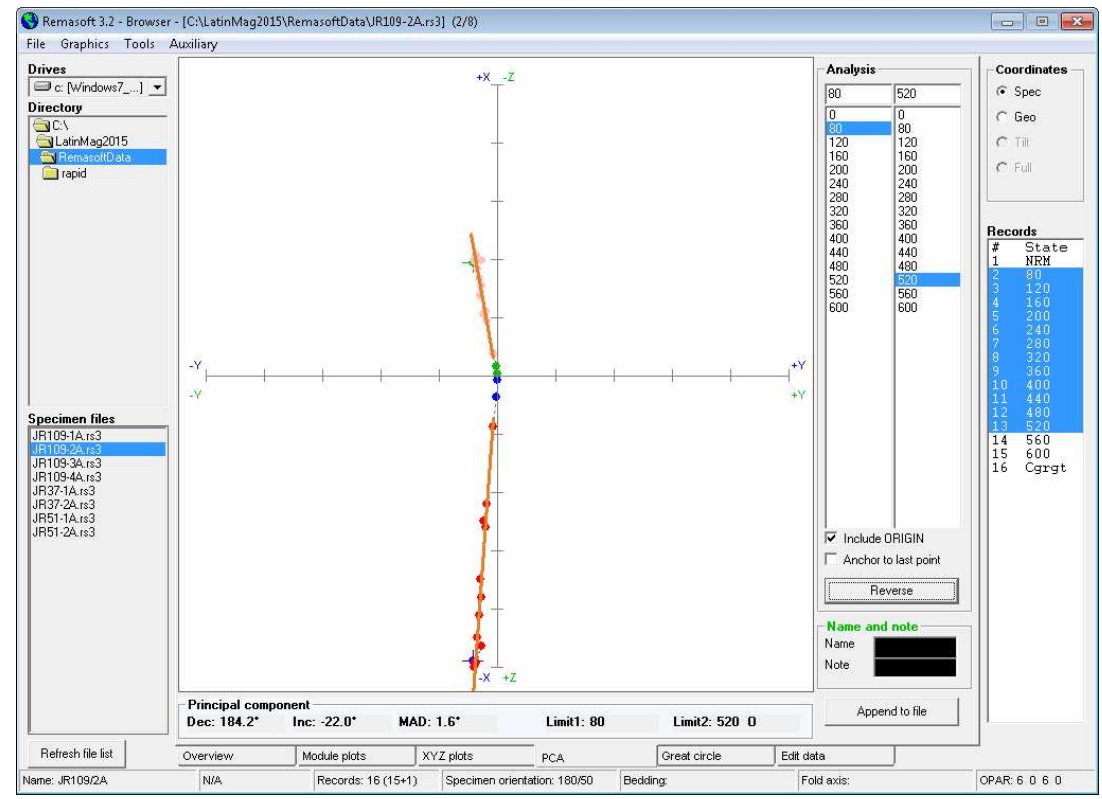

Fig. 4.7 Exemplo da rotina do programa Remasoft para selecionar o intervalo de passos no diagrama de Zijderveldresultando em componentes representadas por retas.

Se a amostra foi totalmente desmagnetizada e apenas uma componente de magnetização estiver presente ao final do processo, então os segmentos de reta convergirão para o centro do sistema de eixos.

\subsection{Mineralogia magnética}

Para a identificação e caracterização da mineralogia magnética utilizam-se várias metodologias: curvas termomagnéticas, ciclos de histerese e curvas de magnetização remanente isotérmica (MRI).

\subsubsection{Curvas termomagnéticas}

Para este procedimento preparou-se material moído e que será submetido a temperaturas extremas, aproximadamente do nitrogênio líquido e do ponto de fusão do alumínio. Logo, são acondicionadas em tubos de quartzo especiais que tem características magnéticas muito estáveis com a mudança da temperatura, como esse da imagem do site da Empresa de Instrumentação Geofísica da República Tcheca, AGICO: 


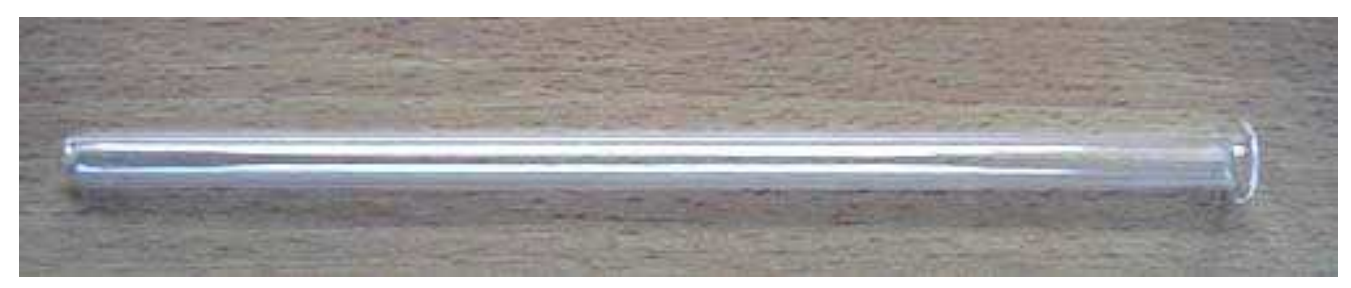

Fig. 4.8 Tubo para realização de curvas termomagnéticas, reprodução do seite da AGICO.

Para obtenção das curvas termomagnéticas, a amostra é submetida a um ciclo de aquecimento desde uma temperatura próxima ao ponto de ebulição do nitrogênio até a temperatura ambiente, para verificar a presença da transição de Verwey. A transição de Verwey acontece a uma temperatura de aproximadamente $-140^{\circ} \mathrm{C}$ e se dá devido à mudança de simetria da estrutura cristalina da magnetita causada pelo balanço das forças fundamentais envolvidas na ordenação dos átomos de ferro na rede, zerando a constante da anisotropia magnetocristalina.

O passo seguinte é obter uma curva termomagnética desde a temperatura ambiente até a temperatura de desbloqueio da magnetização (próxima à temperatura de Curie, $\mathrm{T}_{\mathrm{C}}$ ). Quando as forças caóticas envolvidas na agitação térmica superam a ordenação magnética atingimos a temperatura de desbloqueio do grão. O pico de Hopkinson é um crescimento da susceptibilidade magnética observado próximo à $\mathrm{T}_{\mathrm{C}}$ (Fig.4.9)e acontece, pois a temperatura de desbloqueio dos grãos é menor que a $\mathrm{T}_{\mathrm{C}}$.

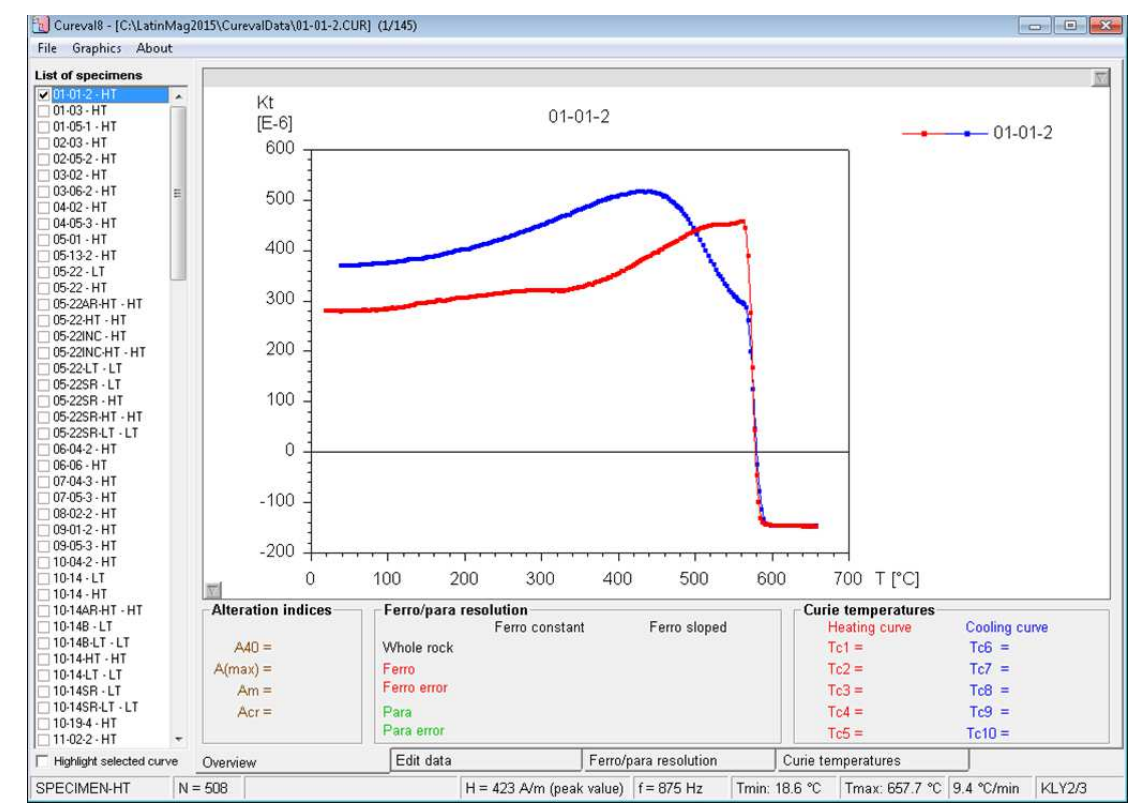

Fig.4.9 Exemplo de curva termomagnética de alta temperatura, onde se observa o pico de Hopkinson. 


\subsubsection{Curvas de histerese e magnetização remanente isotérmica (MRI)}

Um pedaço de amostra de rocha de aproximadamente um centímetro é colocado em um magnetômetro de vibração (VSM) da marca Micromag Princeton amplamente utilizado em laboratórios de paleomagnetismo no mundo. Esse aparelho registra a variação da magnetização adquirida pela amostras à medida que o campo magnético aplicado aumenta. $\mathrm{O}$ campo máximo que o aparelho pode atingir é $1 \mathrm{~T}$, o que é suficiente para atingir a saturação da magnetita, porém não satura a hematita (Fig. 4.10). O procedimento continua, medindo-se a magnetização com campos decrescentes e também com aumento e diminuição do campo em sentido oposto, completando-se assim o ciclo de histerese.

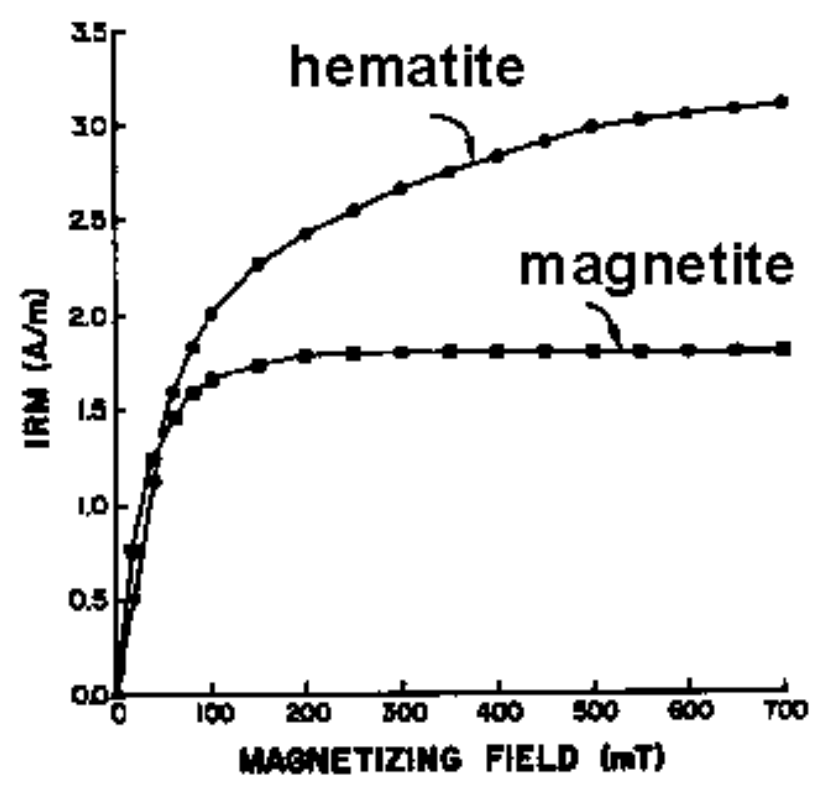

Fig. 4.10 Curvas de aquisição da MRI. Note-se que a magnetita satura rapidamente, porém a hematita não atingiu a magnetização de saturação até o campo de $700 \mathrm{mT}$.

No mesmo equipamento, deixando a amostra no mesmo lugar, pode-se repetir o processo com a aplicação de campos magnéticos sucessivamente maiores e obter a curva de MRI. A MRI avalia apenas a parte ferromagnética, pois a medida da remanência é realizada com campo nulo. 


\section{Capítulo 5 - Apresentação dos Resultados}

\subsection{Mineralogia magnética}

Curvas termomagnéticas (suscetibilidade em função da temperatura) alta e baixa temperatura (Fig. 5.1) para amostras das áreas estudadas indicaram a presença de magnetita como principal portador da remanência. No intervalo de baixas temperaturas é possível verificar, em alguns casos, a inflexão das curvas a temperaturas próximas a $-180^{\circ} \mathrm{C}$, onde acontece a transição de Verwey, caracterísitca da magnetita. A altas temperaturas nota-se o pico de Hopkinson antes da queda de suscetibilidade a temperaturas próximas da $T_{C}$ da magnetita.
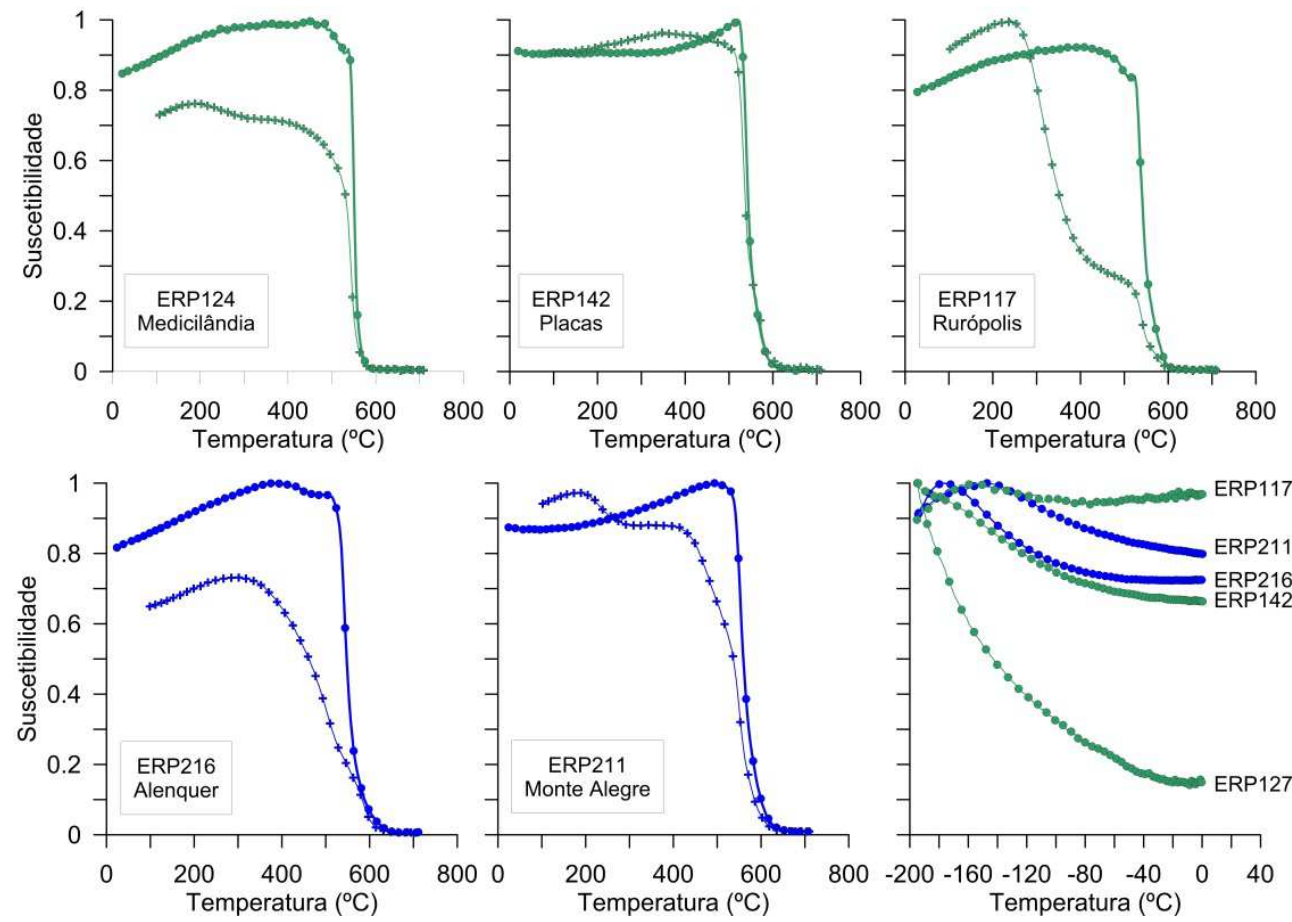

Fig. 5.1.Curvas termomagnéticas de alta e baixa temperatura das áreas estudadas. As curvas foram normalizadas. As curvas da região norte estão em azul e do sul, em verde. Círculos indicam aquecimento e cruzes, resfriamento.

O intervalo observado para essas temperaturas foi de $\sim 500$ a $600{ }^{\circ} \mathrm{C}$. Desta forma, verifica-se que se trata de magnetitas muito oxidadas a altas temperaturas, isto é, com muito baixo conteúdo de Ti. Em alguns sítios nota-se a presença exclusiva de magnetita, como é o caso de ERP142 de Placas. As demais curvas são irreversíveis e, embora não apresentem inflexões durante o 
aquecimento sugestivas da presença de outro mineral, as curvas de resfriamento indicam que houve transformação mineralógica durante o processo. Em lâminas delgadas notou-se a presença de sulfetos que pode ser pirita, uma vez que aparentemente não há indicação de ser portador de remanência. De acordo com Wang et al. (2008), a pirita sofre transformação ao ser aquecida na atmosfera, num processo que leva à formação de hematita (pirita $\rightarrow$ pirrotita $\rightarrow$ magnetita $\rightarrow$ hematita). Desta forma, no final do processo haveria diminuição de suscetibilidade.
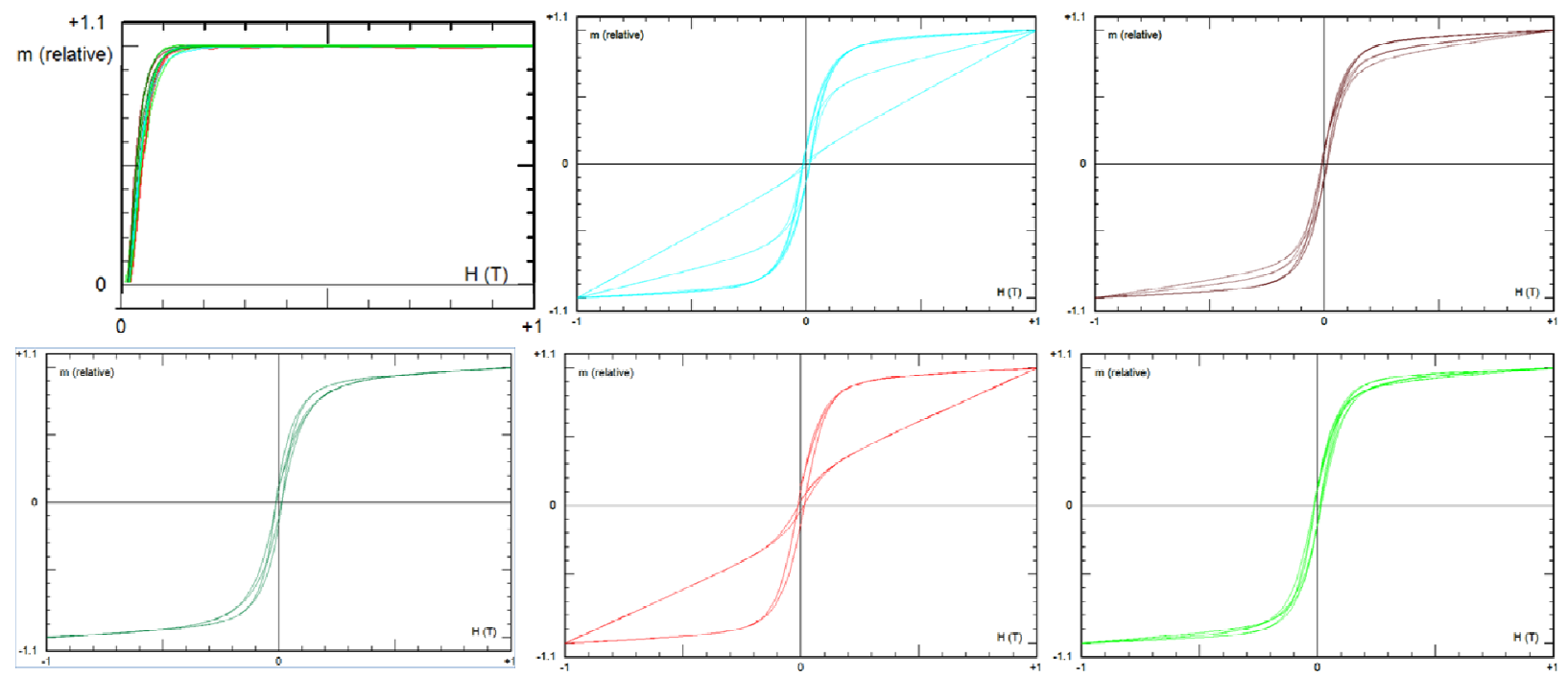

Fig. 5.2.Curvas de aquisição de magnetização (IRM) e histerese para amostras das áreas de estudo. As curvas de IRM e histerese foram normalizadas e o campo máximo aplicado foi de $1 \mathrm{~T}$. Cores identificam,nas curvas de histerese e IRM, as regiões de estudo:azul, Medicilândia; vermelho escuro, Placas; verde escuro, Rurópolis; vermelho claro, Monte Alegree verde claro, Alenquer.

As curvas de aquisição da magnetização isotérmica (IRM)foram obtidas submetendo as amostras a campos máximos de $1 \mathrm{~T}$ e atingem a saturação rapidamente, como esperado para magnetitas. Esse comportamento foi verificado para todas as amostras.As curvas IRM mostradas na Fig. 5.2 são muito similares para todas as regiões e não mostram evidências de um segundo portador magnético.

As curvas de histerese (Fig. 5.2) foram obtidas variando o campo aplicado a até $1 \mathrm{~T}$ e foram corrigidas da parte paramagnética. A magnetização de saturação é atingida rapidamente em torno de $120 \mathrm{mT}$ e o campo coercivo médio é de aproximadamente $15 \mathrm{mT}$, o que é característico de 
minerais de baixa a média coercividade. As curvas são similares, e não apresentam formas ou inflexões (p. ex., cintura de vespa) que indiquem a presença de outras populações de minerais.

Os dados acima apontam claramente para um único portador magnético nas amostras Penatecaua - a magnetita - apontando para magnetização remanente de origem térmica e, portanto, primária.

\subsection{Anisotropia de Susceptibilidade Magnética}

Os resultados de ASM estão dispostos na Fig. 5.3. e estão organizados por áreas, como os demais dados e repreesntou-se os dados por espécime analisado. Foram descartados dados de amostras com claras evidências de não estar in situ.Nos diagramas direcionais, nota-se que existe uma tendência das direções do menor autovalor (eixo k3) de se agrupar ao redor de uma média próximo à vertical; o eixo k1 (maior autovalor), por sua vez, é, em geral, horizontal ou subhorizontal $\left(\mathrm{Inc}<30^{\circ}\right)$. O eixo k2, de forma geral, também se distribui no plano horizontal a subhorizontal, indicando que a máxima suscetibilidade está contida nesses planos. Este padrão é compatível com a ASM esperada para fluxos de magma colocados como derrames ou soleiras. Indicam também que não houve alteração da paleohorizontal depois da colocação dos corpos. 

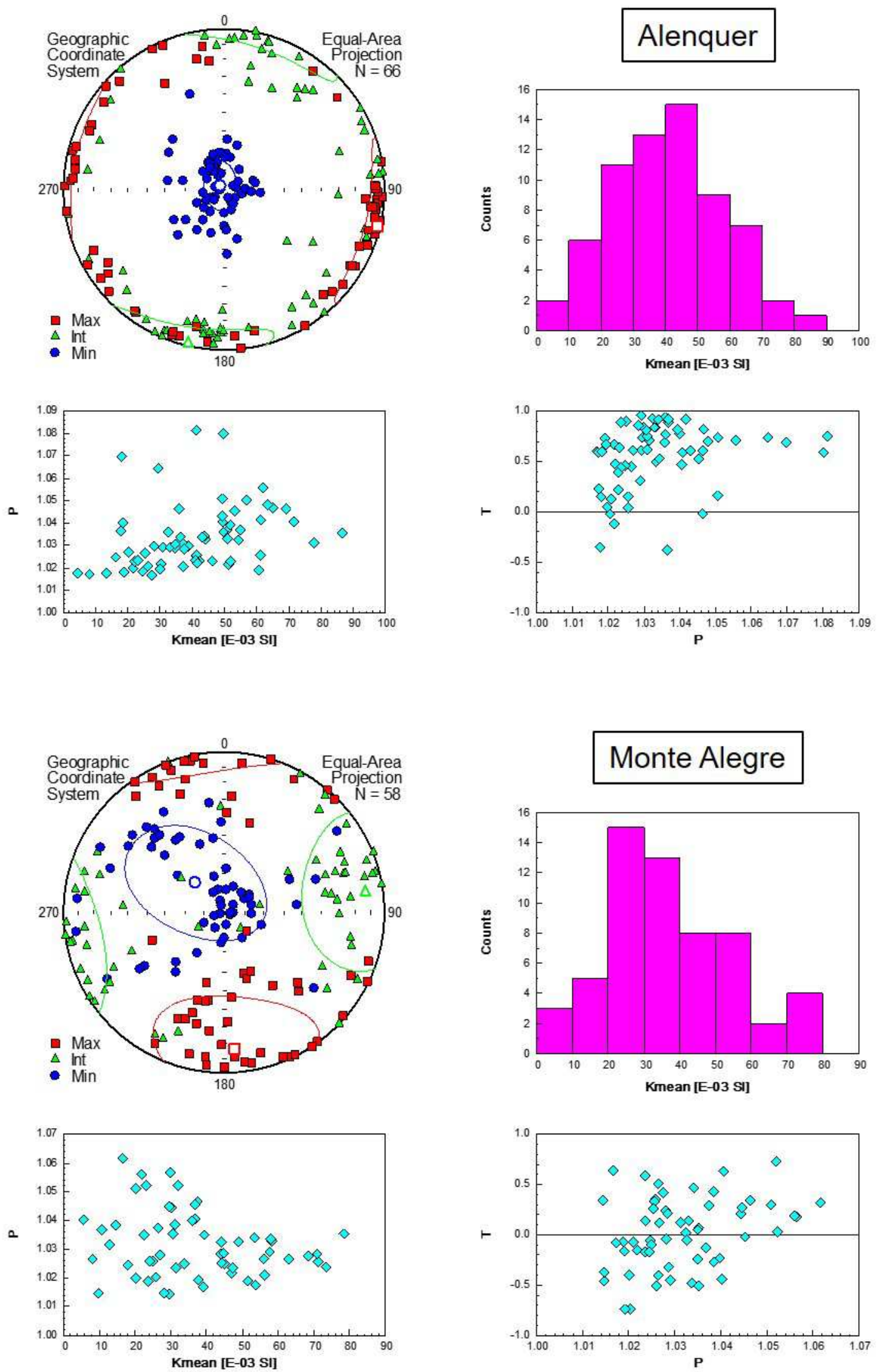

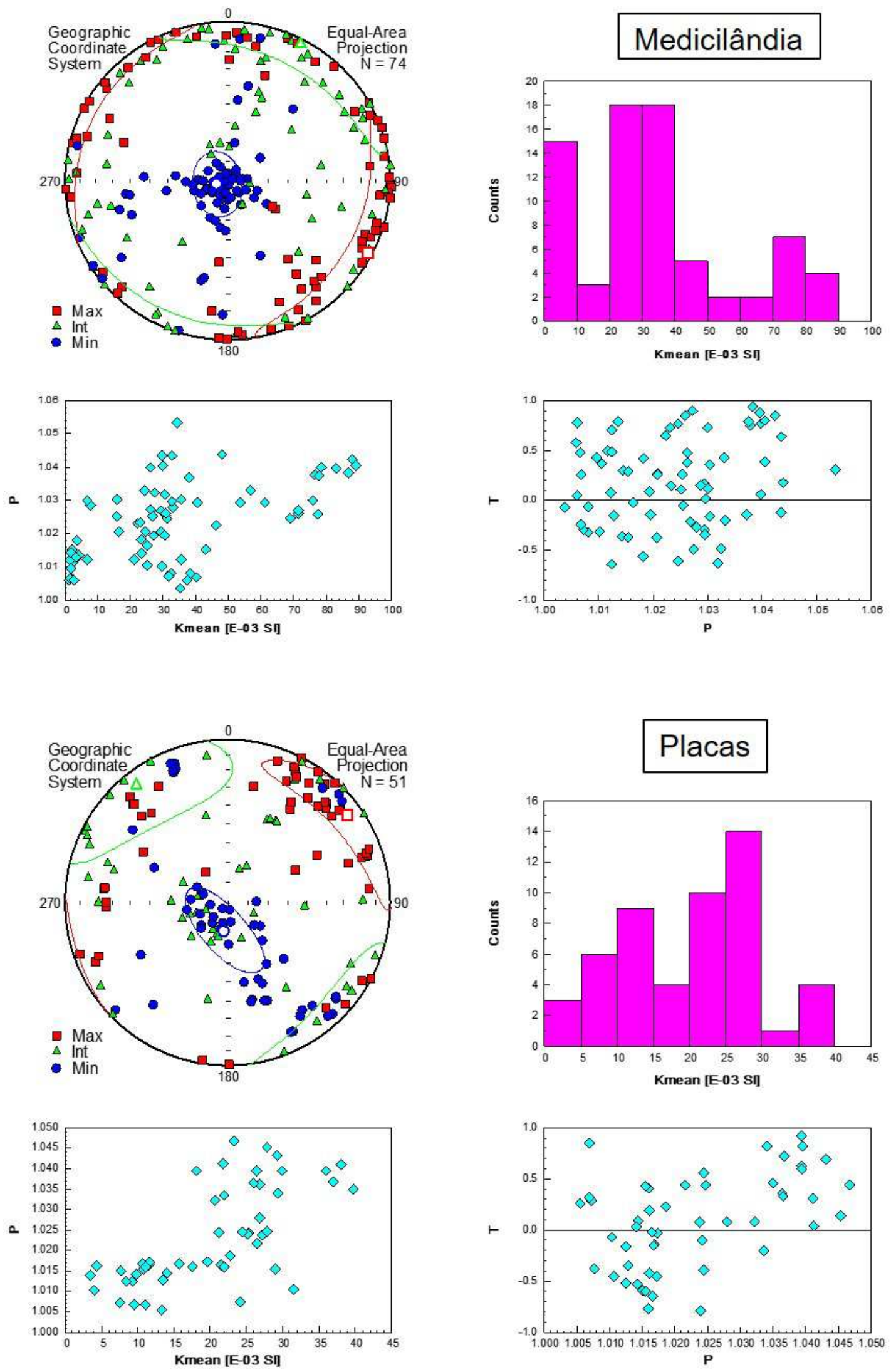

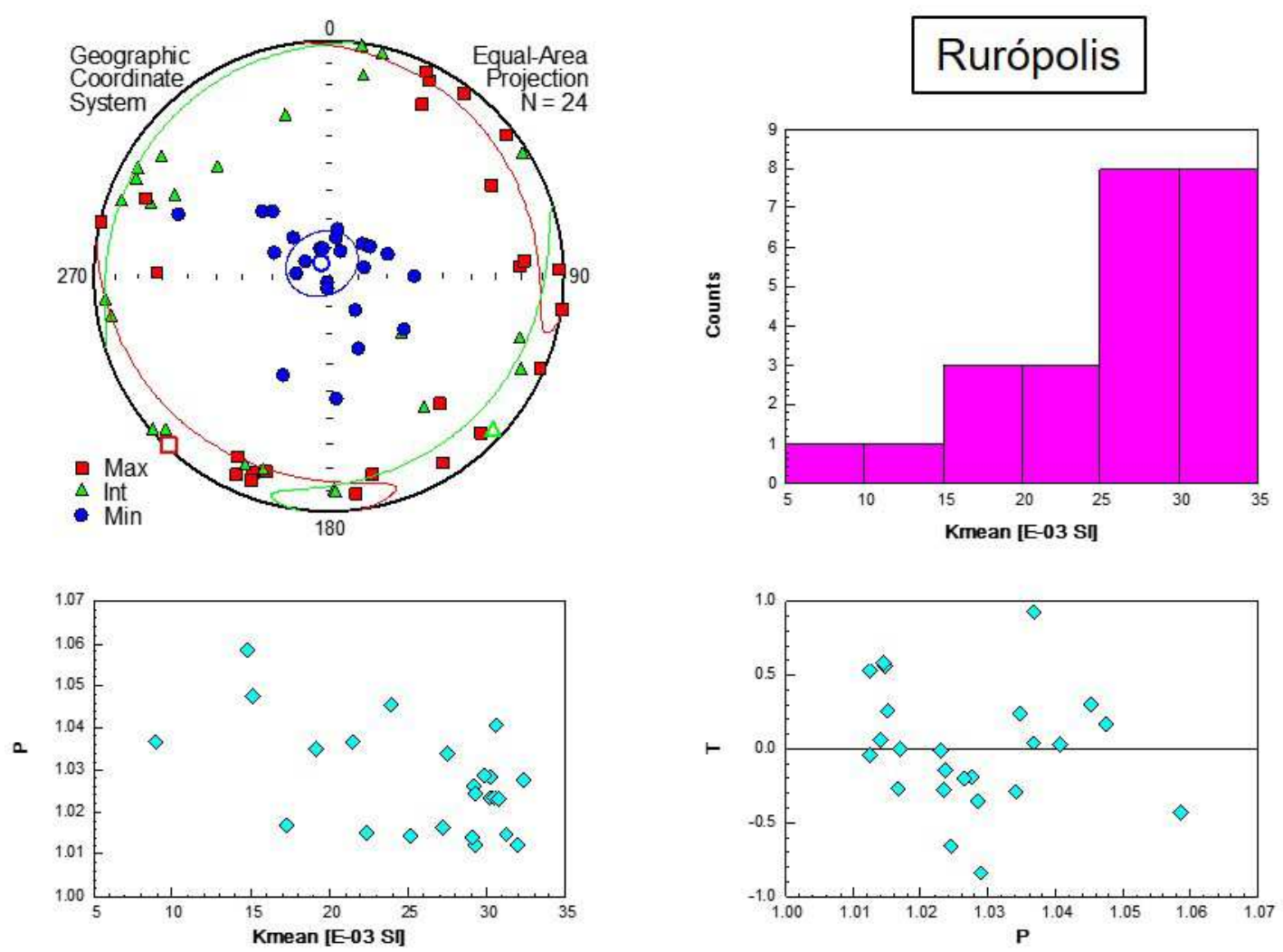

Fig. 5.3. Resultados da ASM, por localidade e se excluindo sítios ou blocos com indícios de não estar in situ, indicando os eixos médios (k1, k2, k3), histograma de susceptibilidade, variação do grau de anisotropia $(\mathrm{P})$ em função da susceptibilidade e variação do fator de forma(T) em função de $\mathrm{P}$.

Entretanto, na região de Monte Alegre, nota-se dispersão maior dos dados, com maiores ângulos para k1 e k2. Essas diferenças podem ser vistas na Fig. 5.4 e correspondem aos sítios ERP101 e ERP214, com inclinações médias de $\mathrm{k} 1$ e $\sim 40^{\circ}$ e $51^{\circ}$, respectivamente. Esses sítios podem corresponder a diques que não foram reconhecidos no campo devido à condição dos afloramentos, mas também podem ter seus resultados alterados devido ao tectonismo da região de Monte Alegre (Domo de Monte Alegre), como descritoem diversos trabalhos (Figueira et al., 2012; Montalvão et al., 1975).Este aspecto será analisado na próxima sessão.

A suscetibilidade magnética de volume apresentada na forma de histogramas (Fig. 5.3) é muito similar entre as diversas regiões. Os histogramas apresentam maior frequência de valores no intervalo $25-40 \times 10^{-3} \mathrm{SI}$. O grau de anisotropia representado pelo parâmetro $\mathrm{P}$ é relativamente baixo, chegando no máximo a 1.09 . 
Os parâmetros de anisotropia relacionados à forma revelam tendência geral para a forma oblata (gráficos T x P) para a maioria das amostras e comportamento de foliação horizontal. Em particular, as amostras de Alenquer mostram essa forma quase que exclusivamente. Embora alguns sítios mostrem agrupamentos dos eixos de maior autovalor, não é possível definir lineação ou tendência clara quando se considera o conjunto de sítios relacionados à mesma soleira. Exceção é feito à região de Alenquer, onde provavelmente a predominância é de diques, com orientação NNW-SSE e o mesmo se verifica na tendeência geral dos eixos k1.O resumo geral de todos os resultados de ASM estão no Anexo I.
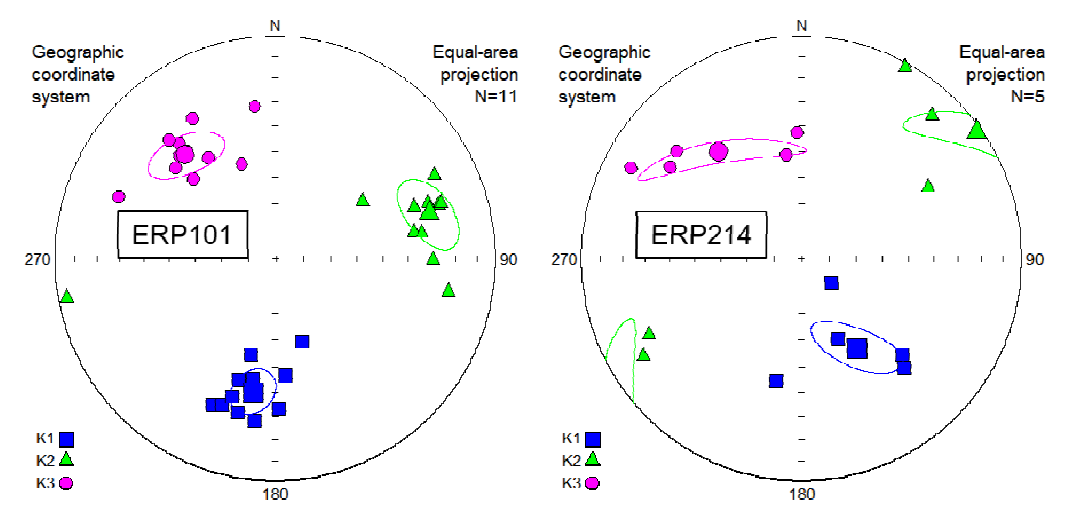

Fig. 5.4. Distribuição dos eixos de anisotropia dos sítios ERP101 e ERP214 de Monte Alegre.

\subsection{Identificação das componentes características de magnetização}

Foi realizada desmagnetização AF em amostras de todos os sítios, em campos de até $60 \mathrm{mT}$, em passos de 5 ou $10 \mathrm{mT}$. Em geral, acima de $50 \mathrm{mT}$ os resultados já apresentavam bastante ruido e dispersão das direções, com intensidades da remanênciamneor do que $10 \%$ do valor total da MRN. (Fig. 5.5a).As desmagnetizações térmicas foram realizadas em temperaturas de até $580^{\circ} \mathrm{C}$, em passos de $50^{\circ} \mathrm{C}$. Antes, porém, realizou-se desmagnetizações $\mathrm{AF}$ de até $15 \mathrm{mT}$ que removem com facilidade as componentes secundárias existentes nos minerais de menor coercividade (Fig. 5.5b). A magnetização remanente foi totalmente eliminada em cerca de $580^{\circ} \mathrm{C}$. Esses resultados confirmam a magnetita ou titanomagnetita com baixo teor de $\mathrm{Ti}$ como principal portador magnético. 


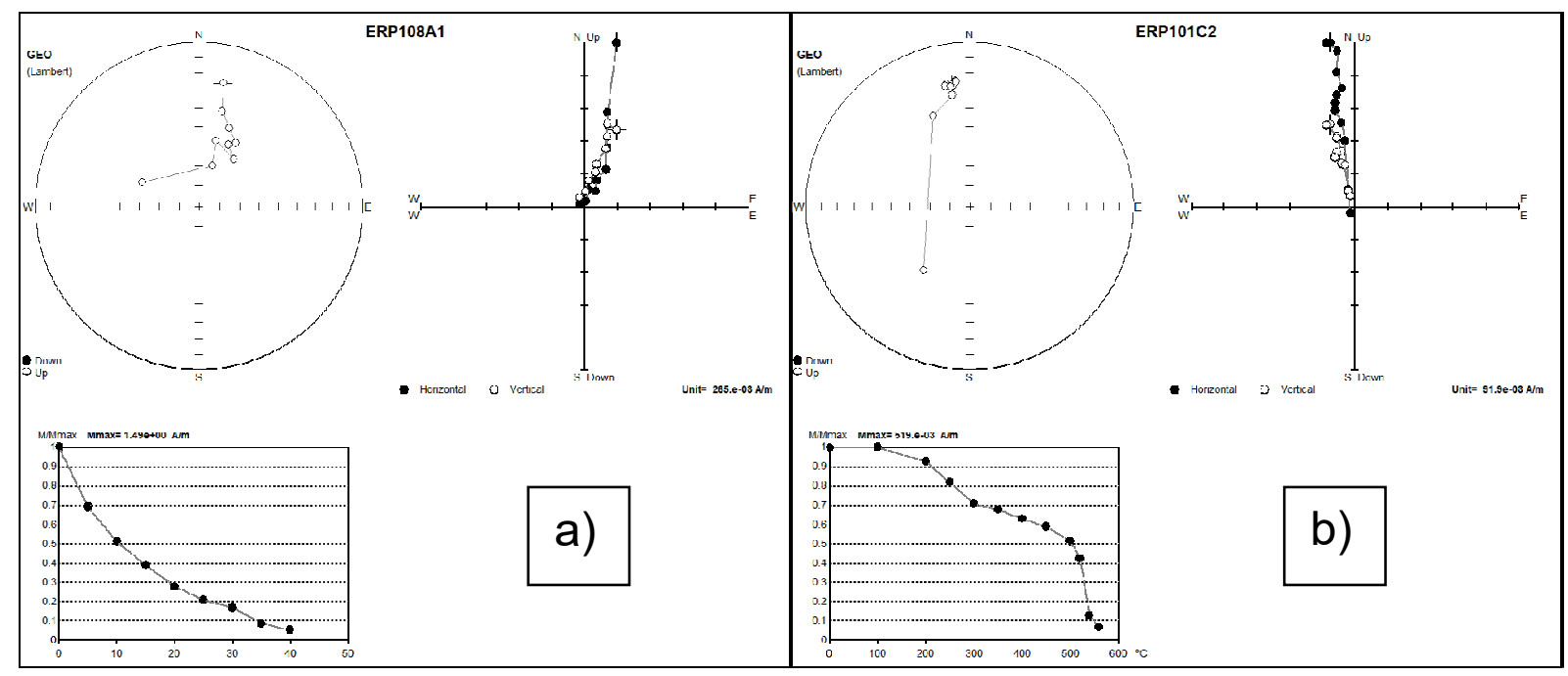

Fig. 5.5. Exemplos de desmagnetização por campos magnéticos alternados (a) e desmagnetização térmica (b). O comportamento do vetor magnetização durante as etapas dos processos de desmagnetização está representado em rede estereográfica e em projeções no plano horizontal e vertical (diagramas de Zijderveld). Os gráficos cartesianos representam a variação da intensidade da remanência em função do campo aplicado ou temperatura.

Ambos os processos foram eficientes em desmagnetizar as amostras e revelar a componente mais estável da remanência, como visto no exemplo da Fig. 5.6, para dois espécimes de um mesmo sítio da região de Medicilândia. Nota-se, entretanto, que as duas amostras apresentam componentes de baixa coercividade facilmente removidas nos passos iniciais das desmagnetizações.

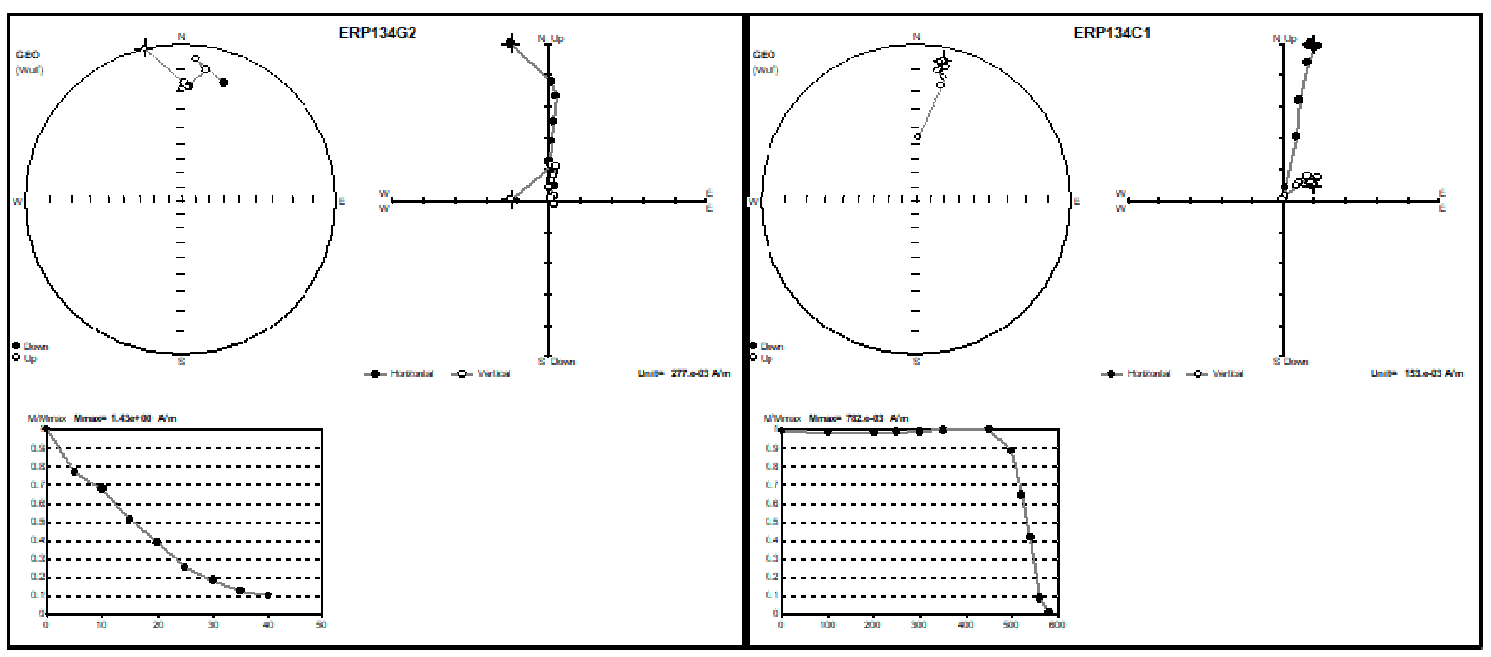

Fig. 5.6. Exemplos de desmagnetização AF (esquerda) e térmica (direita) para espécimes do mesmo sítio. 
Outros exemplos da eficiência da desmagnetização são dados na Fig. 5.7.As componentes de magnetização de cada espécime foram calculadas através daAnálise de Componentes Principais (PCA) e, para cada sítio calculou-se a direção média característica. Os resultados estão dispostos na Tabela 1.

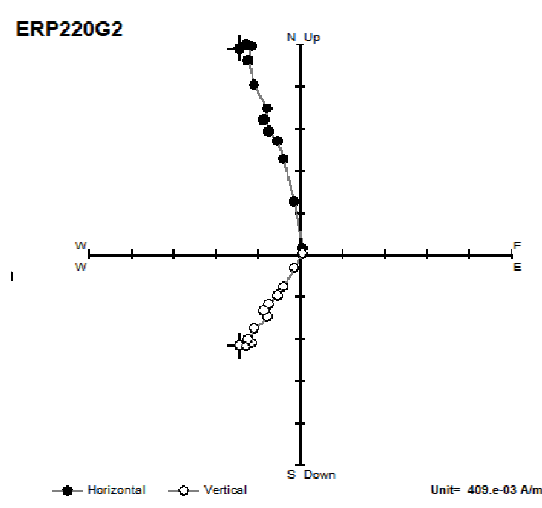

ERP130A1

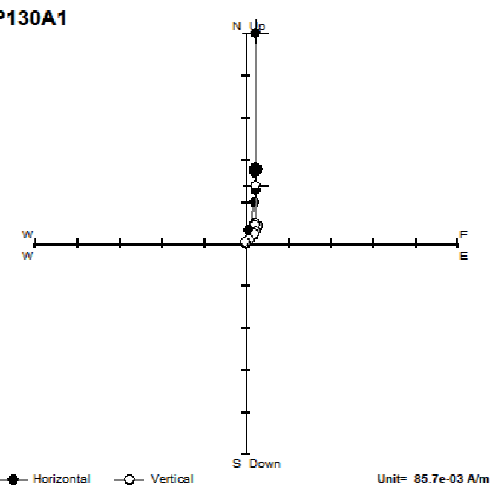

ERP200A2

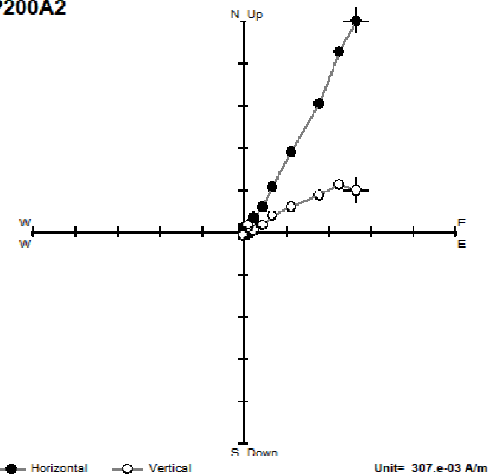

Fig. 5.7. Diagramas de Zijderveld de algumas amostras representativas das localidades analisadas neste estudo.

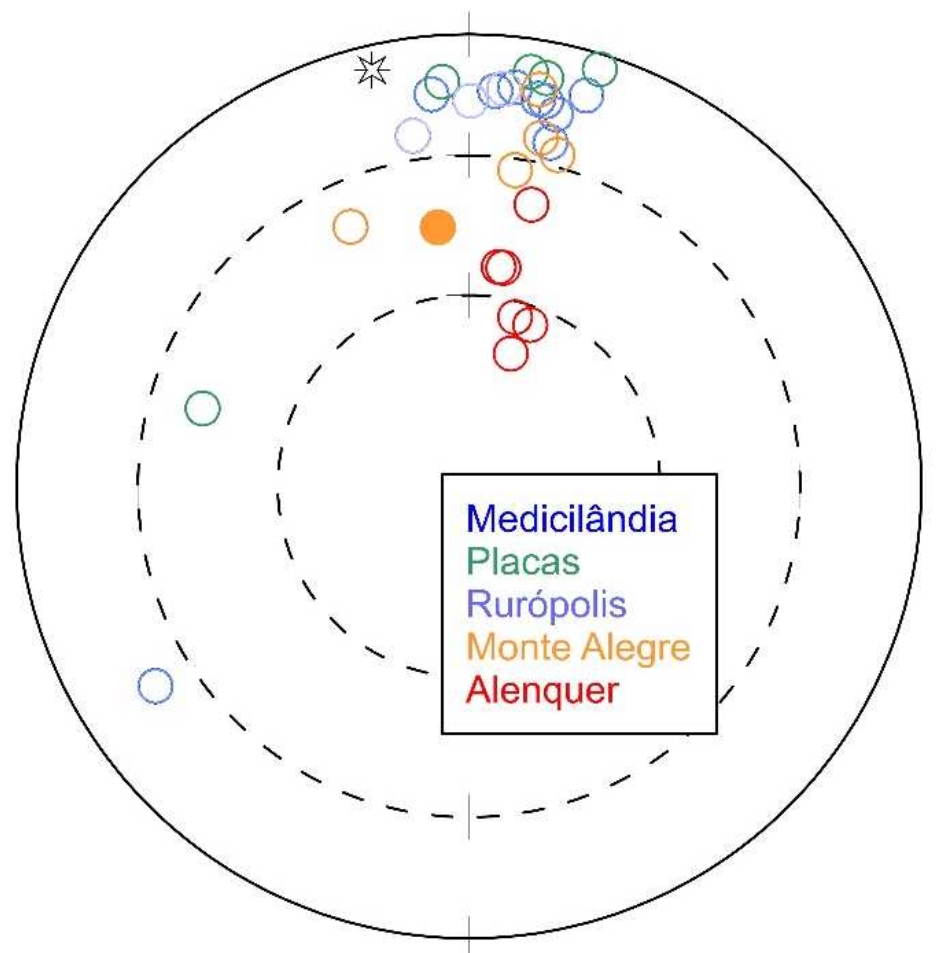

Fig. 5.8. Direções características médias para os sítios das diferentes áreas estudadas. Círculos abertos representam inclinações negativas e o círculo fechado, inclinação positiva. A estrela é o campo magnético atual, calculado para um ponto médio da área. 
Tabela 5.1. Direções médias por sítios de amostragem e respectivos PGVs

\begin{tabular}{|c|c|c|c|c|c|c|c|c|c|}
\hline \multirow[b]{2}{*}{ Localidade } & \multirow[b]{2}{*}{ Sítio } & \multicolumn{6}{|c|}{ Direção de Magnetização Média } & \multicolumn{2}{|c|}{ PGVs } \\
\hline & & $\mathbf{n}$ & Dec. $\left({ }^{\circ}\right)$ & Inc. $\left({ }^{\circ}\right)$ & $\alpha_{95}\left({ }^{\circ}\right)$ & $\mathbf{k}$ & $\mathbf{R}$ & Lat. $\left({ }^{\circ}\right)$ & Long. $\left(^{\circ}\right)$ \\
\hline Alenquer & $215^{*}$ & 7 & 7.70 & -54.10 & 9.8 & 39.17 & 6.85 & 56.1 & 113.6 \\
\hline Alenquer & 216 & 6 & 12.50 & -39.80 & 9.2 & 54.13 & 5.91 & 65.7 & 96 \\
\hline Alenquer & $217^{*}$ & 7 & 15.20 & -63.00 & 8.1 & 56.44 & 6.89 & 44.9 & 109.5 \\
\hline Alenquer & $218^{*}$ & 4 & 20.80 & -63.40 & 11.3 & 67.14 & 3.96 & 43 & 105.1 \\
\hline Alenquer & 219 & 6 & 8.90 & -54.10 & 11 & 38.23 & 5.87 & 55.9 & 112.1 \\
\hline Alenquer & 220 & 5 & 353.10 & 45.80 & 17.6 & 19.82 & 4.80 & 60.3 & 292.9 \\
\hline Medicilândia & 123 & 7 & 354.50 & -14.70 & 5.9 & 106.55 & 6.94 & 83.2 & 280.3 \\
\hline Medicilândia & 124 & 6 & 16.70 & -11.20 & 6.9 & 96.35 & 5.95 & 73.2 & 45.5 \\
\hline Medicilândia & 125 & 6 & 3.80 & -14.10 & 3.1 & 463.23 & 5.99 & 84.7 & 82.6 \\
\hline Medicilândia & 127 & 6 & 13.10 & -17.60 & 4.4 & 232.74 & 5.98 & 75.8 & 61.2 \\
\hline Medicilândia & 130 & 7 & 10.10 & -14.80 & 6.7 & 83.25 & 6.93 & 79.2 & 60 \\
\hline Medicilândia & 132 & 7 & 11.30 & -15.00 & 5.5 & 121.95 & 6.95 & 78 & 57.9 \\
\hline Medicilândia & 134 & 7 & 6.60 & -12.70 & 4.3 & 195.72 & 6.97 & 82.7 & 62.1 \\
\hline Medicilândia & 139 & 7 & 13.30 & -24.70 & 4.8 & 160.30 & 6.96 & 73.8 & 73.5 \\
\hline Medicilândia & $140^{*}$ & 6 & 237.50 & -20.20 & 6.1 & 123.32 & 5.96 & -31 & 202.5 \\
\hline Monte Alegre & 101 & 6 & 10.10 & -12.40 & 8.5 & 63.11 & 5.92 & 79 & 59.4 \\
\hline Monte Alegre & 108 & 5 & 8.30 & -32.70 & 19.1 & 16.97 & 4.76 & 71.9 & 99.5 \\
\hline Monte Alegre & 210 & 6 & 15.00 & -27.10 & 9.8 & 48.00 & 5.90 & 70.7 & 76.7 \\
\hline Monte Alegre & 211 & 7 & 11.70 & -24.10 & 3.8 & 251.62 & 6.98 & 74.2 & 79 \\
\hline Monte Alegre & $214^{*}$ & 6 & 335.50 & -40.50 & 18.7 & 13.85 & 5.64 & 58.1 & 172 \\
\hline Placas & 142 & 6 & 10.70 & -9.30 & 12.1 & 31.47 & 5.84 & 79.3 & 40.2 \\
\hline Placas & 145 & 6 & 356.20 & -11.80 & 9.9 & 47.00 & 5.89 & 85.6 & 186.0 \\
\hline Placas & 205 & 4 & 17.40 & -3.80 & 24.5 & 15.07 & 3.80 & 72.6 & 30.1 \\
\hline Placas & $206^{*}$ & 4 & 286.30 & -42.20 & 7.8 & 140.07 & 3.98 & 16.4 & 191.5 \\
\hline Placas & 208 & 7 & 8.50 & -8.30 & 9.2 & 44.12 & 6.86 & 81.5 & 37.5 \\
\hline Rurópolis & 117 & 6 & 350.90 & -24.30 & 3.6 & 344.01 & 5.99 & 77.4 & 169.9 \\
\hline Rurópolis & 146 & 6 & 0.20 & -16.70 & 4.1 & 263.22 & 5.98 & 85.4 & 122.5 \\
\hline Rurópolis & 200 & 7 & 5.00 & -13.30 & 6.2 & 95.70 & 6.94 & 84.2 & 64.8 \\
\hline
\end{tabular}

Para o cálculo das direções médias selecionou-se as direções obtidas pela PCA de um número $\mathrm{N}>3$ de espécimes com direções concordantes e que não apresentavam indícios de pertencer a blocos que não estavam in situ. As direções de magnetização características da Tabela 1 estão representadas na Fig. 5.8. Note-se que a maioria das direções apresentam inclinações negativas e declinações próximas nos quadrantes um e quatro, o que corresponde a magnetização de polaridade normal. 


\section{Capítulo 6 - Discussão e Conclusões}

$\mathrm{Na}$ sessão anterior, a Fig. 5.8 mostra que as direções paleomagnéticas da parte sul (Medicilândia, Placas e Rurópolis) formam grupos muito coesos, indicando que essas soleiras, apesar do volume de magma, tiveram resfriamento rápido registrando pouca variação do campo geomagnético. Na parte norte (Monte Alegre e Alenquer) existe dispersão muito maior dos dados paleomagnéticos, em especial em Alenquer, cujos dados se afastam mais do grupo do sul, embora sejam coerentes entre si. Considerando que o intervalo de idades determinadas para o magmatismo Penatecaua (Davies et al., 2017) é muito pequeno (201.525 $\pm 0.065 \mathrm{Ma})$, conclui-se que a dispersão dos dados deve significar o registro de diferentes fases da variação secular. De qualquer forma, deve-se ressaltar que todas as direções são de polaridade normal, embora aparentemente alguns sítios (ERP220, ERP140, ERP206) apresentem direções anômalas. Note-se também, que as direções diferem do campo geomagnético atual na área de estudo.

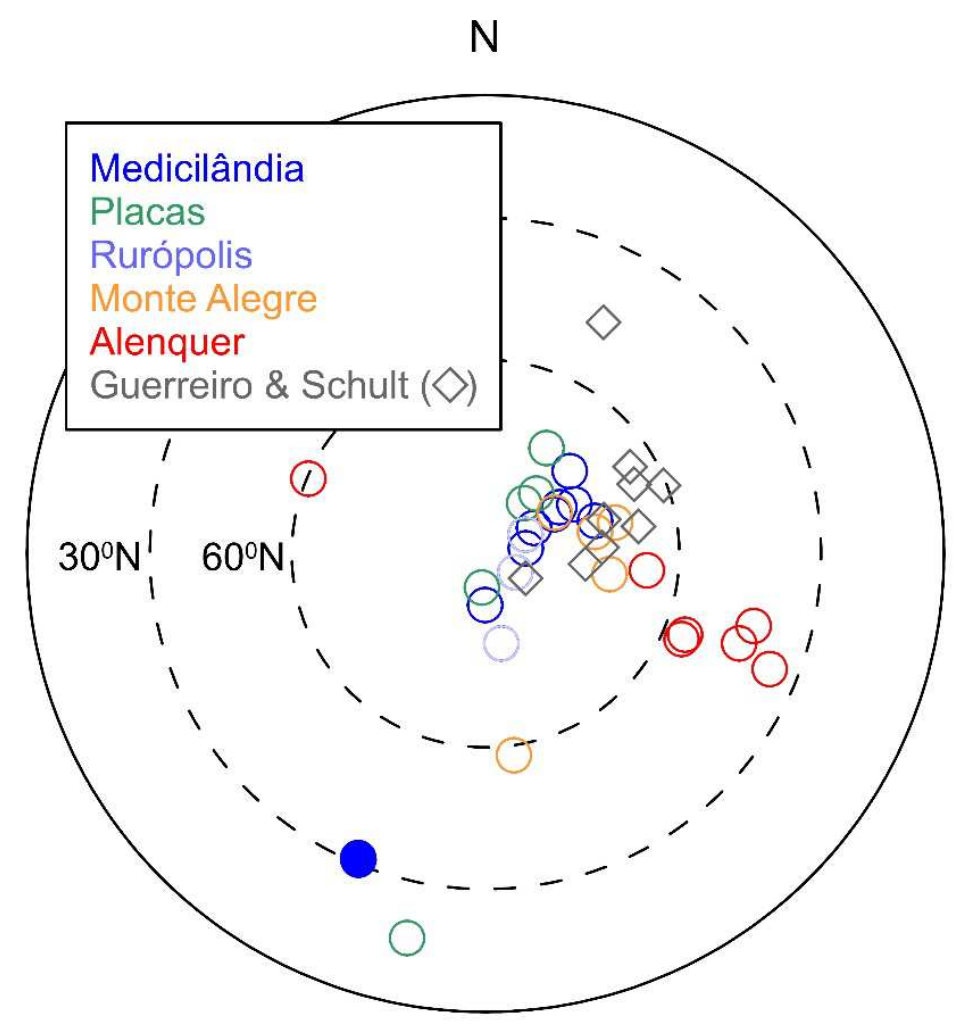

Fig. 6.1. PGVs para correspondentes a cada sítio de amostragem, diferenciando as áreas de proveniência. Os losangos correspondem aos dados de Guerreiro \& Schult (1986) da área de Monte Alegre. Símbolos abertos são PGVs no hemisfério norte e cheio, no hemisfério sul. 
Para cada direção média de magnetização calculou-se o polo geomagnético virtual (PGV) correspondente. Os PGVs estão representados na Fig. 6.1. Nessa figura incluiu-se também os PGVs calculados anteriormente para o Penatecaua (Guerreiro \& Schult, 1986) nas proximidades de Monte Alegre.Os dados de Guerreiro \& Schult (1986) estão listados na tabela da Fig. 6.2. Esses dados combinam muito bem com aqueles calculados neste trabalho. Os dados que diferem do conjunto são os de Alenquer que se situam a menores latitudes. PGVscom latitudes menores do que $60^{\circ}$ também são encontrados em outras áreas e podem estar relacionados a um campo transicional.

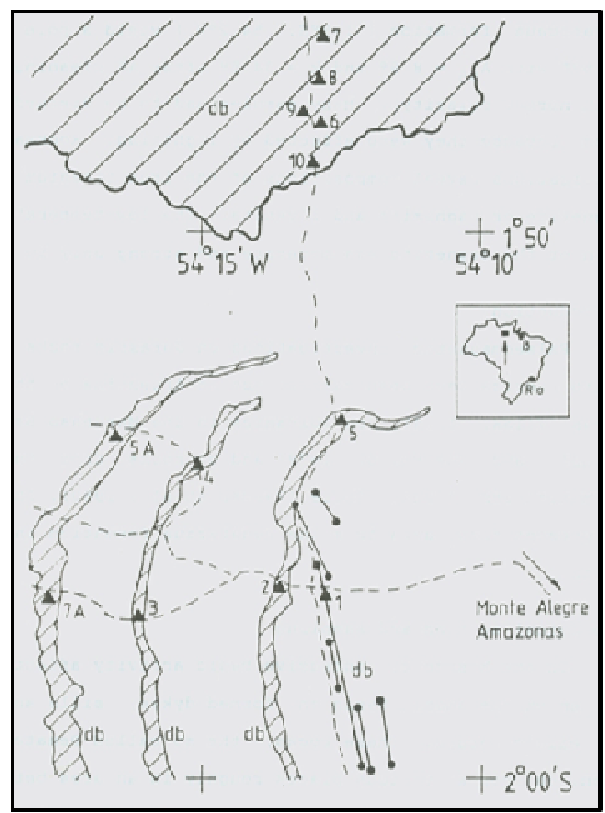

\begin{tabular}{|c|c|c|}
\hline Código & Long. & Lat. \\
\hline SG1 & 87.0 & 73.4 \\
\hline SG2 & 65.0 & 65.4 \\
\hline SG4 & 69.0 & 60.6 \\
\hline SG5 & 27.0 & 47.0 \\
\hline SG6 & 59.0 & 64.6 \\
\hline SG7 & 80.0 & 66.9 \\
\hline SG9 & 96.0 & 76.0 \\
\hline SG5A & 74.0 & 72.4 \\
\hline SG7A & 122.0 & 83.8 \\
\hline
\end{tabular}

Fig. 6.2. Dados paleomagnéticos (PGVs) de Guerreiro \& Schult (1986) para diques da região de Monte Alegre que estão localizados na figura da esquerda.

Para o cálculo do polo paleomagnético, utilizou-se o método de Vandamme (1994) para selecionar os dados que realmente representam a variação secular e eliminar os dados anômalos. Os dados descartados estão identificados na Tabela 5.1 com asteriscos. O polo norte calculado tem coordenadas $80^{\circ} \mathrm{N} 79.6^{\circ} \mathrm{E}(\mathrm{N}=20)$. Incorporando-se os dados de Guerreiro \& Schult (1986) aos dados deste trabalho, recalculou-se o polo e, segundo os critérios de Vandamme obtemos um polo localizado a76.5 $5^{\circ} \mathrm{N} 80.5^{\circ} \mathrm{E}\left(\mathrm{N}=30 ; \alpha_{95}=3.8 ; \mathrm{k}=50\right.$; $\mathrm{R}=29.4$ )que consideramos ser o polo paleomagnético do diabásio Penatecaua. Os dois resultados não diferem significativamente. 
O pólo paleomagnético do Penatecaua satisfaz aos critérios de confiabilidade propostos por Van der Voo (1990), numa escala de $0 \leq \mathrm{Q} \leq 7$, a saber:

1) Idade da rocha bem determinada e a pressuposição de que a magnetização é da mesma idade.

2) O polo deve apresentar um número suficiente de amostras ( $N>24, k \geq 10$ e $\left.\alpha_{95} \leq 16\right)$.

3) Desmagnetização adequada.

4) Testes de campo que limitam a idade da magnetização (este critério refere-se principalmente a testes de contato).

5) Controle estrutural e coerência tectônica com o craton ou bloco envolvido:

6) Presença de reversões:

7) O polo não se assemelha a paleopolos de idades mais jovens:

Esses critérios, entretanto, não são adequados para situações como a estudada aqui, pois tratase de área com estabilidade cratônica, magnetizações adquiridas dentro de um único intervalo de polaridade e pouco deslocamento da placa da América do Sul durante o Mesozóico o que pode dificultar a discriminação dos polos de outras idades mais jovens.

Com idades da maior qualidade possível e com um controle estatístico e mineralógico detalhado foi estabelecido um pólo magnético com fator de qualidade de no mínimo 6 em uma escala de 0 a 7 (Van der Voo, 1990). Portanto, um polo de referência. Ressalte-se que temos: titanomagnetita com baixo teor de titânio como principal mineral portador da magnetização termorremanente de idade compatível com a formação da rocha; paleohorizontal mantida, não existindo evidências apreciáveis que indiquem um tectonismo significante na região e controlada através da ASM; indicações de um campo anômalo com indícios de uma reversão, que precedeu ou que iria ocorrer após a magnetização de polaridade normal do maior conjunto de sítios estudados.

O polo paleomagnético resultante pode ser apreciado (Tabela 6.2. e Fig. 6.5.) junto com outros polos associados ao CAMP na América do Sul (Ernesto et.al., 2003). A dispersão angular da média dos PGVs $\left(S=8.6^{\circ}\right)$ está menor do que o esperado, para o intervalo de paleolatitude e idades similares, seguindo uma estimativa média de $18.5^{\circ}$, com limites estatísticos inferiores e superiores com $95 \%$ de confiança entre $16.6^{\circ}$ e $21^{\circ}$ (McFadden et. 
al., 1991). Porém se utilizarmos os dados em conjunto com os antigos para o Penatecaua produzimos um polo combinado com uma dispersão angular um pouco maior $13.2^{\circ}$, possivelmente mais adequado ao amostrar a variação secular e removê-la na média.

Tabela 6.2. Polos associados ao CAMP na América do Sul e desvio angular da média dos respectivos PGVs. Compilados de Ernesto et al. (2003)

\begin{tabular}{|l|l|c|c|c|}
\hline \multicolumn{1}{|c|}{ Região } & $\mathbf{N}$ & $\begin{array}{c}\text { Latitude } \\
\left({ }^{\circ} \mathrm{N}\right)\end{array}$ & $\begin{array}{c}\text { Longitude } \\
\left({ }^{\circ} \mathrm{E}\right)\end{array}$ & $\begin{array}{c}\text { Desvio Angular } \\
\left(\mathbf{(}^{\mathbf{}}\right)\end{array}$ \\
\hline Penatecaua & 20 & 80 & 79.6 & 8.6 \\
\hline Penatecaua- combinado & 30 & 76.5 & 80.5 & 13.2 \\
\hline Venezuela & 10 & 76.1 & 85.8 & 14.3 \\
\hline Suriname & 26 & 81.2 & 55.1 & 4 \\
\hline Guiana & 7 & 63.3 & 42 & 5.2 \\
\hline Caciporé & 17 & 79.8 & 28.6 & 6.6 \\
\hline Roraima & 7 & 80.1 & 55.1 & 3.6 \\
\hline Anari-Tapirapuã & 15 & 65.5 & 70.3 & 5.2 \\
\hline $\begin{array}{l}\text { Magmatismo do NE do } \\
\text { Brasil }\end{array}$ & 33 & 78.1 & 43.9 & \\
\hline
\end{tabular}

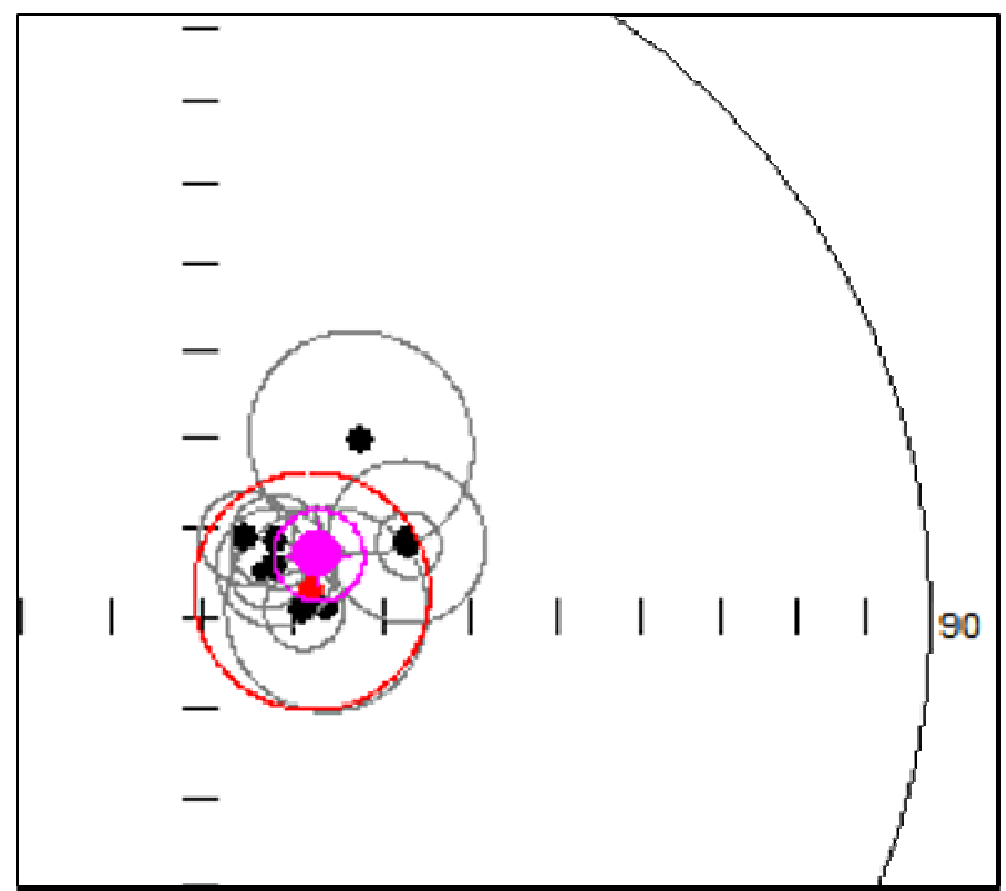

Fig.6.3 Polos paleomagnéticos associados ao CAMP na América do Sul vistos no hemisfério norte, destacando o polo Penatecaua combinado (vermelho) e o polo médio CAMP da América do Sul (lilás). Os círculos de confiança de cada polo também estão representados. 
Como observado na Fig. 6.5. o novo polo Penatecaua está bem de acordo com os demais polos relacionados ao CAMP da América do Sul, com os círculos de confiança se superpondo. Neste caso, entende-se que dentro dos erros de determinação esses polos são de mesma idade e refletem o mesmo intervalo de tempo. Entretanto, alguns polos se afastam um pouco da distribuição principal e podem significar diferenças de idade. Por outro lado, temos que os intervalos de tempo característicos da variação secular, refletida pelas dispersões angulares dos PGVs, são menores que os erros geocronológicos, portanto potencialmente o dado paleomagnético pode resolver diferenças de idades menores que a Geocronologia.

Em trabalho de revisão recente (Marzoli et al., 2017) reuniram os dados radiométricos existentes para as diversas áreas afetadas pelo CAMP em todos os continentes e verificaram que o pico de máxima atividade situa-se em torno de 201Ma (Fig. 6. 4) mas pode se estender por vários milhões de anos em atividades esporádicas. Portanto, algumas áreas já estudadas do CAMP da América do Sul devem ser reestudadas e as datações radiométricas, se existentes, refinadas.

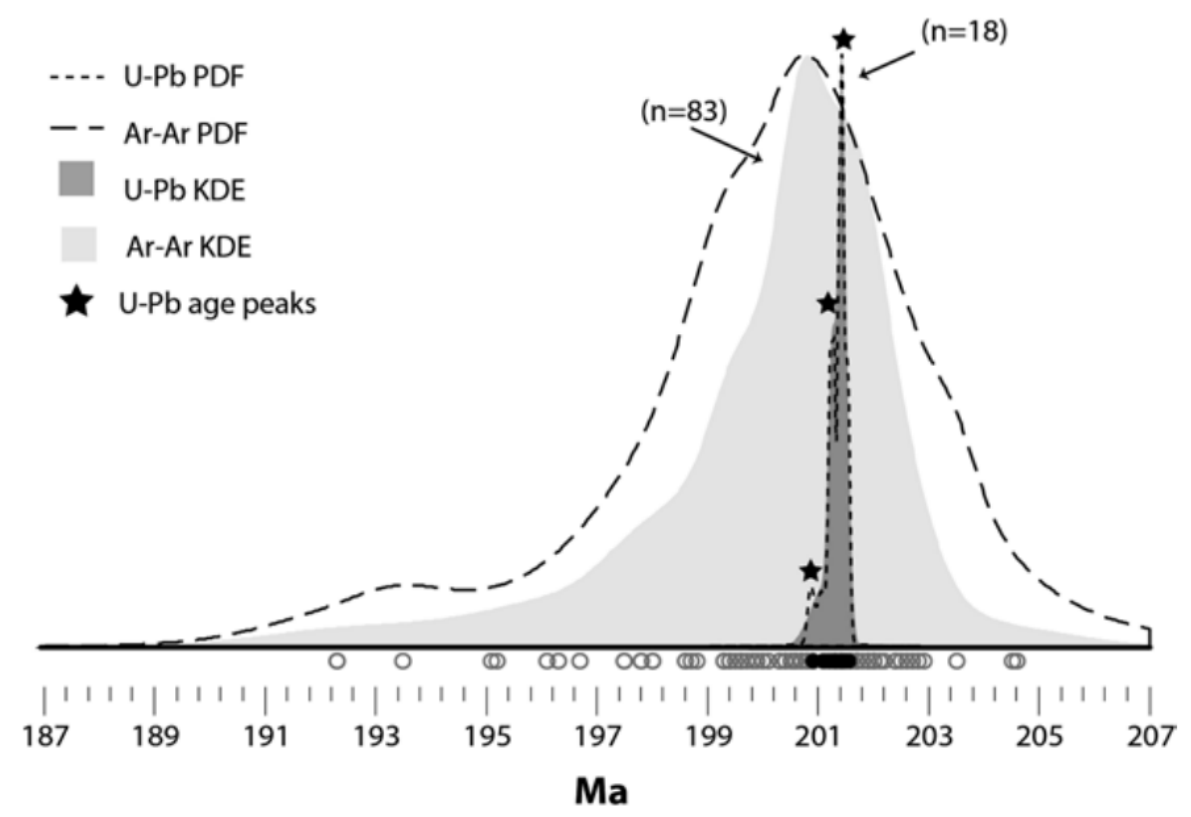

Fig.6.3. Distribuição de probabilidade e densidade de Kernel de uma base de dados de diferentes métodos de geocronológicos. As estrelas são os produtos principais das análises indicando os três principais pulsos de magmatismo sugeridos (Marzoli et. al., 2017).

Uma informação importante resultante deste trabalho é a existência de direções anômalas de magnetização que tanto podem refletir o comportamento da variação secular em um período com alta taxa de reversões ou o próprio campo transicional.Entretanto, esta última hipótese 
não pode ser confirmada porque, como já foi dito anteriormente, a dispersão dos dados é menor do que a esperada para conjuntos de dados que tenham eliminado os efeitos da variação secular. Tanto a distribuição das direções médias (Fig. 5.8), como dos PGVs (Fig. 6.1) não são distribuições Fisherianas (ou Gaussianas na esfera) como se espera para o registro completo da variação secular. É possível então, as direções aparentemente anômalas de Alenquer sejam apenas o registro de outro momento do ciclo de variação secular. $\mathrm{O}$ método de Vandamme para a seleção dos dados para compor a média é muito restritivo e se baseia em excluir os dados que se afastam da distribuição principal e que geram a distribuição esperada para modelos do campo geomagnético atual.

Por outro lado, a qualidade de alguns sítios de amostragem não permitiram a observação de contatos ou planos de acamamento que permitissem inferir se a paleohorizontal estava preservada. Desta forma pode ser que alguns dados estejam afetados por tectonismo, porém são muito poucos, uma vez que a ASM nos deu informações de que essa condição estava satisfeita na maioria dos sítios. Outro ponto a considerar é que para longos intervalos de polaridade única registra-se menor dispersão dos dados paleomagnéticos, ou seja, a variação secular é menos intensa (p.ex., Biggin et al., 2008; Oliveira et al., 2018). Embora o CAMP não esteja inserido num supercron, a escala de reversões para o Jurássico Inferior ainda não é completamente estabelecida e, tampouco o comportamento da variação secular durante esse período. 


\section{Referências}

Bertrand, H., Fornari, M., Marzoli, A., García-Duarte, R., Sempere, T., 2014.The Central AtlanticMagmatic Province extends into Bolivia. Lithos 188:33-43.

Bigarella, J.J., 1973. Geology of the Amazon and Parnaiba Basins, 1973. In: A.E.M. Nairn et al. (eds.), The South Atlantic. Springer Science, New York, 25-86.

Biggin, A. J., Van Hinsbergen, D. J., Langereis, C. G., Straathof, G. B., \& Deenen, M. H. (2008b). Geomagnetic secular variation in the CretaceousNormal Superchron and in the Jurassic. Physics of the Earth and Planetary Interiors, 169(1-4), 3-19.

Bischoff, G. O., 1963 Zur Geologie des Amazonbeckens: Geol. Jb., v. 80, p. 777- 794.

Bispo-Santos, F., 2017. Noções básicas do estudo da anisotropia de susceptibilidade magnética (ASM) em rochas e suas aplicações, Boletim do Museu de Geociências da Amazônia, Ano 4, Número 4, Artigo 7.

Butler, R. F., 1992. Paleomagnetism: Magnetic Domains to Geologic terranes, Blackwell Scientific Publications.

Callegaro, Sara et al. Upper and lower crust recycling in the source of CAMP basaltic dykes from southeastern North America. In: Earth and Planetary Science Letters, 2013, vol. 376, p. 186199. https://archive-ouverte.unige.ch/unige:29379

Caputo, M. V. (1984). Stratigraphy, Tectonics, Paleoclimatology and Paleogeography of Northern Basins of Brazil, A PhD Dissertation of Philosophy in Geology, University of California.

Caputo, Mario Vicente, \& Soares, Emilio Alberto Amaral. (2016). Eustatic and tectonic change effects in the reversion of the transcontinental Amazon River drainage system. Brazilian Journal of Geology, 46(2), 301-328. https://dx.doi.org/10.1590/2317-4889201620160066

Costa, J., Vasconcellos, E.M.G., Barros, C.E.M., Cury, L.F., Juk, K.F.V., 2012. Petrologia e geoquímica da soleira de Medicilândia, diabásio Penatecaua, PA, Rev. Bras. Geoc., 42: 754771.

Courtillot, V., Le Mouel, J.-L., 1988. Time variations of the Earth's magnetic field: from daily to secular. Ann. Rev. Earth Planet. Sci. 16: 389-476.

Cox, A., 2007. Latitude Dependence of the Angular Dispersion of the Geomagnetic Field. Geophys. J. Int. 20: 253-269. 
Cunha P.R.C., Gonzaga EG., Coutinho L.EC., Feijó EJ. 1994. Bacia do Amazonas. Boletim de Geociências da Petrobrás, 8: 47-55.

Cunha, P.R.C., Melo, J.H.G., Silva, O.B., 2007. Bacia do Amazonas. Bol. Geoc. Petrobras 15 (2), $227-251$.

Davies, J.H.F.L., Marzoli, A., Bertrand, H., Youbi, N., Ernesto, M., Chaltegger, U., 2017. EndTriassic mass extintion started by intrusive CAMP activity. Nature Commun. 8:15596: 1-8. doi: 10.1038/ncomms 15596 .

De La Roche H., Leterrier J., Grandclaude P., Marchal M. 1980. A classification of volcanic and plutonic rocks using R1R2 - diagram and major element analyses - its relationships with current nomenclature. Chemical Geology, 29:183-210.

De Min, A., Piccirillo, E. M., \& Marzoli, A. (2003). The Central Atlantic Magmatic Province (CAMP) in Brazil: petrology, geochemistry, 40Ar/39Ar ages, paleomagnetism and geodynamic implications. Geophysical Monograph Series, 136(October), 91-128. https://doi.org/10.1029/136GM06

DNPM - Departamento Nacional de Produção Mineral. Projeto Radam Folha SA.22 Belém; geologia, geomorfologia, solos, vegetação e uso potencial da terra. Rio de Janeiro, 1974.

Ernesto, M., Bellieni, G. et al. 2003. Paleomagnetic and geochemical constraints on the timing and duration of the CAMP activity in northeastern Brazil. In: HAMES, W., MCHONE, J., RENNE, P. \& RUPPEL, C. (eds) The Central Atlantic Magmatic Province: Insights from Fragments of Pangea. American Geophysical Union, Geophysical Monograph Series, 136, 129-149.

Evans, M.E., 2005. Testing the geomagnetic dipole hypothesis: palaeolatitudes sampled by large continents. Geophys.J.Int. 161: 266-267

Figueira I.F.R., Salamuni E., Mancini F., 2012. Deformação rúptil em rochas do magmatismo Penatecaua no domo de Monte Alegre (PA). Revista Brasileira de Geociências 42 (4), 772-784

Guerreiro S.D.C., Schult A., 1986. Palaeomagnetism of Jurassic tholeiitic intrusions in the Amazon Basin. Verõffentlichung des Geophysikalischen Observatoriums Fürstenfeldbruck, Münchener Universitätsschriften, B Series, 10: 61-72. 
Hess, H.H., 1962. History of Ocean Basins. In A.E.J. Engel; Harold L. James; B. F. Leonard. Petrologic studies: a volume in honor of A. F. Buddington. Boulder, CO: Geological Society of America. pp. 599-620.

Irving, E., Palaeomagnetic and palaeoclimatological aspects of polar wandering, Geofis. Pura Appl., 33, 23-41, 1956.

Lopes, E.C.S., Luiz, J.G., Villas, R.N.N., 2013. Modelagem gravimétrica do domo de Monte Algre - PA. Anais do $13^{\circ}$ Simpósio de Geologia da Amazônia, Belém. Atas, 473-477.

Marzolli, A., Renne, P.R., Picirillo, E.M., Ernesto, M., Bellieni, G., Min,A. 1999. Extensive 200Million-year-old continental flood basaltsof the Central Atlantic Magmatic Province. Science, 284:616-618.

Marzoli, A., Callegaro, S., Dal Corso, J., Davies, J. H. F. L., Chiaradia, M., Youbi, N.,Bertrand, H., Reisberg, L., Merle, R., Jourdan, F., 2017. The Central Atlantic Magmatic Province (CAMP): A Review. The Late Triassic World, 91-125.

Merle R., Marzoli A., Bertrand H., Reisberg L., Verati C., Zimmermann C., Chiaradia M., Bellieni G., Ernesto M., 2011. ${ }^{40} \mathrm{Ar} /{ }^{39} \mathrm{Ar}$ ages and Sr-Nd-Pb-Os geochemistry of CAMP tholeiites from Western Maranhão basin (NE Brazil). Lithos, 122:137-151.

McFadden, P. L., Merrill, R. T., McElhinny, M. W., \& Lee, S. (1991). Reversals of the Earth's magnetic field and temporal variations of thedynamo families. Journal of Geophysical Research, 96(B3), 3923-3933. https://doi.org/10.1029/90JB02275

Milani, E.J., Zalán, P.V., 1999. An outline of the geology and petroleum systems of the Paleozoic interior basins of South America. Episodes, 22: 199-205.

Montalvão R.M.G., Oliveira A.S. 1975. Geologia branquianticlinal de Monte Alegre e da Rodovia Monte Alegre - Prainha. Belém, Projeto Radam Brasil, 409 p.

Montes-Lauar, C. R., Pacca, I. G., Melfi, A. J., Piccirillo, E. M., Bellieni, G., Petrini, R., \& Rizzieri, R. (1994). The Anari and Tapirapuã Jurassic formations, western Brazil: paleomagnetism, geochemistry and geochronology. Earth and Planetary Science Letters, 128(3-4), 357-371. https://doi.org/10.1016/0012-821X(94)90156-2 
Moreira, G., \& Ernesto, M. (2017). PALEOMAGNETISM OF THE MEDICILANDIA SILL FROM THE CENTRAL ATLANTIC MAGMATIC PROVINCE, AMAZON BASIN, BRAZIL, Latinmag Letters, Volume 7, Special Issue (2017), PM31, 1-4.

Munis, M. B., 2013. Arco Purus: Um gráben invertido revelado pela geofísica separando as Bacias do Solimões e do Amazonas. Contribuições à Geologia da Amazônia. SBG Núcleo Norte, Belém. Volume 8, 117 - 133.

Nomade S, Theveniaut, H., Chen Y., Pouclet A, Rigollet, C., 2000. Paleomagnetic study of French Guyana Early Jurassicdolerites: hypothesis of a multistage magmatic event. EPSL, 184: 155168.

Oliveira, W. P., Franco, D. R.,Brandt, D., Ernesto, M.,da Ponte Neto, C. F., Zhao, X., et al., 2018. Behavior of the paleosecularvariation during the Permian-Carboniferous Reversed Superchronand comparisons to the low reversalfrequency intervals since Precambriantimes. Geochemistry, Geophysics, Geosystems, 19: 1035-1048.

Panzik, EJ.E., Evans, D.A.D., 2014. Assessing the GAD hypothesis with paleomagnetic data from large Proterozoic dike swarms. EPSL, 406: 134-141.

Piccirillo, E.M. \& Melfi, A.J. (1988). The Mesozoic Flood Volcanism of the Paraná Basin: Petrogenetic and Geophysical Aspects. Instituto Astronômico e Geofísico - University of São Paulo, 600p., São Paulo.

Rezende, W.M., Brito, C.G., 1973. Avaliação geológica da bacia paleozóica do Amazonas. Anais do XXVII Congr.Brasil. Geol., Aracaju, SE, 3: 227--245.

Rogers, J.J.W., Santosh, M., 2004. Continents and Supercontinents. Oxford University Press, Oxford. $289 \mathrm{pp}$

Silva, A.G., Almeida, C.N., Valente, S.C., Almeida, L.F.B., 2017. The petrogenesis of tholeiitic diabases in eastern Parnaíba Basin: evidence for geochemical heterogeneities in the subcontinental lithospheric mantle in NE Brazil Braz. J. Geol., 47: 109-126.

Silva, A.J.P., Lopes, R. C., Vasconcelos, A.M., Ruy B. C. Bahia, R.B.C., 2003. Bacias Sedimentares Paleozóicas e Meso-Cenozóicas Interiores, In: L. A. Bizzi, C. Schobbenhaus, R. M. Vidotti e J. H. Gonçalves (eds.) Geologia, Tectônica e Recursos Minerais do Brasil, 55, CPRM, Brasília. 
Silva, E.F., Pinto, M.B., Peregovich, B.G., Brenner, W.W., 2014.Petrologia do diabásio Penatecaua, soleira de Rurópolis,Pará, Brasil.Comunicações Geológicas 101, Especial I: 213-216.

Santos, J.O.S., Hartmann, L.A., McNaughton, N.J., Fletcher, I.R. 2002. Timing of mafic magmatism in the Tapajós Province (Brazil) andimplications for the evolution of the Amazon craton - Evidencefrom baddeleyite and zircon U-Pb SHRIMP geochronology. J. South American Earth Sci., 15:409-429.

Vandamme D. , 1994. A new method to determine paleosecular variation. Phys. Earth planet. Inter., 85: 131-142.

Van der Voo, R. (1990), The reliability of paleomagnetic data, Tectonophysics, 184, 1-9

Vasquez, M.L., Sousa, C.S., Carvalho, J.M.A. (orgs), 2008. Mapa geológico e de recursos minerais do Estado do Pará, escala 1:1.000.000. Programa Geologia do Brasil.

Veldkamp, J., Mulder, F.G., Zijderveld, J.D.A., 1971. Paleomagnetism of Suriname dolerites. PEPI, 4:370-380.

Zijderveld, J. D. A., 1967. A. C. Demagnetization of Rocks: Analysis of Results. In: Methods and Techiniques in Paleomagnetism, D. W. Collison et. al. (eds.), Elsevier, Amsterdam: 254-286. 


\section{ANEXO I}

\section{Dados de Anisotropia de Suscetibilidade Magnética por Espécime}

\begin{tabular}{|c|c|c|c|c|c|c|c|c|c|c|c|}
\hline Especime & Kmean (SI) & $\mathbf{L}$ & $\mathbf{F}$ & $\mathbf{P}$ & $\mathbf{T}$ & k1D & k1I & k2D & k2I & k3D & k3I \\
\hline ERP101A1 & 2.97E-02 & 1.023 & 1.033 & 1.057 & 175 & 179 & 33 & 72 & 23 & 314 & 48 \\
\hline ERP101A2 & $2.49 \mathrm{E}-02$ & 1.008 & 1.017 & 1.026 & 350 & 162 & 58 & 259 & 5 & 352 & 32 \\
\hline ERP101B1 & $3.67 \mathrm{E}-02$ & 1.007 & 1.033 & 1.041 & 630 & 203 & 29 & 101 & 21 & 340 & 53 \\
\hline ERP101B2 & $2.63 \mathrm{E}-02$ & 1.013 & 1.024 & 1.037 & 292 & 175 & 46 & 63 & 20 & 317 & 37 \\
\hline ERP101C1 & $3.02 \mathrm{E}-02$ & 1.017 & 1.027 & 1.044 & 214 & 195 & 53 & 72 & 22 & 329 & 28 \\
\hline ERP101C2 & $2.21 \mathrm{E}-02$ & 1.022 & 1.033 & 1.056 & 185 & 191 & 44 & 70 & 28 & 320 & 33 \\
\hline ERP101D1 & $2.94 \mathrm{E}-02$ & 1.016 & 1.028 & 1.045 & 266 & 200 & 31 & 91 & 30 & 326 & 45 \\
\hline ERP101D2 & $3.75 \mathrm{E}-02$ & 1.015 & 1.031 & 1.046 & 337 & 194 & 30 & 79 & 36 & 312 & 39 \\
\hline ERP101D3 & $1.67 \mathrm{E}-02$ & 1.021 & 1.040 & 1.062 & 317 & 187 & 27 & 57 & 51 & 291 & 25 \\
\hline ERP101E1 & $3.21 \mathrm{E}-02$ & 1.025 & 1.027 & 1.052 & 27 & 197 & 42 & 70 & 34 & 318 & 29 \\
\hline ERP101E2 & $2.02 \mathrm{E}-02$ & 1.018 & 1.033 & 1.051 & 298 & 198 & 35 & 80 & 33 & 320 & 37 \\
\hline ERP108A1 & $2.95 \mathrm{E}-02$ & 1.005 & 1.010 & 1.014 & 339 & 181 & 19 & 83 & 22 & 309 & 60 \\
\hline ERP108A2 & $5.35 \mathrm{E}-02$ & 1.009 & 1.025 & 1.034 & 473 & 249 & 50 & 340 & 0 & 70 & 40 \\
\hline ERP108B1 & $3.15 \mathrm{E}-02$ & 1.005 & 1.019 & 1.024 & 587 & 27 & 7 & 296 & 14 & 144 & 74 \\
\hline ERP108B2 & $2.58 \mathrm{E}-02$ & 1.018 & 1.003 & 1.020 & -739 & 40 & 1 & 308 & 62 & 130 & 28 \\
\hline ERP108C1 & $5.60 \mathrm{E}-02$ & 1.019 & 1.008 & 1.027 & -404 & 347 & 3 & 256 & 13 & 92 & 76 \\
\hline ERP108D1 & $2.30 \mathrm{E}-02$ & 1.007 & 1.045 & 1.052 & 730 & 208 & 9 & 117 & 8 & 345 & 78 \\
\hline ERP108D2 & $3.91 \mathrm{E}-02$ & 1.003 & 1.014 & 1.017 & 636 & 166 & 11 & 75 & 3 & 331 & 78 \\
\hline ERP108E1 & $3.93 \mathrm{E}-02$ & 1.022 & 1.013 & 1.035 & -242 & 109 & 7 & 201 & 21 & 2 & 67 \\
\hline ERP108E2 & $3.68 \mathrm{E}-02$ & 1.023 & 1.022 & 1.045 & -18 & 116 & 13 & 210 & 14 & 344 & 71 \\
\hline ERP108F1 & 4.38E-02 & 1.015 & 1.013 & 1.028 & -43 & 161 & 54 & 358 & 34 & 262 & 8 \\
\hline ERP108G1 & $3.39 \mathrm{E}-02$ & 1.013 & 1.011 & 1.025 & -65 & 332 & 5 & 78 & 72 & 240 & 18 \\
\hline ERP108G2 & $2.70 \mathrm{E}-02$ & 1.011 & 1.017 & 1.028 & 241 & 44 & 2 & 134 & 1 & 251 & 88 \\
\hline ERP117A1 & $3.23 \mathrm{E}-02$ & 1.016 & 1.011 & 1.028 & -192 & 201 & 12 & 297 & 27 & 90 & 60 \\
\hline ERP117A2 & $2.92 \mathrm{E}-02$ & 1.016 & 1.010 & 1.026 & -199 & 205 & 8 & 296 & 9 & 75 & 77 \\
\hline ERP117A3 & $3.02 \mathrm{E}-02$ & 1.013 & 1.010 & 1.024 & -140 & 173 & 8 & 264 & 5 & 26 & 81 \\
\hline ERP117B2 & $3.06 \mathrm{E}-02$ & 1.020 & 1.021 & 1.041 & 31 & 198 & 14 & 290 & 7 & 46 & 74 \\
\hline ERP117B3 & $2.75 \mathrm{E}-02$ & 1.022 & 1.012 & 1.034 & -292 & 207 & 16 & 299 & 8 & 54 & 73 \\
\hline ERP123A1 & $2.95 \mathrm{E}-02$ & 1.008 & 1.013 & 1.021 & 273 & 298 & 19 & 51 & 49 & 195 & 35 \\
\hline ERP123A2 & $3.27 \mathrm{E}-02$ & 1.024 & 1.019 & 1.044 & -122 & 284 & 2 & 15 & 24 & 189 & 66 \\
\hline ERP123C1 & $3.00 \mathrm{E}-02$ & 1.012 & 1.028 & 1.041 & 394 & 60 & 1 & 330 & 14 & 153 & 76 \\
\hline ERP123D1 & $3.30 \mathrm{E}-02$ & 1.018 & 1.010 & 1.028 & -275 & 91 & 1 & 1 & 26 & 183 & 64 \\
\hline ERP123D2 & $3.09 \mathrm{E}-02$ & 1.013 & 1.012 & 1.026 & -53 & 89 & 2 & 358 & 14 & 185 & 76 \\
\hline ERP123E1 & $2.95 \mathrm{E}-02$ & 1.016 & 1.010 & 1.027 & -215 & 92 & 0 & 1 & 73 & 182 & 17 \\
\hline ERP123F1 & $3.13 \mathrm{E}-02$ & 1.020 & 1.005 & 1.025 & -612 & 94 & 2 & 4 & 9 & 195 & 80 \\
\hline ERP123F2 & $3.06 \mathrm{E}-02$ & 1.011 & 1.008 & 1.020 & -138 & 286 & 4 & 21 & 52 & 193 & 38 \\
\hline ERP123F3 & $3.28 \mathrm{E}-02$ & 1.014 & 1.015 & 1.030 & 15 & 291 & 32 & 37 & 24 & 157 & 48 \\
\hline ERP123G1 & $2.22 \mathrm{E}-02$ & 1.003 & 1.020 & 1.023 & 731 & 331 & 1 & 61 & 8 & 234 & 82 \\
\hline ERP123G2 & $2.44 \mathrm{E}-02$ & 1.009 & 1.023 & 1.033 & 426 & 334 & 2 & 65 & 10 & 233 & 80 \\
\hline ERP123H1 & $2.54 \mathrm{E}-02$ & 1.008 & 1.008 & 1.016 & -16 & 96 & 7 & 3 & 19 & 205 & 69 \\
\hline ERP123H2 & $2.31 \mathrm{E}-02$ & 1.010 & 1.013 & 1.023 & 150 & 65 & 4 & 334 & 9 & 181 & 80 \\
\hline
\end{tabular}




\begin{tabular}{|c|c|c|c|c|c|c|c|c|c|c|c|}
\hline ERP123I1 & $2.70 \mathrm{E}-02$ & 1.009 & 1.011 & 1.019 & 94 & 164 & 4 & 73 & 14 & 272 & 75 \\
\hline ERP124A1 & $7.15 \mathrm{E}-02$ & 1.007 & 1.019 & 1.026 & 480 & 42 & 3 & 132 & 1 & 240 & 86 \\
\hline ERP124B1 & 7.31E-02 & 1.004 & 1.028 & 1.032 & 729 & 178 & 1 & 86 & 65 & 268 & 25 \\
\hline ERP124B2 & $6.62 \mathrm{E}-02$ & 1.004 & 1.013 & 1.018 & 493 & 134 & 49 & 18 & 21 & 273 & 33 \\
\hline ERP124C1 & 7.74E-02 & 1.002 & 1.024 & 1.026 & 846 & 68 & 0 & 158 & 8 & 334 & 82 \\
\hline ERP124D1 & $6.92 \mathrm{E}-02$ & 1.003 & 1.022 & 1.025 & 770 & 298 & 1 & 207 & 7 & 35 & 83 \\
\hline ERP124E1 & $5.70 \mathrm{E}-02$ & 1.020 & 1.013 & 1.033 & -203 & 70 & 0 & 340 & 2 & 163 & 88 \\
\hline ERP124F1 & $6.14 \mathrm{E}-02$ & 1.012 & 1.017 & 1.030 & 172 & 264 & 4 & 174 & 2 & 59 & 86 \\
\hline ERP125A1 & 4.64E-02 & 1.004 & 1.018 & 1.022 & 649 & 158 & 2 & 67 & 17 & 254 & 73 \\
\hline ERP125B1 & $4.80 \mathrm{E}-02$ & 1.018 & 1.026 & 1.044 & 183 & 3 & 7 & 94 & 4 & 211 & 82 \\
\hline ERP125B2 & $3.82 \mathrm{E}-02$ & 1.021 & 1.016 & 1.037 & -142 & 11 & 15 & 104 & 10 & 227 & 72 \\
\hline ERP125C1 & $2.12 \mathrm{E}-02$ & 1.010 & 1.002 & 1.012 & -635 & 288 & 10 & 98 & 79 & 198 & 2 \\
\hline ERP125D1 & $2.34 \mathrm{E}-02$ & 1.010 & 1.005 & 1.014 & -359 & 273 & 8 & 150 & 76 & 5 & 12 \\
\hline ERP125F1 & $1.58 \mathrm{E}-02$ & 1.010 & 1.020 & 1.030 & 357 & 74 & 1 & 344 & 9 & 169 & 81 \\
\hline ERP125G1 & $7.68 \mathrm{E}-03$ & 1.012 & 1.016 & 1.029 & 147 & 81 & 4 & 350 & 4 & 213 & 84 \\
\hline ERP125H1 & $6.83 \mathrm{E}-03$ & 1.002 & 1.011 & 1.012 & 714 & 151 & 1 & 61 & 1 & 267 & 89 \\
\hline ERP125H2 & $6.74 \mathrm{E}-03$ & 1.013 & 1.017 & 1.030 & 115 & 267 & 0 & 177 & 4 & 2 & 86 \\
\hline ERP127A1 & $4.50 \mathrm{E}-03$ & 1.001 & 1.012 & 1.013 & 791 & 233 & 5 & 324 & 9 & 117 & 80 \\
\hline ERP127A2 & $3.86 \mathrm{E}-03$ & 1.005 & 1.013 & 1.018 & 420 & 22 & 4 & 291 & 22 & 121 & 67 \\
\hline ERP127B1 & $1.76 \mathrm{E}-03$ & 1.002 & 1.005 & 1.007 & 484 & 224 & 8 & 315 & 6 & 84 & 80 \\
\hline ERP127B2 & $1.38 \mathrm{E}-03$ & 1.001 & 1.005 & 1.006 & 776 & 183 & 2 & 273 & 8 & 81 & 82 \\
\hline ERP127C2 & $1.41 \mathrm{E}-03$ & 1.002 & 1.004 & 1.007 & 262 & 224 & 3 & 315 & 15 & 123 & 74 \\
\hline ERP127D1 & $2.60 \mathrm{E}-03$ & 1.003 & 1.009 & 1.012 & 504 & 175 & 4 & 85 & 0 & 348 & 86 \\
\hline ERP127E2 & $2.81 \mathrm{E}-03$ & 1.001 & 1.005 & 1.006 & 579 & 96 & 0 & 6 & 6 & 188 & 84 \\
\hline ERP127F2 & $2.15 \mathrm{E}-03$ & 1.011 & 1.005 & 1.015 & -374 & 107 & 0 & 17 & 21 & 197 & 69 \\
\hline ERP127H1 & $1.74 \mathrm{E}-03$ & 1.005 & 1.009 & 1.014 & 304 & 319 & 7 & 229 & 0 & 137 & 83 \\
\hline ERP127H2 & $1.62 \mathrm{E}-03$ & 1.006 & 1.007 & 1.012 & 85 & 327 & 8 & 237 & 2 & 136 & 82 \\
\hline ERP130A2 & $3.52 \mathrm{E}-03$ & 1.007 & 1.005 & 1.013 & -145 & 60 & 12 & 151 & 1 & 246 & 78 \\
\hline ERP130B2 & $1.95 \mathrm{E}-03$ & 1.003 & 1.007 & 1.009 & 432 & 133 & 28 & 240 & 29 & 7 & 48 \\
\hline ERP130B3 & $3.25 \mathrm{E}-02$ & 1.005 & 1.003 & 1.008 & -320 & 300 & 1 & 31 & 12 & 204 & 78 \\
\hline ERP130C2 & $2.96 \mathrm{E}-02$ & 1.007 & 1.004 & 1.010 & -308 & 359 & 9 & 100 & 49 & 261 & 39 \\
\hline ERP130C3 & $2.53 \mathrm{E}-02$ & 1.003 & 1.007 & 1.010 & 369 & 176 & 6 & 80 & 42 & 273 & 47 \\
\hline ERP130D1 & $3.52 \mathrm{E}-02$ & 1.002 & 1.002 & 1.004 & -66 & 19 & 31 & 136 & 38 & 262 & 37 \\
\hline ERP130D2 & $3.57 \mathrm{E}-02$ & 1.003 & 1.009 & 1.012 & 485 & 0 & 24 & 115 & 43 & 250 & 37 \\
\hline ERP130E1 & $1.60 \mathrm{E}-02$ & 1.011 & 1.014 & 1.025 & 107 & 117 & 9 & 208 & 5 & 329 & 80 \\
\hline ERP130F2 & $2.45 \mathrm{E}-02$ & 1.014 & 1.006 & 1.021 & -375 & 121 & 62 & 278 & 26 & 13 & 9 \\
\hline ERP130F3 & $2.36 \mathrm{E}-02$ & 1.014 & 1.004 & 1.018 & -559 & 120 & 65 & 260 & 20 & 355 & 15 \\
\hline ERP130G1 & $3.75 \mathrm{E}-02$ & 1.003 & 1.003 & 1.006 & 53 & 136 & 18 & 7 & 62 & 233 & 20 \\
\hline ERP130G2 & $3.20 \mathrm{E}-02$ & 1.005 & 1.002 & 1.007 & -290 & 141 & 16 & 328 & 74 & 231 & 2 \\
\hline ERP130H1 & $4.03 \mathrm{E}-02$ & 1.004 & 1.003 & 1.007 & -243 & 157 & 19 & 348 & 70 & 249 & 3 \\
\hline ERP130H2 & $3.85 \mathrm{E}-02$ & 1.004 & 1.004 & 1.008 & -63 & 146 & 20 & 333 & 70 & 237 & 2 \\
\hline ERP132A1 & $8.82 \mathrm{E}-02$ & 1.003 & 1.039 & 1.042 & 846 & 84 & 14 & 353 & 5 & 243 & 75 \\
\hline ERP132A2 & $8.70 \mathrm{E}-02$ & 1.001 & 1.037 & 1.038 & 941 & 35 & 9 & 126 & 6 & 248 & 79 \\
\hline ERP132B1 & $8.30 \mathrm{E}-02$ & 1.002 & 1.037 & 1.039 & 877 & 144 & 9 & 52 & 15 & 264 & 73 \\
\hline ERP132C1 & $7.85 \mathrm{E}-02$ & 1.004 & 1.035 & 1.040 & 772 & 106 & 6 & 16 & 5 & 243 & 82 \\
\hline ERP132C2 & $8.90 \mathrm{E}-02$ & 1.004 & 1.036 & 1.040 & 805 & 122 & 4 & 32 & 8 & 237 & 81 \\
\hline
\end{tabular}




\begin{tabular}{|c|c|c|c|c|c|c|c|c|c|c|c|}
\hline ERP132D1 & 7.79E-02 & 1.004 & 1.033 & 1.037 & 786 & 112 & 6 & 21 & 3 & 265 & 83 \\
\hline ERP132E1 & $7.65 \mathrm{E}-02$ & 1.005 & 1.033 & 1.038 & 752 & 115 & 11 & 24 & 5 & 269 & 78 \\
\hline ERP132E2 & $7.59 \mathrm{E}-02$ & 1.004 & 1.026 & 1.030 & 727 & 112 & 11 & 202 & 1 & 298 & 79 \\
\hline ERP134A1 & $4.08 \mathrm{E}-02$ & 1.019 & 1.010 & 1.029 & -290 & 348 & 8 & 256 & 13 & 110 & 75 \\
\hline ERP134A2 & 4.32E-02 & 1.005 & 1.010 & 1.015 & 286 & 152 & 9 & 59 & 18 & 268 & 69 \\
\hline ERP134B1 & $2.98 \mathrm{E}-02$ & 1.008 & 1.036 & 1.044 & 639 & 109 & 5 & 199 & 0 & 294 & 85 \\
\hline ERP134C1 & $3.09 \mathrm{E}-02$ & 1.008 & 1.018 & 1.026 & 378 & 180 & 1 & 270 & 3 & 66 & 87 \\
\hline ERP134D1 & $2.62 \mathrm{E}-02$ & 1.020 & 1.007 & 1.027 & -493 & 140 & 19 & 44 & 17 & 276 & 64 \\
\hline ERP134E1 & $1.66 \mathrm{E}-02$ & 1.008 & 1.013 & 1.021 & 263 & 26 & 5 & 117 & 4 & 245 & 84 \\
\hline ERP134F1 & $2.70 \mathrm{E}-02$ & 1.009 & 1.016 & 1.025 & 261 & 187 & 19 & 277 & 1 & 10 & 71 \\
\hline ERP134F2 & $2.64 \mathrm{E}-02$ & 1.019 & 1.021 & 1.040 & 58 & 341 & 2 & 251 & 6 & 90 & 83 \\
\hline ERP134G2 & $2.74 \mathrm{E}-02$ & 1.024 & 1.008 & 1.032 & -483 & 308 & 6 & 216 & 19 & 55 & 70 \\
\hline ERP139A1 & $3.08 \mathrm{E}-02$ & 1.026 & 1.006 & 1.032 & -626 & 144 & 29 & 22 & 44 & 255 & 32 \\
\hline ERP139B1 & $3.44 \mathrm{E}-02$ & 1.018 & 1.035 & 1.053 & 307 & 143 & 39 & 257 & 27 & 12 & 39 \\
\hline ERP139C1 & $3.56 \mathrm{E}-02$ & 1.017 & 1.013 & 1.030 & -156 & 186 & 48 & 19 & 41 & 283 & 6 \\
\hline ERP139D1 & $7.17 \mathrm{E}-02$ & 1.001 & 1.026 & 1.027 & 897 & 8 & 10 & 103 & 29 & 261 & 59 \\
\hline ERP139E1 & $5.39 \mathrm{E}-02$ & 1.020 & 1.010 & 1.030 & -340 & 309 & 3 & 216 & 50 & 42 & 39 \\
\hline ERP140A1 & $1.94 \mathrm{E}-03$ & 1.002 & 1.006 & 1.009 & 504 & 199 & 6 & 61 & 81 & 289 & 6 \\
\hline ERP140A3 & $1.64 \mathrm{E}-03$ & 1.004 & 1.004 & 1.007 & -2 & 33 & 67 & 188 & 21 & 282 & 9 \\
\hline ERP140B1 & $2.08 \mathrm{E}-03$ & 1.002 & 1.004 & 1.006 & 311 & 323 & 28 & 227 & 10 & 119 & 59 \\
\hline ERP140C1 & $2.30 \mathrm{E}-03$ & 1.001 & 1.004 & 1.006 & 503 & 228 & 51 & 337 & 14 & 77 & 35 \\
\hline ERP140C3 & $1.82 \mathrm{E}-03$ & 1.009 & 1.005 & 1.014 & -304 & 190 & 22 & 310 & 51 & 86 & 30 \\
\hline ERP140D1 & $4.33 \mathrm{E}-03$ & 1.006 & 1.001 & 1.007 & -657 & 126 & 27 & 269 & 57 & 27 & 17 \\
\hline ERP140D2 & $4.77 \mathrm{E}-03$ & 1.005 & 1.007 & 1.011 & 154 & 92 & 7 & 306 & 81 & 183 & 5 \\
\hline ERP140E1 & 4.07E-03 & 1.006 & 1.003 & 1.008 & -389 & 166 & 7 & 261 & 33 & 65 & 56 \\
\hline ERP140G1 & 7.83E-02 & 1.004 & 1.027 & 1.031 & 712 & 47 & 57 & 229 & 32 & 138 & 1 \\
\hline ERP140H1 & $7.25 \mathrm{E}-02$ & 1.006 & 1.025 & 1.031 & 584 & 58 & 51 & 225 & 38 & 320 & 6 \\
\hline ERP140I1 & $7.23 \mathrm{E}-02$ & 1.007 & 1.025 & 1.032 & 573 & 86 & 82 & 227 & 7 & 318 & 5 \\
\hline ERP140J1 & $2.14 \mathrm{E}-03$ & 1.002 & 1.005 & 1.008 & 362 & 4 & 6 & 267 & 52 & 99 & 37 \\
\hline ERP140J2 & $2.03 \mathrm{E}-03$ & 1.003 & 1.006 & 1.009 & 378 & 352 & 10 & 256 & 31 & 97 & 57 \\
\hline ERP140K1 & $3.28 \mathrm{E}-03$ & 1.003 & 1.008 & 1.011 & 462 & 202 & 27 & 19 & 63 & 111 & 1 \\
\hline ERP140K2 & $3.24 \mathrm{E}-03$ & 1.003 & 1.003 & 1.005 & -48 & 240 & 8 & 143 & 39 & 340 & 50 \\
\hline ERP140L1 & $2.31 \mathrm{E}-03$ & 1.004 & 1.004 & 1.008 & -56 & 205 & 25 & 111 & 8 & 4 & 64 \\
\hline ERP140L2 & $2.03 \mathrm{E}-03$ & 1.005 & 1.001 & 1.006 & -604 & 202 & 2 & 108 & 61 & 293 & 28 \\
\hline ERP142A1 & $1.16 \mathrm{E}-02$ & 1.014 & 1.003 & 1.017 & -646 & 43 & 20 & 271 & 61 & 141 & 20 \\
\hline ERP142A2 & $7.71 \mathrm{E}-03$ & 1.012 & 1.003 & 1.015 & -590 & 45 & 15 & 250 & 73 & 137 & 7 \\
\hline ERP142A3 & $9.82 \mathrm{E}-03$ & 1.011 & 1.003 & 1.014 & -531 & 46 & 18 & 253 & 70 & 139 & 8 \\
\hline ERP142A4 & 9.32E-03 & 1.007 & 1.005 & 1.013 & -157 & 51 & 12 & 293 & 65 & 145 & 21 \\
\hline ERP142B1 & $1.16 \mathrm{E}-02$ & 1.012 & 1.005 & 1.017 & -450 & 34 & 32 & 288 & 23 & 168 & 49 \\
\hline ERP142B2 & $1.08 \mathrm{E}-02$ & 1.012 & 1.003 & 1.015 & -598 & 32 & 28 & 286 & 28 & 158 & 48 \\
\hline ERP142B3 & $8.45 \mathrm{E}-03$ & 1.009 & 1.003 & 1.012 & -520 & 37 & 20 & 251 & 66 & 132 & 13 \\
\hline ERP142B4 & $4.11 \mathrm{E}-03$ & 1.005 & 1.005 & 1.010 & -73 & 39 & 7 & 281 & 75 & 131 & 13 \\
\hline ERP142C1 & $1.33 \mathrm{E}-02$ & 1.002 & 1.003 & 1.006 & 258 & 301 & 39 & 37 & 7 & 135 & 50 \\
\hline ERP142C2 & $9.57 \mathrm{E}-03$ & 1.001 & 1.006 & 1.007 & 852 & 12 & 28 & 270 & 22 & 148 & 53 \\
\hline ERP142D1 & $1.97 \mathrm{E}-02$ & 1.009 & 1.008 & 1.017 & -33 & 277 & 24 & 30 & 42 & 166 & 38 \\
\hline ERP142D2 & $2.15 \mathrm{E}-02$ & 1.008 & 1.008 & 1.016 & -21 & 277 & 25 & 32 & 42 & 167 & 38 \\
\hline
\end{tabular}




\begin{tabular}{|c|c|c|c|c|c|c|c|c|c|c|c|}
\hline ERP142E2 & $1.07 \mathrm{E}-02$ & 1.010 & 1.007 & 1.017 & -136 & 268 & 26 & 25 & 44 & 158 & 36 \\
\hline ERP142E3 & $1.57 \mathrm{E}-02$ & 1.010 & 1.007 & 1.017 & -153 & 270 & 26 & 27 & 43 & 159 & 36 \\
\hline ERP142F1 & $7.58 \mathrm{E}-03$ & 1.003 & 1.005 & 1.007 & 290 & 62 & 38 & 192 & 39 & 307 & 28 \\
\hline ERP142F2 & $1.11 \mathrm{E}-02$ & 1.002 & 1.005 & 1.007 & 322 & 44 & 15 & 146 & 37 & 295 & 49 \\
\hline ERP142G1 & $1.34 \mathrm{E}-02$ & 1.009 & 1.004 & 1.013 & -347 & 71 & 12 & 209 & 75 & 339 & 10 \\
\hline ERP142G3 & $1.40 \mathrm{E}-02$ & 1.007 & 1.008 & 1.014 & 86 & 71 & 15 & 203 & 69 & 337 & 15 \\
\hline ERP142H1 & $3.53 \mathrm{E}-03$ & 1.007 & 1.007 & 1.014 & 25 & 71 & 10 & 199 & 73 & 339 & 13 \\
\hline ERP142H2 & $4.35 \mathrm{E}-03$ & 1.007 & 1.010 & 1.016 & 190 & 70 & 11 & 197 & 72 & 337 & 14 \\
\hline ERP142H3 & $1.11 \mathrm{E}-02$ & 1.005 & 1.011 & 1.016 & 414 & 72 & 23 & 227 & 65 & 338 & 9 \\
\hline ERP145A1 & $3.53 \mathrm{E}-02$ & 1.008 & 1.040 & 1.048 & 679 & 47 & 53 & 287 & 21 & 185 & 29 \\
\hline ERP145A2 & $2.79 \mathrm{E}-02$ & 1.009 & 1.029 & 1.039 & 512 & 97 & 5 & 357 & 61 & 190 & 29 \\
\hline ERP145A3 & $2.93 \mathrm{E}-02$ & 1.004 & 1.042 & 1.046 & 841 & 93 & 12 & 341 & 59 & 190 & 28 \\
\hline ERP145A4 & $3.47 \mathrm{E}-02$ & 1.009 & 1.031 & 1.041 & 551 & 75 & 44 & 300 & 36 & 191 & 24 \\
\hline ERP145C1 & $3.98 \mathrm{E}-02$ & 1.009 & 1.025 & 1.035 & 455 & 50 & 18 & 143 & 10 & 260 & 69 \\
\hline ERP145D1 & $3.70 \mathrm{E}-02$ & 1.005 & 1.031 & 1.037 & 717 & 180 & 2 & 89 & 19 & 275 & 71 \\
\hline ERP145D3 & $2.99 \mathrm{E}-02$ & 1.007 & 1.032 & 1.039 & 627 & 34 & 13 & 126 & 8 & 247 & 75 \\
\hline ERP145F1 & $3.81 \mathrm{E}-02$ & 1.014 & 1.027 & 1.041 & 313 & 26 & 19 & 292 & 9 & 178 & 69 \\
\hline ERP145F2 & $2.69 \mathrm{E}-02$ & 1.011 & 1.025 & 1.036 & 362 & 27 & 10 & 296 & 2 & 193 & 79 \\
\hline ERP145G1 & $3.59 \mathrm{E}-02$ & 1.002 & 1.038 & 1.039 & 919 & 329 & 18 & 237 & 8 & 125 & 70 \\
\hline ERP146B1 & $3.02 \mathrm{E}-02$ & 1.019 & 1.009 & 1.028 & -350 & 36 & 4 & 305 & 14 & 142 & 75 \\
\hline ERP146C1 & $2.93 \mathrm{E}-02$ & 1.020 & 1.004 & 1.024 & -656 & 28 & 18 & 292 & 19 & 158 & 63 \\
\hline ERP146C2 & $2.98 \mathrm{E}-02$ & 1.026 & 1.002 & 1.029 & -839 & 27 & 8 & 129 & 57 & 292 & 31 \\
\hline ERP146C3 & $3.05 \mathrm{E}-02$ & 1.015 & 1.008 & 1.023 & -276 & 51 & 5 & 144 & 32 & 314 & 58 \\
\hline ERP146D2 & $3.08 \mathrm{E}-02$ & 1.012 & 1.011 & 1.023 & -9 & 61 & 22 & 314 & 35 & 177 & 47 \\
\hline ERP146D3 & $2.72 \mathrm{E}-02$ & 1.010 & 1.006 & 1.017 & -265 & 87 & 20 & 344 & 31 & 205 & 52 \\
\hline ERP146E1 & $3.20 \mathrm{E}-02$ & 1.006 & 1.006 & 1.012 & -36 & 139 & 30 & 229 & 0 & 319 & 60 \\
\hline ERP146E3 & $3.13 \mathrm{E}-02$ & 1.003 & 1.011 & 1.015 & 558 & 168 & 15 & 259 & 6 & 11 & 73 \\
\hline ERP146F2 & $3.04 \mathrm{E}-02$ & 1.004 & 1.005 & 1.009 & 120 & 288 & 9 & 183 & 59 & 23 & 29 \\
\hline ERP146G1 & $2.93 \mathrm{E}-02$ & 1.003 & 1.009 & 1.012 & 526 & 272 & 27 & 10 & 15 & 125 & 58 \\
\hline ERP200A1 & $2.91 \mathrm{E}-02$ & 1.007 & 1.007 & 1.014 & 57 & 25 & 4 & 116 & 10 & 274 & 79 \\
\hline ERP200A2 & $2.24 \mathrm{E}-02$ & 1.006 & 1.009 & 1.015 & 256 & 201 & 8 & 109 & 16 & 317 & 72 \\
\hline ERP200A3 & $1.73 \mathrm{E}-02$ & 1.008 & 1.008 & 1.017 & 2 & 98 & 0 & 8 & 2 & 196 & 88 \\
\hline ERP200C1 & $2.39 \mathrm{E}-02$ & 1.016 & 1.029 & 1.045 & 300 & 88 & 3 & 179 & 10 & 342 & 80 \\
\hline ERP200C2 & $1.51 \mathrm{E}-02$ & 1.019 & 1.027 & 1.047 & 168 & 136 & 8 & 227 & 5 & 349 & 80 \\
\hline ERP200C3 & 8.93E-03 & 1.017 & 1.019 & 1.037 & 44 & 85 & 18 & 178 & 9 & 294 & 70 \\
\hline ERP200D1 & $2.15 \mathrm{E}-02$ & 1.001 & 1.036 & 1.037 & 932 & 148 & 8 & 58 & 4 & 303 & 81 \\
\hline ERP200D2 & $1.91 \mathrm{E}-02$ & 1.013 & 1.022 & 1.035 & 241 & 284 & 1 & 14 & 4 & 184 & 86 \\
\hline ERP200D3 & $1.48 \mathrm{E}-02$ & 1.042 & 1.016 & 1.059 & -430 & 113 & 3 & 204 & 13 & 12 & 77 \\
\hline ERP200F1 & $2.52 \mathrm{E}-02$ & 1.003 & 1.011 & 1.014 & 576 & 293 & 16 & 199 & 14 & 70 & 68 \\
\hline ERP205A1 & $2.41 \mathrm{E}-02$ & 1.007 & 1.012 & 1.020 & 243 & 140 & 89 & 349 & 1 & 259 & 0 \\
\hline ERP205B1 & $2.30 \mathrm{E}-02$ & 1.003 & 1.016 & 1.019 & 696 & 350 & 54 & 176 & 36 & 84 & 3 \\
\hline ERP205B2 & $2.42 \mathrm{E}-02$ & 1.002 & 1.012 & 1.013 & 763 & 157 & 21 & 342 & 69 & 248 & 2 \\
\hline ERP205C2 & $1.85 \mathrm{E}-02$ & 1.011 & 1.012 & 1.023 & 34 & 138 & 49 & 349 & 37 & 247 & 16 \\
\hline ERP205D1 & $1.84 \mathrm{E}-02$ & 1.015 & 1.015 & 1.030 & 3 & 25 & 17 & 140 & 54 & 284 & 31 \\
\hline ERP205D2 & $2.29 \mathrm{E}-02$ & 1.015 & 1.012 & 1.027 & -134 & 21 & 16 & 132 & 52 & 280 & 34 \\
\hline ERP205E1 & $2.29 \mathrm{E}-02$ & 1.015 & 1.028 & 1.044 & 290 & 186 & 29 & 55 & 49 & 291 & 25 \\
\hline
\end{tabular}




\begin{tabular}{|c|c|c|c|c|c|c|c|c|c|c|c|}
\hline ERP205E2 & $1.12 \mathrm{E}-02$ & 1.009 & 1.031 & 1.041 & 536 & 167 & 37 & 38 & 40 & 281 & 29 \\
\hline ERP205F1 & $3.17 \mathrm{E}-02$ & 1.007 & 1.028 & 1.035 & 602 & 21 & 1 & 112 & 50 & 290 & 40 \\
\hline ERP206A1 & $2.72 \mathrm{E}-02$ & 1.011 & 1.013 & 1.024 & 76 & 246 & 12 & 18 & 73 & 153 & 12 \\
\hline ERP206A2 & $2.78 \mathrm{E}-02$ & 1.007 & 1.018 & 1.025 & 443 & 324 & 71 & 57 & 1 & 147 & 19 \\
\hline ERP206B1 & $2.42 \mathrm{E}-02$ & 1.005 & 1.002 & 1.008 & -381 & 189 & 3 & 280 & 14 & 87 & 76 \\
\hline ERP206C1 & $2.28 \mathrm{E}-02$ & 1.007 & 1.011 & 1.019 & 230 & 251 & 5 & 346 & 44 & 157 & 45 \\
\hline ERP206C2 & $1.75 \mathrm{E}-02$ & 1.011 & 1.005 & 1.016 & -422 & 248 & 15 & 27 & 70 & 154 & 13 \\
\hline ERP206D1 & $2.65 \mathrm{E}-02$ & 1.006 & 1.016 & 1.022 & 439 & 131 & 6 & 250 & 78 & 40 & 10 \\
\hline ERP206D2 & $2.53 \mathrm{E}-02$ & 1.013 & 1.011 & 1.024 & -99 & 137 & 13 & 293 & 76 & 46 & 6 \\
\hline ERP206E1 & $2.51 \mathrm{E}-02$ & 1.021 & 1.002 & 1.024 & -790 & 315 & 26 & 45 & 1 & 137 & 64 \\
\hline ERP206E2 & $2.90 \mathrm{E}-02$ & 1.004 & 1.011 & 1.016 & 429 & 317 & 13 & 114 & 76 & 226 & 5 \\
\hline ERP206F1 & $2.19 \mathrm{E}-02$ & 1.014 & 1.002 & 1.016 & -768 & 320 & 28 & 92 & 51 & 216 & 24 \\
\hline ERP206F2 & $2.13 \mathrm{E}-02$ & 1.017 & 1.007 & 1.024 & -386 & 316 & 17 & 160 & 71 & 49 & 7 \\
\hline ERP208A1 & $1.81 \mathrm{E}-02$ & 1.008 & 1.031 & 1.039 & 602 & 27 & 0 & 117 & 17 & 296 & 73 \\
\hline ERP208A2 & $2.20 \mathrm{E}-02$ & 1.020 & 1.013 & 1.034 & -201 & 26 & 8 & 295 & 5 & 172 & 80 \\
\hline ERP208B1 & $2.18 \mathrm{E}-02$ & 1.020 & 1.021 & 1.041 & 41 & 42 & 2 & 312 & 3 & 164 & 86 \\
\hline ERP208B2 & $2.78 \mathrm{E}-02$ & 1.019 & 1.025 & 1.045 & 137 & 35 & 3 & 125 & 12 & 289 & 77 \\
\hline ERP208C1 & $2.68 \mathrm{E}-02$ & 1.013 & 1.015 & 1.028 & 84 & 316 & 18 & 226 & 2 & 130 & 72 \\
\hline ERP208C2 & $2.07 \mathrm{E}-02$ & 1.015 & 1.017 & 1.032 & 84 & 118 & 1 & 28 & 4 & 223 & 86 \\
\hline ERP208D1 & $2.45 \mathrm{E}-02$ & 1.005 & 1.019 & 1.024 & 563 & 120 & 6 & 28 & 16 & 231 & 73 \\
\hline ERP208D2 & $3.15 \mathrm{E}-02$ & 1.008 & 1.003 & 1.011 & -451 & 64 & 52 & 331 & 2 & 239 & 38 \\
\hline ERP208E1 & $2.34 \mathrm{E}-02$ & 1.013 & 1.034 & 1.047 & 444 & 29 & 13 & 298 & 3 & 196 & 76 \\
\hline ERP208E2 & $2.60 \mathrm{E}-02$ & 1.012 & 1.024 & 1.037 & 326 & 84 & 15 & 351 & 11 & 227 & 72 \\
\hline ERP208F1 & $2.65 \mathrm{E}-02$ & 1.003 & 1.036 & 1.039 & 820 & 69 & 8 & 159 & 2 & 264 & 81 \\
\hline ERP208F2 & $2.93 \mathrm{E}-02$ & 1.006 & 1.036 & 1.043 & 694 & 50 & 12 & 319 & 3 & 216 & 77 \\
\hline ERP208F3 & $2.94 \mathrm{E}-02$ & 1.003 & 1.031 & 1.034 & 819 & 19 & 9 & 110 & 5 & 227 & 80 \\
\hline ERP210A1 & 4.47E-02 & 1.019 & 1.010 & 1.029 & -315 & 3 & 28 & 104 & 20 & 224 & 54 \\
\hline ERP210A2 & $3.11 \mathrm{E}-02$ & 1.011 & 1.027 & 1.038 & 431 & 16 & 42 & 127 & 22 & 237 & 40 \\
\hline ERP210A3 & $4.40 \mathrm{E}-02$ & 1.016 & 1.016 & 1.032 & 18 & 1 & 37 & 119 & 32 & 236 & 37 \\
\hline ERP210B1 & $2.01 \mathrm{E}-02$ & 1.014 & 1.006 & 1.020 & -402 & 172 & 7 & 264 & 14 & 55 & 74 \\
\hline ERP210B2 & $2.80 \mathrm{E}-02$ & 1.011 & 1.004 & 1.015 & -457 & 170 & 6 & 80 & 1 & 340 & 84 \\
\hline ERP210C1 & $9.81 \mathrm{E}-03$ & 1.010 & 1.005 & 1.015 & -366 & 155 & 2 & 247 & 38 & 63 & 52 \\
\hline ERP210C2 & $2.35 \mathrm{E}-02$ & 1.011 & 1.008 & 1.019 & -160 & 345 & 3 & 76 & 11 & 242 & 79 \\
\hline ERP210DA1 & $6.31 \mathrm{E}-02$ & 1.012 & 1.015 & 1.027 & 118 & 153 & 1 & 244 & 6 & 49 & 84 \\
\hline ERP210DA2 & 7.12E-02 & 1.008 & 1.017 & 1.025 & 329 & 349 & 1 & 259 & 3 & 106 & 87 \\
\hline ERP210DA3 & $5.83 \mathrm{E}-02$ & 1.014 & 1.019 & 1.033 & 139 & 158 & 4 & 68 & 0 & 338 & 86 \\
\hline ERP210DE1 & 4.49E-02 & 1.014 & 1.011 & 1.025 & -105 & 344 & 14 & 75 & 5 & 186 & 75 \\
\hline ERP210DE2 & $3.59 \mathrm{E}-02$ & 1.024 & 1.015 & 1.040 & -227 & 339 & 6 & 70 & 7 & 209 & 81 \\
\hline ERP210DE3 & $7.84 \mathrm{E}-02$ & 1.016 & 1.019 & 1.035 & 74 & 352 & 6 & 262 & 0 & 171 & 84 \\
\hline ERP210DE4 & $6.82 \mathrm{E}-02$ & 1.008 & 1.020 & 1.028 & 424 & 338 & 2 & 248 & 4 & 90 & 86 \\
\hline ERP210G1 & $7.08 \mathrm{E}-02$ & 1.011 & 1.017 & 1.028 & 212 & 131 & 3 & 41 & 5 & 252 & 85 \\
\hline ERP210G2 & 7.35E-02 & 1.010 & 1.013 & 1.024 & 139 & 326 & 2 & 235 & 2 & 90 & 87 \\
\hline ERP211A1 & $2.24 \mathrm{E}-02$ & 1.017 & 1.018 & 1.035 & 47 & 323 & 10 & 54 & 8 & 181 & 77 \\
\hline ERP211A2 & $2.42 \mathrm{E}-02$ & 1.019 & 1.006 & 1.026 & -506 & 144 & 2 & 241 & 75 & 54 & 15 \\
\hline ERP211B1 & $3.07 \mathrm{E}-02$ & 1.027 & 1.009 & 1.035 & -510 & 333 & 13 & 68 & 21 & 213 & 65 \\
\hline ERP211B2 & $3.78 \mathrm{E}-02$ & 1.017 & 1.002 & 1.019 & -739 & 340 & 22 & 84 & 30 & 219 & 51 \\
\hline
\end{tabular}




\begin{tabular}{|c|c|c|c|c|c|c|c|c|c|c|c|}
\hline ERP211C1 & $5.14 \mathrm{E}-02$ & 1.010 & 1.009 & 1.019 & -66 & 147 & 0 & 237 & 12 & 55 & 78 \\
\hline ERP211C2 & $4.70 \mathrm{E}-02$ & 1.013 & 1.009 & 1.022 & -154 & 116 & 1 & 206 & 14 & 20 & 76 \\
\hline ERP211EA1 & $4.90 \mathrm{E}-02$ & 1.017 & 1.015 & 1.033 & -54 & 17 & 0 & 287 & 20 & 107 & 70 \\
\hline ERP211EA2 & 4.72E-02 & 1.014 & 1.010 & 1.024 & -174 & 194 & 11 & 286 & 10 & 59 & 75 \\
\hline ERP211EC1 & $5.63 \mathrm{E}-02$ & 1.011 & 1.010 & 1.021 & -69 & 188 & 11 & 279 & 7 & 41 & 77 \\
\hline ERP211EC2 & $5.38 \mathrm{E}-02$ & 1.009 & 1.008 & 1.017 & -81 & 176 & 11 & 266 & 2 & 5 & 78 \\
\hline ERP211EE1 & $5.79 \mathrm{E}-02$ & 1.025 & 1.009 & 1.034 & -480 & 180 & 5 & 274 & 37 & 84 & 53 \\
\hline ERP211EE2 & $5.75 \mathrm{E}-02$ & 1.021 & 1.008 & 1.029 & -454 & 187 & 6 & 278 & 13 & 74 & 76 \\
\hline ERP213A1 & 4.42E-02 & 1.009 & 1.016 & 1.025 & 257 & 7 & 7 & 134 & 78 & 276 & 9 \\
\hline ERP214A1 & $1.08 \mathrm{E}-02$ & 1.021 & 1.016 & 1.037 & -126 & 137 & 33 & 238 & 17 & 351 & 51 \\
\hline ERP214B1 & $1.45 \mathrm{E}-02$ & 1.024 & 1.014 & 1.039 & -268 & 134 & 37 & 244 & 24 & 358 & 43 \\
\hline ERP214B2 & $5.69 \mathrm{E}-03$ & 1.029 & 1.011 & 1.040 & -439 & 146 & 45 & 238 & 2 & 330 & 45 \\
\hline ERP214C1 & $9.75 \mathrm{E}-03$ & 1.017 & 1.007 & 1.024 & -421 & 290 & 14 & 74 & 73 & 198 & 10 \\
\hline ERP214C2 & $1.94 \mathrm{E}-02$ & 1.014 & 1.016 & 1.030 & 60 & 272 & 2 & 64 & 87 & 182 & 1 \\
\hline ERP214D1 & $1.57 \mathrm{E}-02$ & 1.019 & 1.010 & 1.030 & -298 & 273 & 12 & 140 & 73 & 6 & 12 \\
\hline ERP214D2 & $1.52 \mathrm{E}-02$ & 1.013 & 1.009 & 1.022 & -173 & 274 & 16 & 120 & 72 & 6 & 7 \\
\hline ERP214E1 & $1.29 \mathrm{E}-02$ & 1.014 & 1.017 & 1.031 & 124 & 156 & 57 & 43 & 14 & 305 & 29 \\
\hline ERP214F1 & $8.27 \mathrm{E}-03$ & 1.007 & 1.020 & 1.027 & 505 & 192 & 43 & 61 & 35 & 310 & 27 \\
\hline ERP214F2 & $1.80 \mathrm{E}-02$ & 1.014 & 1.010 & 1.024 & -166 & 129 & 76 & 29 & 3 & 298 & 14 \\
\hline ERP215A1 & $4.13 \mathrm{E}-02$ & 1.001 & 1.024 & 1.025 & 896 & 106 & 4 & 16 & 5 & 233 & 84 \\
\hline ERP215A2 & $2.17 \mathrm{E}-02$ & 1.009 & 1.010 & 1.020 & 46 & 192 & 15 & 93 & 30 & 304 & 56 \\
\hline ERP215B1 & $3.10 \mathrm{E}-02$ & 1.006 & 1.024 & 1.029 & 614 & 197 & 6 & 106 & 11 & 316 & 78 \\
\hline ERP215B2 & $4.11 \mathrm{E}-02$ & 1.012 & 1.013 & 1.026 & 44 & 94 & 6 & 185 & 11 & 335 & 78 \\
\hline ERP215C1 & $4.20 \mathrm{E}-02$ & 1.004 & 1.019 & 1.023 & 644 & 120 & 7 & 211 & 6 & 342 & 81 \\
\hline ERP215C2 & $4.08 \mathrm{E}-02$ & 1.001 & 1.022 & 1.024 & 890 & 95 & 5 & 186 & 12 & 342 & 77 \\
\hline ERP215D1 & $3.59 \mathrm{E}-02$ & 1.004 & 1.027 & 1.031 & 710 & 216 & 7 & 121 & 36 & 315 & 53 \\
\hline ERP215D2 & $2.75 \mathrm{E}-02$ & 1.003 & 1.013 & 1.017 & 597 & 37 & 9 & 130 & 19 & 283 & 69 \\
\hline ERP215D3 & $2.22 \mathrm{E}-02$ & 1.009 & 1.014 & 1.023 & 223 & 168 & 12 & 72 & 26 & 280 & 61 \\
\hline ERP215E1 & $2.81 \mathrm{E}-02$ & 1.004 & 1.026 & 1.029 & 735 & 51 & 11 & 141 & 2 & 240 & 79 \\
\hline ERP215E2 & $1.79 \mathrm{E}-02$ & 1.025 & 1.011 & 1.037 & -380 & 106 & 8 & 12 & 23 & 214 & 66 \\
\hline ERP215F1 & $3.05 \mathrm{E}-02$ & 1.012 & 1.010 & 1.022 & -117 & 128 & 6 & 36 & 24 & 232 & 65 \\
\hline ERP215F2 & $2.62 \mathrm{E}-02$ & 1.010 & 1.010 & 1.021 & -16 & 121 & 10 & 25 & 31 & 226 & 57 \\
\hline ERP216A1 & $2.54 \mathrm{E}-02$ & 1.007 & 1.019 & 1.026 & 452 & 306 & 8 & 39 & 21 & 197 & 67 \\
\hline ERP216A2 & $3.73 \mathrm{E}-02$ & 1.009 & 1.012 & 1.021 & 126 & 316 & 7 & 224 & 14 & 73 & 75 \\
\hline ERP216B1 & $5.14 \mathrm{E}-02$ & 1.004 & 1.018 & 1.022 & 672 & 311 & 2 & 42 & 18 & 214 & 71 \\
\hline ERP216C1 & $5.69 \mathrm{E}-02$ & 1.006 & 1.044 & 1.051 & 742 & 149 & 2 & 59 & 2 & 283 & 87 \\
\hline ERP216D1 & $6.14 \mathrm{E}-02$ & 1.002 & 1.040 & 1.042 & 916 & 333 & 2 & 243 & 6 & 82 & 84 \\
\hline ERP216E1 & $6.51 \mathrm{E}-02$ & 1.004 & 1.042 & 1.047 & 820 & 296 & 9 & 206 & 2 & 104 & 81 \\
\hline ERP216E2 & $7.15 \mathrm{E}-02$ & 1.011 & 1.030 & 1.041 & 473 & 294 & 9 & 203 & 5 & 86 & 80 \\
\hline ERP216F1 & $6.90 \mathrm{E}-02$ & 1.009 & 1.037 & 1.046 & 608 & 88 & 7 & 357 & 11 & 211 & 77 \\
\hline ERP216F2 & $5.31 \mathrm{E}-02$ & 1.011 & 1.034 & 1.045 & 528 & 284 & 3 & 15 & 11 & 180 & 79 \\
\hline ERP216G1 & $6.35 \mathrm{E}-02$ & 1.007 & 1.041 & 1.048 & 701 & 286 & 5 & 17 & 5 & 153 & 83 \\
\hline ERP216G2 & $3.58 \mathrm{E}-02$ & 1.023 & 1.022 & 1.046 & -23 & 278 & 7 & 13 & 32 & 177 & 57 \\
\hline ERP217A1 & $4.97 \mathrm{E}-02$ & 1.016 & 1.063 & 1.080 & 593 & 98 & 6 & 7 & 5 & 240 & 82 \\
\hline ERP217A2 & $2.93 \mathrm{E}-02$ & 1.008 & 1.056 & 1.065 & 737 & 111 & 6 & 19 & 12 & 228 & 76 \\
\hline ERP217B1 & $4.11 \mathrm{E}-02$ & 1.010 & 1.071 & 1.081 & 753 & 337 & 3 & 67 & 7 & 226 & 83 \\
\hline
\end{tabular}




\begin{tabular}{|c|c|c|c|c|c|c|c|c|c|c|c|}
\hline ERP217C1 & $6.19 \mathrm{E}-02$ & 1.008 & 1.047 & 1.056 & 705 & 282 & 6 & 12 & 3 & 127 & 83 \\
\hline ERP217C2 & $1.82 \mathrm{E}-02$ & 1.011 & 1.059 & 1.070 & 689 & 351 & 10 & 261 & 2 & 160 & 79 \\
\hline ERP217D1 & $1.63 \mathrm{E}-02$ & 1.007 & 1.018 & 1.025 & 459 & 262 & 1 & 352 & 4 & 157 & 85 \\
\hline ERP217D2 & $1.88 \mathrm{E}-02$ & 1.008 & 1.010 & 1.018 & 150 & 80 & 1 & 170 & 14 & 346 & 76 \\
\hline ERP217E1 & $1.34 \mathrm{E}-02$ & 1.012 & 1.006 & 1.018 & -347 & 238 & 15 & 130 & 48 & 340 & 37 \\
\hline ERP217F1 & $8.22 \mathrm{E}-03$ & 1.003 & 1.014 & 1.017 & 589 & 94 & 14 & 2 & 7 & 245 & 75 \\
\hline ERP217F2 & $4.41 \mathrm{E}-03$ & 1.007 & 1.011 & 1.017 & 233 & 133 & 9 & 38 & 29 & 239 & 60 \\
\hline ERP217G1 & $5.17 \mathrm{E}-02$ & 1.004 & 1.019 & 1.023 & 636 & 348 & 18 & 79 & 3 & 179 & 72 \\
\hline ERP217G2 & $6.07 \mathrm{E}-02$ & 1.003 & 1.017 & 1.019 & 732 & 229 & 5 & 319 & 2 & 67 & 85 \\
\hline ERP217H1 & 4.95E-02 & 1.021 & 1.029 & 1.051 & 160 & 271 & 1 & 181 & 26 & 3 & 64 \\
\hline ERP217H2 & $6.13 \mathrm{E}-02$ & 1.011 & 1.015 & 1.026 & 151 & 113 & 10 & 203 & 2 & 302 & 80 \\
\hline ERP217I1 & $8.65 \mathrm{E}-02$ & 1.005 & 1.030 & 1.036 & 690 & 101 & 2 & 11 & 0 & 278 & 88 \\
\hline ERP217I2 & 7.79E-02 & 1.006 & 1.025 & 1.031 & 624 & 111 & 5 & 202 & 6 & 337 & 82 \\
\hline ERP217I3 & $3.48 \mathrm{E}-02$ & 1.010 & 1.019 & 1.029 & 311 & 273 & 5 & 4 & 7 & 146 & 82 \\
\hline ERP218A1 & $2.47 \mathrm{E}-02$ & 1.004 & 1.015 & 1.018 & 595 & 176 & 10 & 84 & 10 & 311 & 76 \\
\hline ERP218A2 & $2.04 \mathrm{E}-02$ & 1.005 & 1.022 & 1.027 & 610 & 120 & 9 & 29 & 7 & 262 & 79 \\
\hline ERP218B1 & $2.99 \mathrm{E}-02$ & 1.003 & 1.016 & 1.020 & 673 & 353 & 20 & 84 & 1 & 177 & 70 \\
\hline ERP218B2 & $2.31 \mathrm{E}-02$ & 1.007 & 1.017 & 1.024 & 444 & 331 & 25 & 64 & 6 & 166 & 64 \\
\hline ERP218C1 & $4.41 \mathrm{E}-02$ & 1.003 & 1.030 & 1.033 & 840 & 92 & 2 & 183 & 8 & 351 & 82 \\
\hline ERP218C2 & $3.25 \mathrm{E}-02$ & 1.004 & 1.032 & 1.036 & 769 & 174 & 2 & 84 & 4 & 289 & 85 \\
\hline ERP218D1 & 4.64E-02 & 1.007 & 1.016 & 1.023 & 391 & 96 & 7 & 189 & 17 & 346 & 71 \\
\hline ERP218E1 & $3.88 \mathrm{E}-02$ & 1.002 & 1.027 & 1.030 & 835 & 101 & 3 & 192 & 18 & 3 & 72 \\
\hline ERP218E2 & $3.33 \mathrm{E}-02$ & 1.001 & 1.029 & 1.029 & 955 & 242 & 4 & 151 & 16 & 344 & 73 \\
\hline ERP218F1 & $3.67 \mathrm{E}-02$ & 1.004 & 1.027 & 1.031 & 754 & 137 & 12 & 231 & 20 & 17 & 67 \\
\hline ERP218F2 & $3.74 \mathrm{E}-02$ & 1.002 & 1.026 & 1.028 & 861 & 234 & 12 & 142 & 11 & 10 & 74 \\
\hline ERP218G1 & $3.61 \mathrm{E}-02$ & 1.008 & 1.025 & 1.034 & 505 & 200 & 5 & 291 & 18 & 95 & 72 \\
\hline ERP218G2 & $1.84 \mathrm{E}-02$ & 1.004 & 1.035 & 1.040 & 775 & 187 & 5 & 278 & 15 & 77 & 74 \\
\hline ERP218H1 & $4.16 \mathrm{E}-02$ & 1.006 & 1.016 & 1.022 & 477 & 217 & 8 & 308 & 11 & 93 & 76 \\
\hline ERP219A2 & $4.38 \mathrm{E}-02$ & 1.008 & 1.026 & 1.034 & 534 & 105 & 3 & 196 & 16 & 3 & 74 \\
\hline ERP219B1 & $4.93 \mathrm{E}-02$ & 1.008 & 1.032 & 1.041 & 594 & 96 & 10 & 189 & 13 & 330 & 74 \\
\hline ERP219B2 & 4.94E-02 & 1.008 & 1.035 & 1.043 & 612 & 100 & 6 & 192 & 18 & 353 & 71 \\
\hline ERP219C1 & $5.09 \mathrm{E}-02$ & 1.002 & 1.035 & 1.037 & 888 & 91 & 5 & 182 & 11 & 336 & 77 \\
\hline ERP219C2 & $4.98 \mathrm{E}-02$ & 1.001 & 1.035 & 1.036 & 940 & 90 & 7 & 182 & 14 & 335 & 74 \\
\hline ERP219C3 & $3.48 \mathrm{E}-02$ & 1.003 & 1.028 & 1.031 & 810 & 234 & 6 & 142 & 18 & 343 & 71 \\
\hline ERP219D1 & $5.44 \mathrm{E}-02$ & 1.001 & 1.031 & 1.032 & 929 & 200 & 7 & 109 & 8 & 331 & 80 \\
\hline ERP219D2 & $5.19 \mathrm{E}-02$ & 1.004 & 1.036 & 1.039 & 815 & 89 & 7 & 180 & 13 & 331 & 75 \\
\hline ERP219D3 & $5.09 \mathrm{E}-02$ & 1.003 & 1.030 & 1.033 & 835 & 97 & 8 & 188 & 10 & 327 & 77 \\
\hline ERP219E1 & $5.50 \mathrm{E}-02$ & 1.001 & 1.035 & 1.037 & 918 & 275 & 7 & 184 & 4 & 61 & 82 \\
\hline ERP219E2 & $4.31 \mathrm{E}-02$ & 1.001 & 1.033 & 1.034 & 924 & 245 & 11 & 154 & 6 & 37 & 77 \\
\hline ERP220A1 & $9.02 \mathrm{E}-03$ & 1.012 & 1.032 & 1.045 & 441 & 94 & 83 & 332 & 4 & 242 & 6 \\
\hline ERP220A2 & $2.55 \mathrm{E}-02$ & 1.009 & 1.036 & 1.046 & 594 & 76 & 79 & 330 & 3 & 239 & 11 \\
\hline ERP220B1 & $1.47 \mathrm{E}-02$ & 1.002 & 1.035 & 1.037 & 895 & 352 & 72 & 134 & 14 & 227 & 11 \\
\hline ERP220C1 & $1.26 \mathrm{E}-02$ & 1.006 & 1.046 & 1.052 & 761 & 125 & 57 & 328 & 31 & 231 & 11 \\
\hline ERP220C2 & $3.25 \mathrm{E}-03$ & 1.003 & 1.029 & 1.032 & 817 & 322 & 28 & 109 & 58 & 224 & 15 \\
\hline ERP220D1 & $1.17 \mathrm{E}-02$ & 1.008 & 1.031 & 1.040 & 581 & 109 & 47 & 328 & 36 & 223 & 20 \\
\hline ERP220E1 & $1.93 \mathrm{E}-02$ & 1.009 & 1.038 & 1.047 & 627 & 114 & 53 & 326 & 32 & 226 & 16 \\
\hline
\end{tabular}




\begin{tabular}{|l|r|r|r|r|r|r|r|r|r|r|r|}
\hline ERP220E2 & $1.65 \mathrm{E}-02$ & 1.007 & 1.031 & 1.038 & 630 & 134 & 45 & 323 & 45 & 229 & 4 \\
\hline ERP220F1 & $1.68 \mathrm{E}-02$ & 1.009 & 1.039 & 1.048 & 629 & 43 & 25 & 306 & 15 & 187 & 60 \\
\hline ERP220F2 & $2.49 \mathrm{E}-03$ & 1.006 & 1.034 & 1.041 & 687 & 40 & 21 & 306 & 11 & 189 & 66 \\
\hline ERP220G1 & $2.05 \mathrm{E}-02$ & 1.014 & 1.035 & 1.050 & 416 & 36 & 27 & 303 & 6 & 202 & 62 \\
\hline ERP220G2 & $1.56 \mathrm{E}-02$ & 1.006 & 1.034 & 1.040 & 714 & 36 & 24 & 301 & 9 & 192 & 64 \\
\hline
\end{tabular}

